Aus der Klinik für Mund-, Kiefer- und Gesichtschirurgie

(Prof. Dr. med. Dr. med. dent. H. Schliephake)

im Zentrum Zahn-, Mund- und Kieferheilkunde

der Medizinischen Fakultät der Universität Göttingen

\title{
Die Wirkung von Sexual- und Phytohormonen auf das Remodelling des osteoporotischen Knochens der orchiektomierten Ratte nach Trepanation und Vibration
}

\author{
INAUGURAL-DISSERTATION \\ zur Erlangung des Doktorgrades \\ für Zahnheilkunde \\ der Medizinischen Fakultät der \\ Georg-August-Universität zu Göttingen
}

vorgelegt von

Sonja Wilma Thole

aus

Oldenburg

Göttingen 2014 
Dekan:

I. Berichterstatter:

II. Berichterstatter:
Prof. Dr. rer. nat. H. K. Kroemer

Prof. Dr. med. Dr. med. dent. K. G. Wiese PD Dr. med. M. Tezval

Tag der mündlichen Prüfung: 26.03.2014 


\section{Inhaltsverzeichnis}

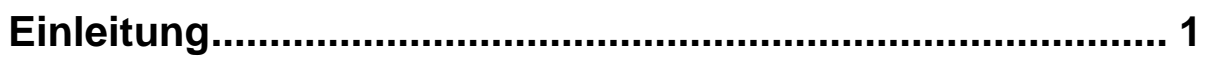

2

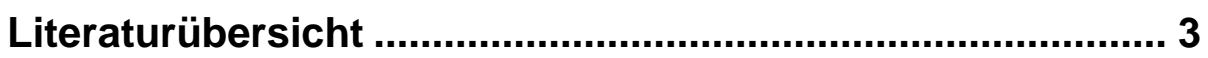

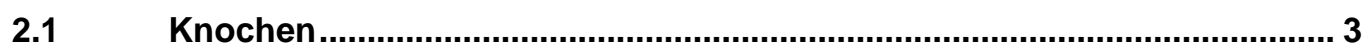

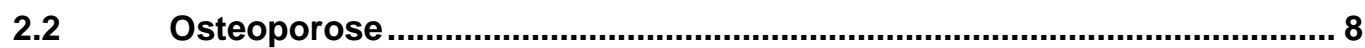

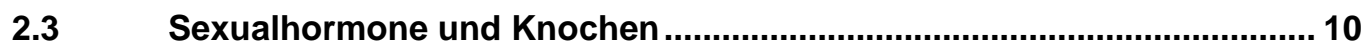

$2.5 \quad$ Phytohormone und Knochen............................................................. 12

2.6 Die polychrome Sequenzmarkierung …................................................ 15

$3 \quad$ Material und Methoden ..................................................... 17

3.1 Durchführung des Tierversuchs ...................................................... 17

3.2 Versuchsablauf ............................................................................ 18

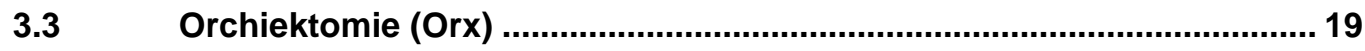

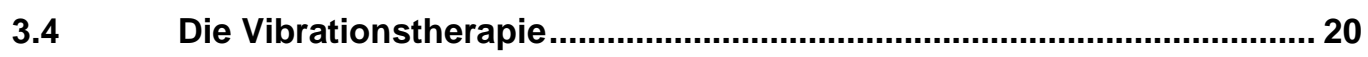

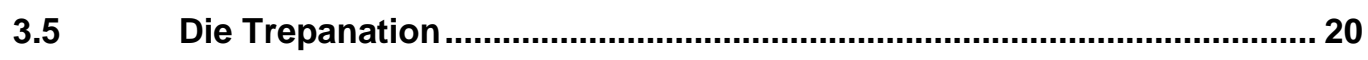

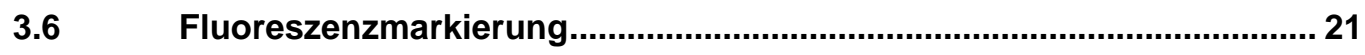

3.7 Histologische Aufarbeitung ............................................................. 21

3.8 Histometrie und Imageanalyse der Appositionsrate............................... 22

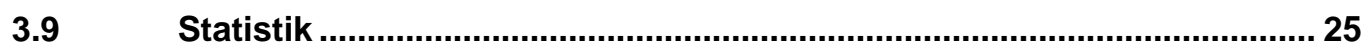

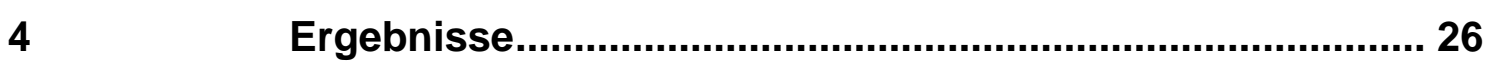

4.1 Ergebnisse der polychromen Sequenzmarkierung .............................. 26

4.2 Analyse des Geflechtknochens ........................................................... 28

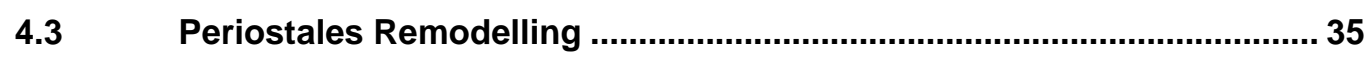

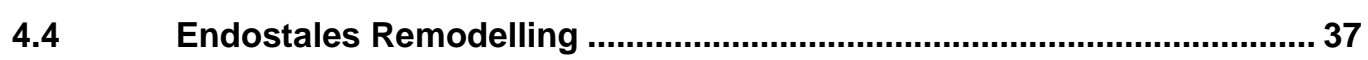

4.5 Trabekuläres Remodelling .................................................................. 39

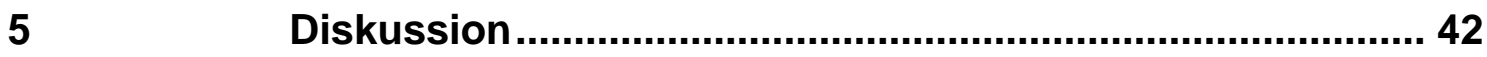

5.1 Diskussion der Methodik....................................................................... 43

5.2 Diskussion der Ergebnisse ........................................................... 45

5.2.1 Versuchsbedingte Effekte auf die Geflechtknochenbildung................. 45

5.2.2 Effekte auf die Kortikalis ............................................................... 49

5.2.3 Effekte auf den trabekulären Knochen ................................................. 53

$6 \quad$ Zusammenfassung ................................................................. 55

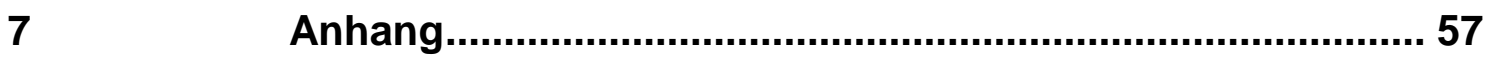

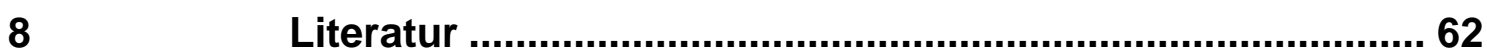

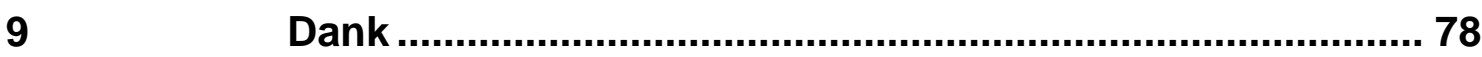




\section{Abkürzungsverzeichnis}

\begin{tabular}{|c|c|}
\hline Abb. & Abbildung \\
\hline AR & Androgenrezeptor \\
\hline BMD & Knochendichte bzw. bone mineral density \\
\hline $\mathrm{Cl}$ of Mean & Confidence interval of mean \\
\hline$d$ & Tag bzw. day \\
\hline DFG & Deutsche Forschungsgemeinschaft \\
\hline DHT & 5a-Dihydrotestosteron \\
\hline E2 & $17 \beta$-Östradiol bzw. Estradiolbenzoat \\
\hline EQ & Equol \\
\hline ER & Östrogenrezeptor \\
\hline ERa & Östrogenrezeptor $\alpha$ \\
\hline ER $\beta$ & Östrogenrezeptor $\beta$ \\
\hline et al. & et alii \\
\hline Fa. & Firma \\
\hline GEN & Genistein \\
\hline GKV & Ganz-Körper-Vibration \\
\hline HRT & Hormonersatztherapie bzw. hormone replacement therapy \\
\hline KG & Körpergewicht \\
\hline $\mathrm{N}$ & Anzahl bzw. Stichprobenumfang \\
\hline MAR & Mineralappositionsrate bzw. mineral apposition rate \\
\hline Mean & Mittelwert \\
\hline Median & Medianwert \\
\hline Orx bzw. orx & Orchiektomie bzw. orchiektomiert \\
\hline Ovx bzw. ovx & Ovariektomie bzw. Ovariektomiert \\
\hline p & Signifikanzniveau \\
\hline $25 \%$ Perz. & $25 \%$ Perzentil \\
\hline $75 \%$ Perz. & $75 \%$ Perzentil \\
\hline Range & Streuung \\
\hline s.c. & subkutan \\
\hline SD-Ratte & Sprague-Dawley-Ratte \\
\hline SD & Standardabweichung bzw. standard deviation \\
\hline SEM & Standardfehler bzw. standard error of the mean \\
\hline SF & sojafrei \\
\hline Tab. & Tabelle \\
\hline WHO & Weltgesundheitsorganisation \\
\hline
\end{tabular}





\title{
$1 \quad$ Einleitung
}

\author{
„Osteoporose?! Frag doch lieber deine Mutter!" \\ H. Thole
}

Ähnlich werden wahrscheinlich die meisten deutschen Männer reagieren, wenn man sie zum Thema Osteoporose befragen möchte. Diese Aussage zeigt, dass in weiten Kreisen der Bevölkerung die Osteoporose als Erkrankung der Frau angesehen wird. Dabei betrifft diese Krankheit nicht nur Frauen. Insgesamt sind in Deutschland etwa 6 Millionen Menschen an Osteoporose erkrankt, davon ist jeder Fünfte ein Mann (Bartl 2011). Im Alter verlieren Männer im Durchschnitt jährlich 1\% ihrer Knochenmineraldichte (Hannan et al. 2000). Auch wird davon ausgegangen, dass die im Alter häufig auftretenden Oberschenkelhalsbrüche schätzungsweise bei 20-30 \% der Männer durch Osteoporose verursacht werden (Bartl 2011, Johnell und Kanis 2006). Das Auftreten einer Fraktur bedeutet aber gleichzeitig auch ein erhöhtes Risiko für das Vorkommen einer weiteren Fraktur (Klotzbuecher et al. 2000). So besitzen Patienten mit einer Wirbelkörperfraktur ein 2,3-fach erhöhtes Risiko für eine Hüftfraktur und ein 1,4-faches Risiko für eine Unterarmfraktur (Sambrook und Cooper 2006). In der älteren Bevölkerung ist das Auftreten einer Fraktur, besonders an der Hüfte, mit einer höheren Folgemortalität vergesellschaftet, wobei das Risiko für Männer grundsätzlich größer ist als für Frauen (Center et al. 1999). Infektionen im Krankenhaus oder postoperative Komplikationen stellen dabei weitere Folgegefahren dar.

Mit dem demographischen Wandel der Bevölkerung wächst der Anteil der älteren Gesellschaft und folglich wird die Inzidenz von Frakturen sowohl für Frauen als auch für Männer weiter zunehmen (European Prospective Osteoporosis Study (EPOS) Group 2002). Die Anzahl der Hüftfrakturen soll weltweit von 1,7 Millionen Fällen im Jahre 1990 auf 6,3 Millionen 2050 ansteigen (Sambrook und Cooper 2006). Diese Entwicklungen bedeuten eine gewaltige finanzielle Last für das öffentliche Gesundheitssystem. Nach Angabe des statistischen Bundesamtes betrugen die Gesamtkosten im Jahre 2006 für männliche Osteoporose-Patienten 211 Mio. €. Im Jahr 2008 stiegen diese auf 230 Mio. $€$ mit zunehmender Tendenz. Der größte Kostenanteil lag bei den 65- bis 85-Jährigen (Statistisches Bundesamt 2010). Trotz der mittlerweile anerkannten gesellschaftlichen Bedeutung wird die Osteoporose, insbesondere beim Mann, oft unterschätzt und unterdiagnostiziert (Castel et al. 2001). 
Seit der Women's Health Initiative-Studie wird der exogene Einsatz von Östrogenen zur Behandlung der Osteoporose der Frau durch das Auftreten von gravierenden Nebenwirkungen stärker in Frage gestellt. Deshalb erfahren Alternativen im Bereich der Hormonersatztherapie (HRT) immer größere Beachtung und auch deren osteoprotektiver Effekt auf den Knochen des Mannes rückt stärker in den Fokus.

Als alternative Behandlungsmöglichkeit erscheinen Phytoöstrogene, die durch ihre chemische Ähnlichkeit mit Östrogen in der Lage sind, an deren Rezeptoren zu binden. Für sie konnten bereits positive Effekte auf den Knochen von Frauen belegt werden (Bitto et al. 2010, Sehmisch et al. 2010).

Für die Aufrechterhaltung des männlichen Knochenstoffwechsels konnten außerdem Androgene wie Testosteron oder 5a-Dihydrotestosteron (DHT) verantwortlich gemacht werden (Bland 2000, Lindberg et al. 2002). Ihr Defizit durch Hypogonadismus kann beim Mann unter anderem zur Osteoporose führen. Neben Androgenen spielen auch Östrogene für den männlichen Knochenstoffwechsel eine entscheidende Rolle und tragen im männlichen Körper zusammen mit Testosteron zum Skelettwachstum bei (Niethard et al. 2009).

Neben diesen pharmakologischen Ansätzen zur Therapie der Osteoporose darf jedoch die naturgemäße „Form folgt Funktion“-Eigenschaft des Knochens nicht ausgeblendet werden, denn dieser reagiert auf die mechanische Beanspruchung. Schon 1892 erkannte Julius Wolff in dem von inm veröffentlichten Gesetz von der Transformation der Knochen, dass sich die äußere Form und innere Struktur des Knochens an die mechanische Beanspruchung anpasst (Wolff 1892).

Ziel der nachfolgenden Untersuchungen war es, den Einfluss von mechanischer Belastung und die Gabe von Phyto- oder Sexualhormonen auf die Wundheilung und das Remodelling der defekten Tibia zu untersuchen. Als Sexualhormone wurden 17ßÖstradiol (E2) und Dihydrotestosteron (DHT) und als Phytohormone Genistein (GEN) und Equol (EQ) getestet. Die orchiektomierte Sprague-Dawley-Ratte diente als Tiermodell, das einer mechanischen Belastung in Form der Ganz-Körper-Vibration ausgesetzt wurde. Als Zielorgan wurde die Tibia und als Parameter für das Remodelling die Mineralappositionsrate gewählt. 


\section{Literaturübersicht}

\section{$2.1 \quad$ Knochen}

Unser Skelett setzt sich aus 220 Knochen zusammen, wiegt ca. $10 \mathrm{~kg}$ und macht damit ungefähr 10 \% unseres Körpergewichtes aus (Bartl 2011). Das Knochengewebe ist ein spezialisiertes Bindegewebe, das zum größten Teil aus einer Knochenmatrix besteht. Diese umfasst zu etwa $50 \%$ anorganisches Material wie Kalzium und Phosphat in Form von Hydroxylapatitkristallen, die von einer Hydratationshülle umgeben sind. Der organische Anteil besteht zu $95 \%$ aus Kollagen I und zu $5 \%$ aus Proteoglykanen und Glykoproteinen. Durch diese spezifische Zusammensetzung erhält der Knochen seine charakteristische Härte und seine Widerstandsfähigkeit (Junqueira und Carneiro 2005). Gleichzeitig erfüllt er viele Aufgaben wie zum Beispiel die Stütz- oder Fortbewegungsfunktion, auch schützt er vor äußeren Einwirkungen und dient als Mineraldepot (Bartl 2011). Makroskopisch sind am Knochen zwei unterschiedliche Bauweisen zu unterscheiden: Die Spongiosa und die Kompakta. Im Inneren des Knochens befindet sich ein schwammartiges Netzwerk aus Knochenbälkchen (Spongiosa), wobei diese als Trajektorien bezeichnet werden und abhängig von ihrer mechanischen Beanspruchung in Zug- und Drucktrajektorien unterschieden werden können. Die Räume zwischen den Bälkchen sind mit Knochenmark gefüllt (Abb. 1a). Die Kompakta des Knochens wird als Kortikalis bezeichnet (Lüllmann-Rauch 2009, Niethard et al 2009). Sämtliche inneren Oberflächen sind von Endost bedeckt (Abb. 1a). Das Periost bedeckt die äußere Oberfläche des Knochens, bestehend aus einem äußeren Stratum fibrosum und einem inneren Stratum osteogenicum. Die äußere Schicht besteht aus straffem Bindegewebe, das über Sharpey-Fasern mit der Knochenmatrix verbunden ist. Das Stratum osteogenicum ist mit den gleichen Zellen wie das Endost ausgestattet (Abb. 1d). Der Knochen kann folglich über das Periost und Endost ernährt werden, auch können Zellen für Wachstum und Reparatur zur Verfügung gestellt werden (Lüllmann-Rauch 2009).

Histologisch lässt sich der Geflechtknochen vom Lamellenknochen unterscheiden. Der Geflechtknochen entsteht überall dort, wo Knochen schnell gebildet werden muss und ist durch eine zufällige Anordnung der Kollagenfibrillen charakterisiert, um dann im Laufe der Zeit durch Lamellenknochen ersetzt zu werden. 


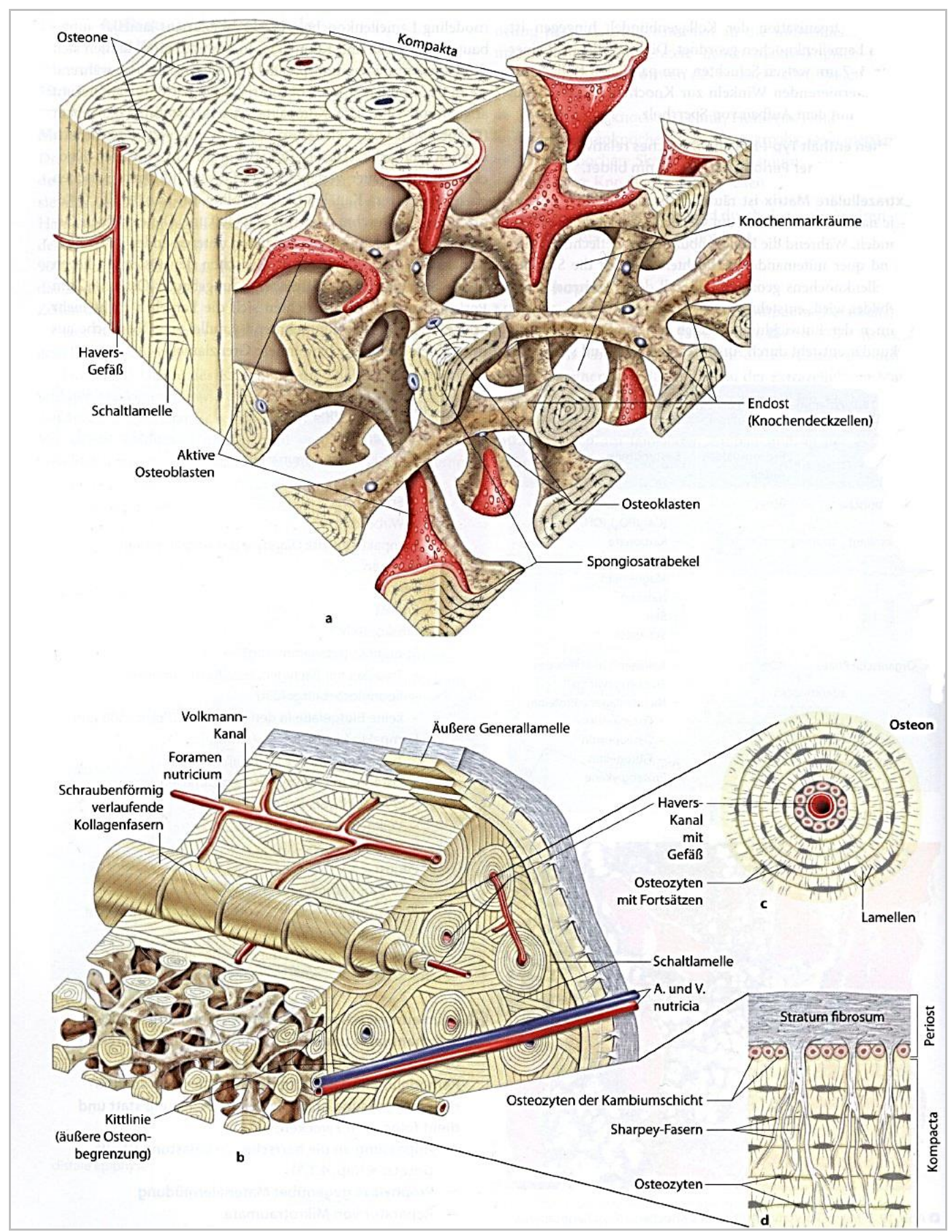

Abb. 1 Darstellung des Knochenaufbaus mit Vergrößerung der Spongiosa (a). Die Kortikalisübersicht (b) zeigt die parallel zur Knochenoberfläche verlaufenden Osteone, wobei diese in (c) im Querschnitt abgebildet sind. In (d) wird die Verbindung von Periost und Kompakta mittels Sharpey-Fasern verdeutlicht (Quelle: Harder und Kuster 2011, S.358).

Im Lamellenknochen bilden die Kollagenfasern und die Matrix 3-5 $\mu \mathrm{m}$ dicke Knochenlamellen, 5-20 Lamellen sind dabei konzentrisch um den Havers-Kanal (Durchmesser mind. $20 \mu \mathrm{m}$ ) angeordnet. Diese Baueinheit wird als Osteon bezeichnet (Abb. 1c). Osteozyten befinden sich dabei zwischen und manchmal auch in den Lamellen. Innerhalb einer Lamelle verlaufen die Kollagenfasern parallel zueinander, 
wobei sich die Verlaufsrichtung von Lamelle zu Lamelle ändert und sich Kollagenfasern mit benachbarten Kollagenfasern annähernd im rechten Winkel schneiden. Jedes Osteon verläuft entlang der Längsachse des Knochens, wobei im zentralen HaversKanal Blutgefäße, Nerven und Bindegewebe mitgeführt werden. Schräg verlaufende Volkman-Kanäle verbinden die Havers-Kanäle untereinander. Folglich ist eine Kommunikation der Kanäle untereinander sowie mit dem Periost und der Markhöhle möglich (Abb. 1b). Jedes Osteon wird von einer mineralisierten Matrix umschlossen, die als Zement bezeichnet wird. Die Zwischenräume zwischen den Osteonen sind mit Schaltlamellen gefüllt, die Reste von alten Osteonen darstellen. Die äußere Kompakta wird von einer großen Generallamelle umschlossen, wobei zum Markraum noch eine innere Generallamelle vorhanden sein kann. In der Spongiosa verlaufen die Lamellen zum größten Teil parallel und flächig zur Oberfläche, wobei sie über die Gefäße des Knochenmarks mittels Diffusion versorgt werden.

Neben den bereits erwähnten Osteozyten lassen sich im Knochen auch noch charakteristische Zellen wie Osteoblasten oder Osteoklasten vorfinden. Die Osteoblasten sind so genannte „Knochenbildner“, die für die Synthese von Kollagen und die anschließende Mineralisation zuständig sind. Dabei lassen sie sich immer an freier Knochenoberfläche vorfinden, denn neue Knochenmatrix kann nur auf schon bereits mineralisierter Matrix abgelegt werden. Osteoblasten besitzen an ihrer Oberfläche Östrogenrezeptoren (ER) (Colvard et al. 1989, Eriksen et al. 1988, Komm et al. 1988, Qu et al. 1998). Später werden die Osteoblasten zu Osteozyten, indem sie zwischen die Knochenlamellen eingemauert werden. Andere Blasten gehen durch Apoptose zugrunde oder wandern zum Endost. Die Osteozyten liegen in Lakunen, von denen Kanalikuli abgehen, in denen die Fortsätze der Osteozyten verlaufen. Die Knochenkanälchen verlaufen dabei sowohl senkrecht als auch parallel zu den Lamellen. Die einzelnen Osteozyten sind über Gap Junctions der Fortsätze miteinander verbunden, dadurch ist ein Stoffaustausch zwischen den einzelnen Osteozyten möglich. Dieses Osteozyten-Netzwerk überwacht die materielle und strukturelle Stärke des Knochens. Im Gegensatz dazu bauen Osteoklasten die mineralisierte Matrix in nur wenigen Tagen (d) ab. Sie sind große (50-100 $\mu \mathrm{m})$ und mehrkernige Zellen, die der Knochenmatrix direkt anliegen und Howship-Lakunen in die Trabekeloberfläche und Kanäle in die Kompakta fressen. Diese Lücken müssen dann durch die Osteoblasten mit neuen Lamellen aufgefüllt werden. Osteoklasten weisen ebenfalls ERs auf (Kameda et al. 1997, Oursler et al. 1991). 
Im Jahre 1892 erkannte der Anatom und Chirurg Julius Wolff, dass sich der Knochen an seine mechanische Beanspruchung anpasst. Aus dieser Erkenntnis formulierte er „Das Gesetz der Transformation der Knochen“ (Wolff 1892). Im „Utah Paradigm of Skeletal Physiology" von 1960 entwickelte der Osteologe Harald Frost das Wolffsche Transformationsgesetz durch seine Mechanostat-Hypothese weiter. In dieser macht er elastische Verformungen für die Veränderungen am Knochen nach der Geburt verantwortlich. Wachstumsfaktoren wie Zytokine, Vitamine oder Proteine sind für die Umsetzung wichtig, stellen jedoch nicht den Auslöser dar (Frost 1998). Auf dieser Grundlage kommt der Vibrationstherapie unter anderem in der Raumfahrt eine besondere Bedeutung zu, um den durch die Schwerelosigkeit hervorgerufenen Knochenverlust zu verhindern (Rubin et al. 2001).

Die Ganz-Körper-Vibration (GKV) erhält zunehmend mehr Aufmerksamkeit in der Forschung als therapeutische Methode zur Verbesserung der Knochenmasse und Knochendichte (BMD). So konnten Rubin et al. (2001) durch mechanische Stimulierung einen Anstieg der Spongiosadichte an Schafen aufzeigen (Rubin et al. 2001). Auch an weiblichen osteoporotischen Nagern sowie postmenopausalen Frauen konnten protektive Effekte der GKV auf den Knochen ermittelt werden, die die Vibration als Prävention oder mögliche Therapieform aufzeigen (Ruan et al. 2008, Rubin et al. 2004, Sehmisch et al. 2009, Verschueren et al. 2004). Doch besonders im Hinblick auf das Krankheitsbild der Osteoporose beim Mann sind Studien mit männlichen Probanden bzw. Versuchstieren unterrepräsentiert. Aus diesem Grund integriert der vorliegende Versuch den Faktor der Vibration auf den Knochen der männlichen, orchiektomierten Ratte.

Frakturen stellen eine partielle oder vollständige Kontinuitätsunterbrechung des Knochens dar. Dabei können unterschiedliche Formen der Fraktur unterschieden werden. Eine so genannte traumatische Fraktur wird durch eine unphysiologische äußere Gewalteinwirkung hervorgerufen, die die Festigkeit des Gewebes übersteigt. Von einer pathologischen Fraktur kann gesprochen werden, wenn eine physiologische äußere Kraft an einem pathologisch veränderten Knochen, wie es bei der Osteoporose der Fall ist, eine Kontinuitätsunterbrechung hervorruft. Im Gegensatz dazu stellt die Ermüdungsfraktur einen Bruch dar, der durch eine kontinuierliche lokale Beanspruchung bewirkt wird. Als Beispiel ist an dieser Stelle die Marschfraktur am Ossa metatarsalis zu nennen.

Grundsätzlich kann zwischen der primären, der direkten, und der sekundären bzw. indirekten Frakturheilung unterschieden werden. Die primäre osteonale Frakturheilung zeichnet sich durch ein direktes Migrieren der Osteone in das gegenüberliegende 
Frakturende aus. Dadurch können die Frakturenden gegeneinander fixiert werden und es entsteht kein Kallus, der späteren Umbauvorgängen unterworfen ist. Diese Art der Heilung tritt nicht spontan auf, kann jedoch durch eine stabile Osteosynthese und vollständige Ruhigstellung erreicht werden. Die sekundäre bzw. nicht osteonale Frakturheilung zeichnet sich durch die überschießende Bildung eines bindegewebigen Kallus aus. Dieser stabilisiert die Fraktur und reduziert die interfragmentären Bewegungen. Erst sekundär setzt die Ossifikation des Kallus ein. Insgesamt werden mehrere Phasen durchlaufen, die sich zum Teil überlappen. Durch die Gewalteinwirkung werden periostale und medulläre Blutgefäße zerstört, sodass sich im Frakturspalt und den angrenzenden Weichteilen ein Frakturhämatom bildet. Dies geht mit einer akuten Entzündungsreaktion und Aktivierung der Gerinnungskaskade einher. Der gebildete Thrombus wird durch Granulationsgewebe ersetzt. Dieser weiche Kallus führt zu einer ersten Überbrückung der Frakturenden. Gleichzeitig kommt es zur vermehrten Gefäßeinsprossung und folglich zur Einschwemmung von mesenchymalen Stammzellen, die sich zu Fibroblasten und Chondrozyten differenzieren. Der gebildete knorpelige Kallus wird im Zuge der Ossifikation mit Hilfe des Zusammenspiels von Osteoklasten und Osteoblasten durch Geflechtknochen ersetzt. Abschließend erfolgt die Modelling-Phase, in der der Geflechtknochen gegen den belastbareren Lamellenknochen ersetzt wird. Die Bildung orientiert sich dabei an den Kraftlinien. Mit Abschluss dieser Phase ist in der Regel eine Restitutio ad integrum erreicht (Harder und Kuster 2011).

Die Erkrankung der Osteoporose führt zu einem erhöhten Frakturrisiko und zu Frakturen an besonderen Prädilektionsstellen wie beispielsweise den Wirbelkörpern (Hobusch und Holzer 2011). Frakturen im osteoporotischen Knochen sind den gleichen regenerativen Phasen des gesunden Knochens unterworfen (Shi et al. 2010). Allerdings zeigte sich anhand von Tierversuchen, dass sich die Frakturheilung nach Ovarektomie mit Verzögerung vollzieht. Kubo et al. (1999) machen dafür eine Verlängerung der späten und Namkung-Matthai et al. (2001) der frühen Heilphase verantwortlich (Kubo et al. 1999, Namkung-Matthai et al. 2001). Die GKV als eine nicht-pharmakologische Therapiealternative übt auf die Knochenheilung einen positiven Effekt durch beschleunigte Kallusbildung und Mineralisation aus (Leung et al. 2009). Gleichzeitig erwies sich die Vibrationstherapie als wirksam für die Knochenheilung in einem durch Ovarektomie induzierten, osteoporotischen Knochen (Chow et al. 2011, Shi et al. 2010). Es gilt dabei zu klären, wie sich die Frakturheilung am Tiermodell der männlichen osteoporotischen Ratte verhält und inwieweit eine Beeinflussung durch eine GKV besteht. 


\section{$2.2 \quad$ Osteoporose}

Die Osteoporose stellt definitionsgemäß eine Skeletterkrankung dar, die mit einer geringen Knochenmasse sowie einer Verschlechterung der Mikroarchitektur und folglich einer erhöhten Knochenbrüchigkeit einhergeht (Cummings und Melton 2002). In erster Linie macht sich diese Erkrankung durch einen Verlust der Spongiosastruktur bemerkbar, sodass sich daraus eine Frakturgefährdung für diejenigen Knochen ergibt, die einen hohen Anteil an spongiösem Knochen aufweisen wie beispielsweise Wirbelkörper, der Oberschenkelhals oder das Handgelenk (Bartl 2011). Insgesamt muss eine negative Skelettbilanz vorliegen, die sich entweder aus einer verstärkten Knochenresorption (high turnover) oder aus einer verringerten Knochenneubildung (low turnover) ergibt (Niethard et al. 2009). Wie für die Frau lässt sich die Osteoporose des Mannes in eine primäre und sekundäre Form einteilen. Die primäre tritt im Gegensatz zur sekundären Osteoporose nicht als Folgeerscheinung einer anderen Erkrankung auf. Unter diese lässt sich die idiopathische Osteoporose junger Menschen oder auch die senile Osteoporose subsumieren. Als Beispiele für sekundäre Osteoporoseursachen sind Alkoholabusus, Hypogonadismus, Glukokortikoidtherapie, starkes Rauchen, Hyperthyreose oder auch Lebererkrankungen zu nennen (Abb. 2). Osteoporose ist bei Männern vielfach das Ergebnis eines multifaktoriellen Geschehens, hervorgerufen durch endokrine oder genetische Faktoren sowie Veränderungen von Wachstumsfaktoren. Ebenfalls wird dem Lebensstil, geprägt durch Ernährung oder körperliche Aktivität, eine große Bedeutung beigemessen

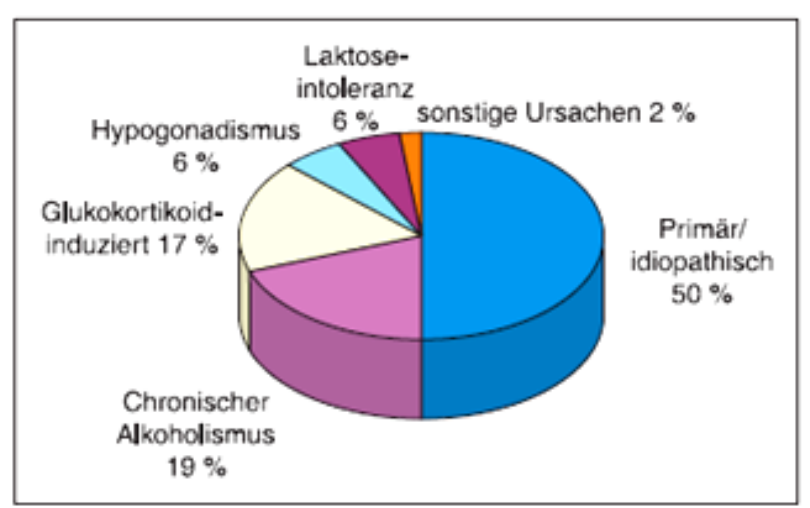

Abb. 2 Primäre und sekundäre Osteoporoseursachen des Mannes. Primäre Ursachen umfassen $50 \%$. Beispiele für die sekundären Ursachen sind chronischer Alkoholismus oder Hypogonadismus.

(Quelle: Pietschmann 2004, S.12)
(Pietschmann et al. 2004). Die sekundäre Form der Osteoporose ist bei Männern häufig, denn der prozentuale Anteil beträgt bei den Männern 45 - $50 \%$, bei den Frauen dagegen nur 10\% (Bartl 2011, Pietschmann 2004). Im übertragenen Sinn imitiert unser Tiermodell durch die Orchiektomie den Hypogonadismus des Mannes. Auch wenn weniger Männer als Frauen an Osteoporose erkranken, stellt die männliche Osteoporose dennoch eine

häufige und schwerwiegende Erkrankung dar, die erst im letzten Jahrzehnt mehr Aufmerksamkeit in der Forschung erfahren hat. 
Wenige Therapiestudien beschäftigen sich mit der männlichen Osteoporose. Doch gibt es einige Behandlungsoptionen. Der hohe Anteil an sekundärer Osteoporose eröffnet die Möglichkeit der Kausaltherapie, um die Ursachen der Grunderkrankung zu beheben. Zu nennen ist an dieser Stelle die exogene Applikation von Testosteron bei diagnostiziertem Hypogonadismus. Dies kann in Form von Pflastern, Tabletten oder intramuskulären Injektionen geschehen, wobei ein bestehendes Prostatakarzinom zuvor ausgeschlossen werden muss (Bartl 2011). Grundsätzlich gilt es, eine ausreichende Kalzium- und Vitamin D-Supplementation zu gewährleisten. Dies kann einerseits durch die exogene Gabe erreicht werden oder durch eine ausreichende Sonnenlichtexposition sowie kalziumreiche Nahrung (Weber 2008). Eine Maßnahme stellt zugleich die analgetische Therapie dar, um einer Immobilisation, bedingt durch die schmerzhafte Fraktur, vorzubeugen. Auch kann es zum medikamentösen Einsatz der zugelassenen Bisphophonate Alendronat, Zoledronat und Risedronat kommen (Bartl 2011, DVO-Leitlinien 2009). Diese können entweder oral oder intravenös verabreicht werden. Dazu liegen gute Studienergebnisse vor, die vergleichbar sind mit denen von postmenopausalen Frauen (Orwoll et al. 2000). Pharmakologische Therapiealternativen sind zusätzlich in der Gabe von Strontium, Parathormon oder Fluor zu sehen. Gleichzeitig sind nicht-pharmakologische Ansätze wie die Sturzprophylaxe, die Physiotherapie oder auch das Tragen von Hüftprotektoren bedeutungsvoll (Weber 2008). 


\subsection{Sexualhormone und Knochen}

Östrogene sind Steroidhormone, die sowohl durch die Frau als auch durch den Körper des Mannes synthetisiert werden (Abb. 3). Dabei beeinflussen sie unter anderem im weiblichen Organismus die Bildung und Entwicklung der Geschlechtsmerkmale. Im männlichen Körper tragen sie zusammen mit dem Testosteron zum Skelettwachstum bei (Niethard et al. 2009). Die natürlich vorkommenden Östrogene sind 17ß-Östradiol (E2), Östron (E1) und Östriol (E3). Die beiden Letzten werden hauptsächlich in der Leber aus Östradiol gebildet. In der Zelle können Östrogene ihre Wirkung über zwei unterschiedliche Rezeptoren entfalten: Östrogenrezeptor $\alpha(E R \alpha)$ und Östrogenrezeptor $\beta$ (ERß) (Enmark und Gustafsson 1999). Östrogene spielen für die Aufrechterhaltung der Knochenmineraldichte eine etablierte Rolle. So konnte die Wirkung des weiblichen Sexualhormons mittels Östrogenrezeptoren auf die Osteoblasten (Colvard et al. 1989, Eriksen et al. 1988, Komm et al. 1988, Qu et al. 1998) und Osteoklasten (Kameda et al. 1997, Oursler et al. 1991) nachgewiesen werden. Auch hemmen Östrogene die IL-6-Produktion (Girasole et al. 1992, Jilka et al. 1992). Dies ist insoweit

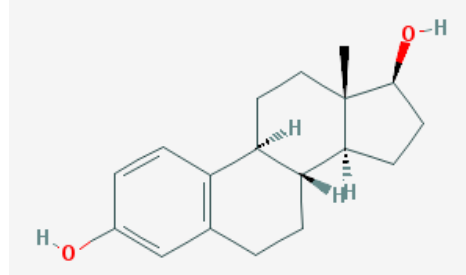
interessant als Interleukin 6 die Osteoklastenreifung induzieren und damit auch einen Einfluss auf die Knochenresorption ausüben kann (Kurebasyashi et al. 1997). Gleichzeitig führen Östrogenverluste zu einer Interleukin-6 vermittelten Stimulation der Osteoklastogenese und folglich zu einer Resorption des Knochens (Jilka et al. 1992). Vielfach werden Östrogene für eine endostale Apposition verantwortlich gemacht, wobei an der periostalen Kortikalis hemmende Wirkungen erzeugt werden sollen (Kim et al. 2003, Seeman 2001a, Turner et al. 1989).

Dass Östrogene nicht nur für Frauen, sondern auch für Männer und deren Knochenstoffwechsel entscheidend sind, wurde mittlerweile ermittelt (Carani et al. 1997, Faustini-Fustini et al. 1999). Für die Aufrechterhaltung des trabekulären Knochens männlicher Mäuse konnten sowohl der Androgenrezeptor (AR) als auch der ERa verantwortlich gemacht werden (Lindberg et al. 2002). Klinische Beobachtungen zeigen die Bedeutung der Aromatisierung von Testosteron zu Östrogenen (Carani et al. 1997, Miyaura et al. 2001, Oz et al. 2000, Rochira et al. 2001, Vanderschueren et al. 1997, Vanderschueren et al. 2000, Vanderschueren et al. 2004).

Östrogenmangel führt zu einem Ungleichgewicht zwischen Knochenabbau und Knochenaufbau. Diese Dysbalance manifestiert sich vielfach in der Menopause der 
Frau in Form von Osteoporose. Dabei ist der Einsatz von Östrogenen als Hormonersatztherapie für die Frau umstritten, denn diese erhöht das Risiko für Brustkrebs, Thromben, Schlaganfälle oder kardiovaskuläre Erkrankungen (Kanis und Reginster 2008).

Östrogene sind sowohl für den Mann als auch für die Frau unerlässlich für die Balance zwischen Knochenaufbau und Knochenabbau.

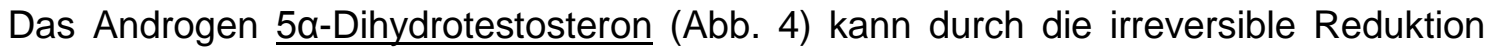
einer Doppelbindung aus dem Testosteron mittels des Enzyms 5a-Reduktase gebildet werden. Androgene stellen synthetisierte Steroidhormone dar, die sowohl bei Männern als auch bei Frauen in den Gonaden bzw. in der Nebennierenrinde produziert werden. Beim Mann findet die Synthese in den Leydigzellen des Hodens statt, dabei sind die wichtigsten Androgene das Testosteron und das DHT. Der Transport findet im Blut über einen Albumin-Komplex oder ein spezifisches, Sexualhormon-bindendes Protein statt. In den Zielzellen angekommen, wird der größte Teil

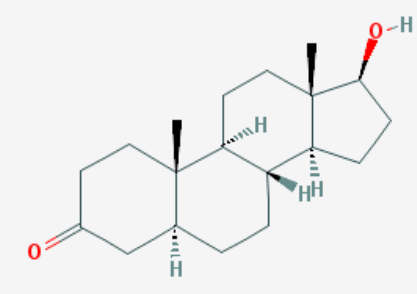

Abb. 4 Strukturformel von Dihydrotestosteron (DHT) mit der Summenformel: $\mathrm{C}_{19} \mathrm{H}_{30} \mathrm{O}_{2}$ (Quelle: PubChem.2012b) des Testosterons in DHT umgewandelt, das an die gleichen Rezeptorproteine wie Testosteron bindet, allerdings mit einer höheren Affinität für den AR (Kumar et al. 1999).

Zusätzlich kann Testosteron durch eine Aromatasereaktion in Östrogen umgewandelt werden (Rochira et al. 2002, Rochira et al. 2005). In eugo-nadalen Männern soll bis zu $80 \%$ des zirkulierenden Östradiols aus der Aromatasereaktion stammen (Sakhri und Gooren 2007). DHT stellt dagegen ein reines Androgen dar und kann nicht zu Östradiol aromatisiert werden (Sakhri und Gooren 2007). Neben den Geschlechtsmerkmalen sind Androgene für die Ausbildung sowie die Aufrechterhaltung des männlichen Knochenaufbaus verantwortlich und rufen den Muskelaufbau hervor (Bland 2000, Lindberg et al. 2002). Besonders die Effekte auf den Knochenstoffwechsel sind im Hinblick auf die Behandlung der Osteoporose interessant. Dass Androgene wie Testosteron und DHT auf den Knochen wirken, konnte unter anderem an männlichen orchiektomierten Nagern (Ophoff et al. 2009, Vandenput et al. 2002, Vanderschueren et al. 1992) sowie an Männern aufgezeigt werden (Anderson et al. 1997). In der männlichen Adoleszenz führen Androgene zu einer starken periostalen Apposition und folglich zu einer dickeren Kortikalis (Seeman 2001a, Seeman 2001b). Dabei kann nur die Wirkung mittels DHT als reiner AndrogenEffekt verstanden werden, denn Testosteron kann über die Aromatasereaktion auch 
auf ER $\alpha$ und ER $\beta$ wirken (Lindberg et al. 2002). Aus diesem Grund wurde den Ratten im vorliegenden Versuch DHT als Futterzusatz verabreicht.

\section{$2.5 \quad$ Phytohormone und Knochen}

Isoflavone sind neben Lignanen, Flavonen und Coumestanen pflanzliche Inhaltsstoffe, die auch als Phytoöstrogene bezeichnet werden. Sie besitzen durch ihren Phenolring eine chemische Ähnlichkeit zum menschlichen Östrogen (Abb. 5). Erkenntnisse deuten darauf hin, dass eine phytoöstrogenreiche Nahrung in der Lage ist, Schutz gegen Brust-, Prostata- und Darmkrebs sowie Herzkreislauferkrankungen und Osteoporose zu bieten (Bingham et al. 1998). Insgesamt gibt es 1000 Arten von Isoflavonen, wobei Genistein und Diadzein die am häufigsten untersuchten Phytoöstrogene darstellen

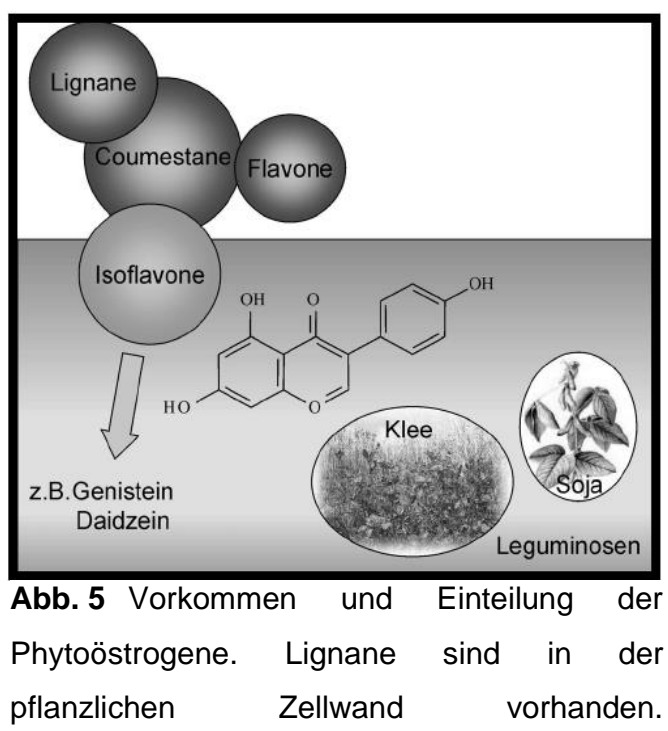

Coumestane, Flavone und Isoflavone werden zu den Isoflavonoiden zusammengefasst. Zu den bekanntesten Isoflavone zählen Genistein und Daidzein (Quelle: Mau 2007, S.13).
(Bundesinstitut für Risikobewertung 2007, Glazier und Bowman 2001). Durch diese strukturelle Verwandtschaft sind sie in der Lage, selbst oder nach ihrer Verstoffwechselung die Wirkung von endogenen Östrogenen zu imitieren oder zu modellieren (Foth 2007). In der Natur sind sie in Soja und anderen Leguminosen wie Klee $\mathrm{zu}$ finden (Bundesinstitut für Risikobewertung 2007, Mau 2007).

Isoflavone lassen sich als freie, sogenannte Aglukone wie Daidzein, Genistein oder Glycitein vorfinden oder an ein Zuckermolekül gebunden wie Daidzin, Genistin oder Glycitin, wobei die glykosilierten Isoflavone weniger aktiv sind als die Freien (Bundesinstitut für Risikobewertung 2007). Genistein, Daidzein, Formononetin und Biochanin A stellen dabei die wichtigsten Vertreter innerhalb der Isoflavon-Klasse von Phytoöstrogenen dar und werden weitgehend in Soja und Sojaprodukten vorgefunden (Foth 2007, Messina 1999). Nach oraler Aufnahme scheinen Aglukone schneller resorbiert zu werden als die jeweilige, glykosilierte Form, bedingt durch die nicht notwendige Spaltung mit Hilfe von B-Glukosidasen im unteren Dünndarm. (Bundesinstitut für Risikobewertung 2007). Genistein und Daidzein werden zu 20-25\% resorbiert und dann bevorzugt in Brustgewebe und Eierstöcken eingelagert (Wolters und Hahn 2004). In Abhängigkeit von der Kolonflora ist im Dickdarm eine weitere Verstoffwechselung möglich. Das bis 
dahin noch nicht resorbierte Isoflavon Daidzein kann zu Equol und ODemethylangolensin metabolisiert werden, wobei aus Genistein 6’-Hydroxy-ODemethylangolensin entstehen kann, das dann weiter zu p-Ethylphenol metabolisiert wird (Wolters und Hahn 2004). In die Zellen gelangen Isoflavone durch passive Diffusion. Wenn sie dann im Zytosol auf einen ERa treffen, bilden sie mit diesem Isoflavon- $\alpha-K o m p l e x e$, die dann im Zellkern die Produktion neuer Proteine anregen (Chen und Anderson 2002).

Oft werden Flavone im Zusammenhang mit klimakterischen Beschwerden der Frau aufgeführt. Japanische Frauen klagen weniger häufig über das Auftreten von menopausalen Beschwerden. In diesem Zusammenhang wird als Begründung der hohe Verzehr an phytoöstrogenreicher Nahrung angeführt (Messina 2002). Dies lässt sich damit begründen, dass Isoflavone durch ihre chemische Ähnlichkeit mit dem menschlichen 17ß-Östradiol in der Lage sind, mit ERa und ER $\beta$ zu interagieren. Allerdings scheinen sie eine höhere Affinität zu ERB zu besitzen. Dennoch ist ihre Wirkung 100- bis 10.000-mal schwächer als die des menschlichen Östrogens einzustufen (Kulling und Watzl 2003). Durch die kritische Hinterfragung der klassischen Hormonersatztherapie (HRT) mit Östrogen rücken die Phytoöstrogene stärker in den Mittelpunkt von Studien. Nebenwirkungen der HRT sind beispielsweise die Erhöhung des Brustkrebsrisikos, Thrombosen oder Herzinfarkte (Carlson et al. 2008). Dabei sind die Phytoöstrogene möglicherweise in der Lage, eine Vielzahl von menopausalen Begleiterscheinungen zu lindern (Bitto et al. 2009, Messina 2002), wobei dies nicht unumstritten ist (Wuttke et al. 2008). Gleichzeitig konnten osteoprotektive Wirkungen hervorgerufen werden ( $\mathrm{Ma}$ et al. 2008, Sugiyama et al. 2006, Tezval et al. 2010, Wuttke et al. 2008). Zusätzlich sollen diese im Gegensatz zur möglicherweise exogenen Gabe von Testosteron (Lenk 2005) ein geringeres Prostatakrebsrisiko zur Folge haben (Cook et al. 1999, Travis et al. 2009). Aus diesem Grund wurde neben den Sexualhormonen auch die Wirkung von Phytohormonen auf die Knochenapposition der männlichen Ratte untersucht.

Das Aglukon Genistein (GEN) stellt neben Daidzein eines der wichtigsten Isoflavone dar (Abb. 6). 1931 wurde es zum ersten Mal von Walter (1941) aus Sojabohnen isoliert (Walter 1941). Der hormonelle Einfluss dieses Stoffes wurde jedoch erst anhand unfruchtbarer Schafe, die auf der Weide Klee zu sich nahmen, deutlich (Bennetts 1946). Als Isoflavon ist GEN in der Lage an ERa und ERß zu binden. Allerdings besitzt Genistein im Vergleich zu 17ß-Östradiol mit $87 \%$ eine höhere Affinität für ER $\beta$ als für ERa mit $4 \%$ (Kuiper et al. 1998). Nach Verzehr von gebackenem Soja-Pulver weist GEN im Gegensatz zu Daidzein die höchste Plasmakonzentration auf und besitzt 
zugleich die längste Halbwertszeit. Zusätzlich konnte eine höhere Bioverfügbarkeit durch die Auswertung der Summe von Urin- und Faeceswerten ermittelt werden (Watanabe et al. 1998). Im Hinblick auf die Therapie der Osteoporose sind besonders die Wirkungen auf den Knochen von Bedeutung. Dabei konnten in vitroVersuche eine Stimulation der Osteoblasten (Sugimoto und Yamaguchi 2000, Uchiyama und Yamaguchi 2007) und eine Inhibition der Osteoklasten (Gao und Yamaguchi et al. 2000) ermitteln. Gleichzeitig wurden osteoprotektive Wirkungen des GEN sowohl auf weibliche Nager (Ishimi et al. 1999, Ishimi et al. 2000) als auch auf männliche Nager (Fujioka et al. 2007, Ishimi et al. 2002) erfasst. Auch der kombinierte Einfluss

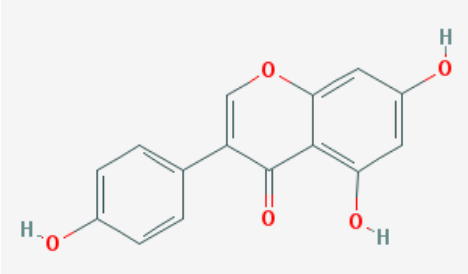
von Bewegung und GEN-Gabe zeigte positive Effekte auf den Knochen (Hertrampf et al. 2007, Wu et al. 2003). Zusätzlich wurden Wirkungen auf den Knochen von postmenopausalen Frauen beobachtet, die GEN als mögliche Alternative für die Hormonersatztherapie in Betracht ziehen (Marini et al. 2007, Morabito et al. 2002). GEN scheint zudem in der Lage zu sein, die postmenopausalen Begleiterscheinungen zu lindern, indem es unter anderem den systolischen Blutdruck und die Plasmalipide reduziert sowie den HDL-Cholesterinspiegel verbessert (Bitto et al. 2009).

Equol (EQ) ist ein nicht-steroidales Phytoöstrogen der Isoflavon-Klasse (Abb. 7). Der Name leitet sich von dem lateinischen Begriff „equus“ (dt. Pferd) ab, denn EQ wurde erstmals 1932 von Marian und Haslewood aus dem Urin trächtiger Stuten isoliert. Ein halbes Jahrhundert später konnte es als ein Hauptmetabolit der Soja-Isoflavone, Daidzin und

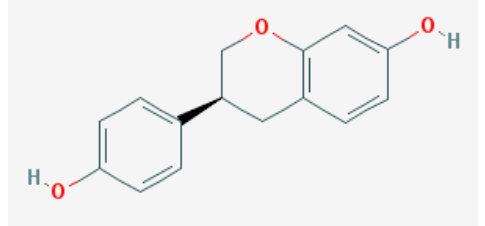

Abb. 7 Stukturformel von Equol (EQ) mit der Summenformel: $\mathrm{C}_{15} \mathrm{H}_{14} \mathrm{O}_{3}$ (PubChem $2012 \mathrm{~d}$ ).
Daidzein, identifiziert werden (Mathey et al. 2007, Setchell und Clerici 2010). Dabei stellt EQ das Endprodukt des intestinalen, bakteriellen Metabolismus aus Diadzein dar. Allerdings können zwei Subpopulationen von Menschen unterschieden werden. Nur 20 - 35 \% der Erwachsenen sind in der Lage EQ zu bilden. Demnach wird in der Literatur zwischen EquolProduzenten und NonEquol-Produzenten unterschieden (Setchell et al. 2002). EQ kann sowohl als S- als auch R-Enantiomer vorliegen. Jedoch werden von den menschlichen Darmbakterien nur S-Enantiomere synthetisiert (Setchell et al. 2005). Genau diese Struktur besitzt eine hohe Bindung zum ER $\beta$ 
(Setchell et al. 2002, Setchell et al. 2005), wobei Equol sogar eine höhere Affinität zum ERß besitzt als sein Vorläufer Daidzein und diese vergleichbar ist mit der Affinität von Genistein (Muthyala et al. 2004, Setchell et al. 2002, Weaver und Legette 2010). Braidman et al. (2001) konnten den ER $\beta$ sowohl auf Osteoblasten als auch vielfach auf Osteoklasten lokalisieren (Braidman et al. 2001). Dennoch konnte die Wirkungsweise von $E Q$ auf den Knochen noch nicht vollständig aufgeklärt werden (Jackson et al. 2011). Von allen Daidzein-Metaboliten weist EQ in hohen Dosen die beste Fähigkeit auf, die Osteoklastenaktivität zu unterdrücken (Hwang et al. 2006). Gleichzeitig wurde festgestellt, dass Phytoöstrogene, besonders Equol, zu einer verbesserten Knochenqualität führen können (Kolios et al. 2009, Mathey et al. 2007, Tousen et al. 2011) und als Hormonersatztherapie bei fehlenden Nebenwirkungen in Betracht kämen (Sehmisch et al. 2010).

\subsection{Die polychrome Sequenzmarkierung}

Fluoreszenz stellt die kurzzeitige Emission von Licht beim Übergang von einem angeregten Zustand in einen Zustand niedrigerer Energie dar. Dies tritt genau dann ein, wenn Licht einer bestimmten Wellenlänge (Anregung) auf ein Molekül trifft und dadurch für die Absorption von Photonen sorgt.
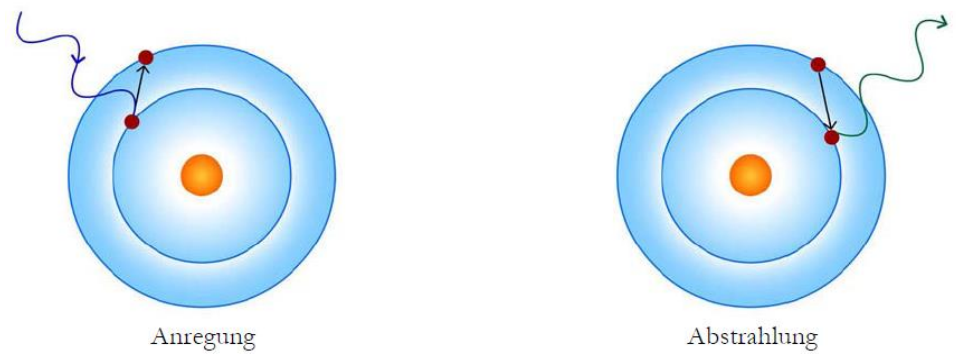

Abb. 8 Fluoreszenzemission - Beim Übergang eines angeregten Zustandes in einen Zustand niedrigerer Energie wird die Energiedifferenz unter anderem in Form von charakteristischer Floureszenzstrahlung frei (Quelle: http://www.univie.ac.at/mikroskopie/pdf/3_Fluoreszenz.pdf).

Gleichzeitig werden Elektronen auf ein energiereicheres Niveau gehoben (Abb. 8). Wenn sie dann in den ursprünglichen Zustand, also ein niedrigeres Energieniveau, zurückfallen, wird die überschüssige Energie in Form von Fluoreszenzlicht und Wärme frei. Durch das Freiwerden der Energie in Licht und Wärme ist das Fluoreszenzlicht langwelliger und dadurch energieärmer als das Licht, mit dem das Molekül angeregt wurde. Dieser Unterschied der Wellenlängen wird nach seinem Entdecker als StokesShift bezeichnet. 
In der Fluoreszenz-Mikroskopie kann unterschieden werden zwischen einer Primärund einer Sekundärfluoreszenz. Als Paradebeispiel für die erstere kann das Chlorophyll der Pflanzen genannt werden, das selbst fluoreszierende Eigenschaften aufweist. Die in diesem Versuch verwendeten Substanzen Calcein und Alizarin sind den Sekundärfluoreszenzen zuzuordnen. Durch sie ist es möglich, die Mineralisation des Knochens darzustellen, indem sie sich an mineralisierte Substanzen anlagern (Fluorochromierung). Folglich kann entkalkter Knochen keine fluoreszierenden Markierungen aufweisen. Der bekannteste Vertreter dieser sekundären Fluorochrome stellt das Tetrazyklin dar. Schon Andre erkannte 1956, dass aus der intravenösen Gabe von Tetrazyklin eine Anreicherung im Knochen der Maus resultiert (Andre 1956). Auch konnte Milch et al. 1957 feststellen, dass die Gabe von Tetrazyklin zu einer Fluoreszenzeinlagerung im Knochen und Weichgewebe mit Ausnahme des Gehirns führte, wobei diese nur im Knochen persistierte. Dies zeigte sich in einer gelb-goldenen Fluoreszenz bei Bestrahlung mit ultraviolettem Licht (Milch et al. 1957). Die Anlagerung des Tetrazyklins an die Mineralisationsfronten beruht auf

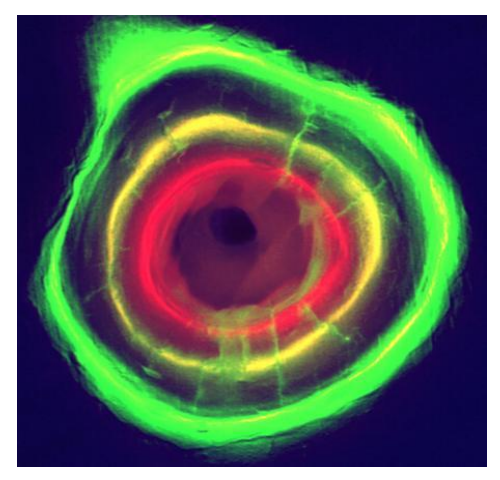

Abb. 9 Rippenquerschnitt mit Fluoreszenzmarkierungen durch Calcein (grün), Tetrazyklin (gelb), Xylenol (rot) (Quelle: Funk 2004, S. 53). der Eigenschaft über freie Elektronenpaare mehrwertige Kationen in ringförmigen Komplexen zu fixieren. Diese Fähigkeit des Chelators Tetrayzyklin führt zu einer Bindung des $\mathrm{Ca}^{2+}$. Auch für die übrigen Fluorochrome wie Calcein oder Alizarin wird angenommen, dass sie sich im verkalkten Gewebe an anorganische Bindungsstellen des Hydroxylapatits heften und Kalzium-Fluorochrom-Chelate bilden (Kerschbaumer 2006). Die Ähnlichkeit der Bandenfarbe der Fluorochrome der Tetrazyklinderivate stellte ein Problem für die einwandfreie Unterscheidung der Banden dar. Harris zeigte eine zweifarbige Markierung des Knochens mittels Tetrazyklin und Alizarin (Harris 1960). Durch die Entdeckung weiterer Fluorochrome wie Calcein blue (Rahn und Perren 1970), Xylenol orange (Rahn und Perren 1971) oder Alizarin-Komplexon (Rahn und Perren 1972) wurde die polychrome Sequenzmarkierung möglich. Diese ist beispielhaft in der Abb. 9 veranschaulicht. Die einzigen für die Menschen zugelassenen Fluorochrome stellt die Gruppe der Tetrazykline dar. Die polychrome Sequenzmarkierung ist Gegenstand der vorliegenden Arbeit. So konnte durch die Verwendung von Alizarin und Calcein die Mineralisationsfront zu unterschiedlichen Zeitpunkten dargestellt und ausgewertet werden. 


\section{Material und Methoden}

Der Tierversuch sollte Auskunft über die mögliche Beeinflussung des Knochenremodellings der defekten Tibia durch die Verabreichung von Hormonen und der Vibration geben. Als Maß für das Knochenremodelling wurde die knöcherne Appositionsrate gewählt, die in der englischen Literatur auch als mineral apposition rate (MAR) bezeichnet wird. Die MAR lässt sich anhand der Fluoreszenzbanden bestimmen. Dafür wurden die histologischen Präparate mit einem Fluoreszenzmikroskop digital aufgenommen, um anschließend mit einem ImageAnalyse-System vermessen und statistisch ausgewertet zu werden.

\subsection{Durchführung des Tierversuchs}

Diese Arbeit basiert auf einem tierexperimentellen Versuch, bei dem die männliche, orchiektomierte Ratte als Modell für die Osteopenie bzw. Osteoporose dient. Dem Versuch lag die Genehmigung durch das Niedersächsische Landesamt für Verbraucherschutz und Lebensmittelsicherheit Oldenburg (LAVES; AZ: G 43.09) zugrunde.

Der Versuch wurde an 172 männlichen Sprague-Dawley Ratten (SD-Ratten, Züchter der Tiere: Winkelmann, Borchen) durchgeführt. Bei Versuchsbeginn waren die Ratten 3 Monate alt und wiesen ein Gewicht von durchschnittlich $355,4 \mathrm{~g}( \pm 18,8 \mathrm{~g})$ auf. Es wurden jeweils 4, zufällig gewählte Ratten pro Käfig gehalten (Makrolonkäfig Typ 4, Firma (Fa) Tecniplast Deutschland $\mathrm{GmbH}$, Hohenpreißenberg), wobei die Tiere von je 3 Käfigen eine Versuchsgruppe bildeten. Zur eindeutigen Identifizierung wurde den Tieren während der Gewöhnungsphase unter Inhalationsnarkose ein Transponder subkutan (s.c.) unter die Nackenhaut implantiert (ISO-Transponder (12 mm), Fa. UNO ROESVASTSTAAL BV Zevenaar, Niederlande). Die Nummer jedes Transponders konnte mit Hilfe eines tragbaren Transponder-Lesegeräts (Gesreader II Ge S008: ISO kompatibler Taschenleser, Fa. UNO ROESVASTSTAAL BV Zevenaar, Niederlande) ermittelt und folglich jede Ratte eindeutig zugeordnet werden.

Die Tiere lebten unter Standardbedingungen bei einer konstanten Raumtemperatur von 21 bis $24{ }^{\circ} \mathrm{C}$ und einer Luftfeuchtigkeit von 50-55 \%. Während der gesamten Zeit waren die Ratten einem Hell-Dunkel-Rhythmus von je 12 Stunden (6-18 h) ausgesetzt. Die Tiere hatten uneingeschränkten Zugang zu sojafreiem Pelletfutter (ssniff® R-Z phytoöstrogenarm, V 1355, Soest) und frischem Trinkwasser. 


\subsection{Versuchsablauf}

Die Tiere wurden gemäß der Tabelle $A 1$ in fünf Futtergruppen und 3 unterschiedliche Versuchslaufzeiten eingeteilt. In der 4-wöchigen Gewöhnungsphase erhielten alle Tiere sojafreies Pelletfutter. Sämtliche Ratten wurden innerhalb von 5 Tagen orchiektomiert. Unter Einhaltung einer 3-tägigen Regenerationszeit erfolgte postoperativ an 5 Tagen in der Woche über einen Zeitraum von 4 Wochen eine 15-minütige Ganz-KörperVibration der Ratten. Nach Abschluss des Vibrationstrainings erfolgte die Trepanation der Tibiae sowie der Austausch des sojafreien Futters (Zeitpunkt 0 siehe Abb. 10). Das neue Futter enthielt industriell beigemischtes Östradiolbenzoat (E2), Dihydrotestosteron (DHT), Genistein (GEN) oder Equol (EQ). Diese mit den Testsubstanzen benötigten Futterarten stellte die Firma Ssniff Spezialitäten GmbH auf Basis des Haltungsfutters „R-Z“ her (Tab. 1). Eine Referenzgruppe (SF) wurde jedoch weiterhin mit sojafreien Pellets versorgt. Die Konzentration der Stoffe orientierte sich an Ergebnissen vorangegangener Studien und veröffentlichter Literatur (Rachón et al. 2007, Sehmisch et al. 2010).

Tab. 1 Futterzusätze E2, DHT, GEN und EQ in $\mathrm{mg} / \mathrm{kg}$; zusätzlich sind sowohl die tatsächliche Futterzusatzaufnahme in $\mathrm{mg} / \mathrm{d}$ als auch die durchschnittliche Futteraufnahme in $\mathrm{g} / \mathrm{d}$ angegeben.

\begin{tabular}{lccc}
\hline Zusätze & $\begin{array}{c}\text { Durchschnittliche } \\
\text { Futteraufnahme } \\
\text { in } \mathbf{~} / \mathbf{d}\end{array}$ & $\begin{array}{c}\text { Futterzusatz } \\
(\mathbf{m g} / \mathbf{k g})\end{array}$ & $\begin{array}{c}\text { Tatsächliche } \\
\text { Futterzusatzaufnahme } \\
\text { in } \mathbf{~ m g / d ~}\end{array}$ \\
\hline E2 & 17,2 & 10 & 0,17 \\
DHT & 21,2 & 1000 & 21,2 \\
GEN & 20,7 & 1000 & 20,7 \\
EQ & 20,5 & 400 & 8,2 \\
\hline
\end{tabular}

Für die spätere Fluoreszenzauswertung wurden den Ratten die Fluorochrome Calcein und Alizarin injiziert. Die Applikation von Calcein fand 10 Tage nach Beginn des 1. Vibrationstrainings statt. Alizarin ist dagegen 3 Tage nach Abschluss der Trepanation aller Tibiae und Futterumtausch (Abb. 10, $\mathrm{t}_{0}$ ) verabreicht worden. Insgesamt lagen 28 Tage zwischen der Gabe der Fluoreszenzen.

Zwei Wochen nach dem Futterumtausch wurde die 1. Serie und nach 3 Wochen die 2. Serie der Tiere geopfert. Die Hälfte der Ratten der 3. Serie wurde erneut über einen Zeitraum von 4 Wochen vibriert. Danach fand die Opferung aller Tiere der 3. Serie statt. Dafür wurden die Ratten durch die inhalative Gabe von $\mathrm{CO}_{2}$-Gas in Narkose 
versetzt, um dann dekapitiert zu werden. Nachfolgend konnte mit der histologischen Aufarbeitung begonnen werden.

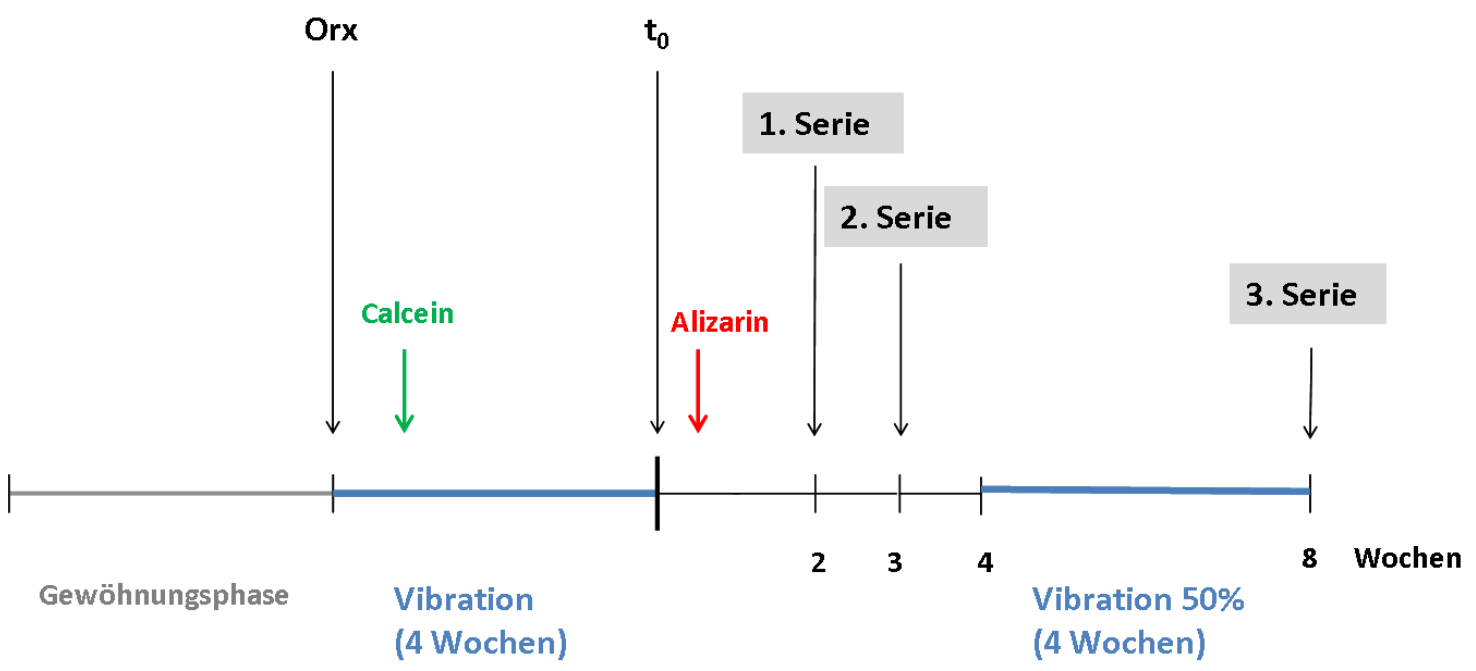

Abb. 10 Darstellung des Versuchsablaufs; 172 Ratten wurden anfänglich einer 4-wöchigen Gewöhnungsphase unterzogen, um anschließend orx zu werden. Im Anschluss erfogte eine GKV über 4 Wochen. Am 10. Tag der Vibrationsphase wurde die Calcein-Gabe verabreicht. $T_{0}$ stellt den Zeitpunkt des Futtertausches und der Tibia-Trepanation dar. 3 Tage nach $\mathrm{T}_{0}$ wurde die Fluoreszenz Alizarin appliziert. Die Tiere der 1. und 2. Serie wurden nach 2 bzw. 3 Wochen geopfert. Die Opferung der 3. Serie fand dagegen nach 8 Wochen statt, wobei $50 \%$ der Tiere einer zusätzlichen GKV unterzogen wurden.

\subsection{Orchiektomie (Orx)}

Nach der Eingewöhnungsphase wurden alle Ratten orchiektomiert. Der Eingriff fand in Inhalationsnarkose mit Isoflurane statt. Die Inhalationsmaske war dabei mit einem Flowmeter (SF3, UNO ROESVASTSTAAL BV, Zevenaar, Niederlande) und einem Kleintiernarkosegerät (Penlon Sigma Delta, Penlon Limited Abington, Oxon, Großbritannien) verbunden.

Nach Rasur des Fells wurde die Skrotalhaut über dem getasteten Hoden medial inzidiert. Das darunter liegende, viszerale Peritoneum musste durchtrennt werden. Nach Freipräparation des Hodens und dadurch eindeutige Darstellung wurde der Ductus epididymidis und dessen Blutversorgung durch chirurgisches Nahtmaterial ligiert und nachfolgend entfernt.

Dieses Vorgehen wurde auf der kontralateralen Seite ebenfalls durchgeführt. Nach der Blutstillung erfolgte der Verschluss aller eröffneten Strukturen mit sterilem Nahtmaterial (Vicryl $^{\mathrm{TM}}$ 3-0, resorbierbares Nahtmaterial, Ethicon $\mathrm{GmbH}$, Norderstedt) per Einzelknopf-Nahttechnik. Zur postoperativen Entzündungshemmung und Schmerztherapie wurde den Tieren subkutan 0,1 mg Metacam ${ }^{\circledR}$ (Wirkstoff: Meloxicam, 
Boehringer Ingelheim Vetmedica $\mathrm{GmbH}$, Ingelheim/Rhein) verabreicht. Zum Aufwachen aus der Narkose befanden sich die Tiere in einem gesonderten Käfig ohne Einstreu und standen unter Beobachtung, um anschließend in ihren ursprünglichen Haltungskäfig umgesetzt zu werden.

\subsection{Die Vibrationstherapie}

Drei Tage nach Orchiektomie wurden alle Ratten einer Ganz-Körper-Vibration (GKV) unterzogen. Diese fand über 4 Wochen an fünf Tagen statt. Zwischen 8:00 und 16:00 Uhr wurden die Ratten in immer wieder wechselnder Reihenfolge der Käfige den Schwingungen ausgesetzt. Für die Hälfte der Tiere der 3. Serie ist dieses Training zu einem späteren Zeitpunkt unter gleichen Bedingungen nochmals über 4 Wochen vollzogen worden. Zur Verfügung stand das SwingVibe® Ganz-Körper-Vibrationsgerät (SwingVibe Professional, Softwareversion:v.4.03; Fa. Best-Sportequipment GmbH, Weilburg/Hirschhausen) im Modus „Monoswing“. Durch diesen Modus verlaufen die Schwingungen vertikal zur Vibrationsplatte und sind an jeder Stelle der Platte gleich stark. Je 2 Käfige wurden ohne Einstreu, Futter und Wasser auf die Rüttelplatte gestellt, um dann mit Nylongurten an dieser fixiert werden zu können. Insgesamt erfolgte die Ganz-Körper-Vibration über 15 Minuten, wobei unterschiedliche Frequenzen gewählt wurden. Die ersten 5 Minuten wurden bei $25 \mathrm{~Hz}$ festgelegt, um dann von einer $30 \mathrm{~Hz}$ Frequenz für 10 Minuten abgelöst zu werden.

\subsection{Die Trepanation}

Auf die Orchiektomie folgte nach 4 Wochen die Trepanation beider Tibiae jeder Ratte. Während der Behandlung waren die Tiere durch Isoflurane anästhesiert. Zur Analgesie wurden 0,1 ml pro $500 \mathrm{~g}$ Körpergewicht (KG) Metacam® (Fa. Boeringer) s.c. verabreicht.

Der erste Schritt ist das Entfernen des Rattenfells im Bereich der hinteren Extremitäten mit einem Elektrorasierer gewesen (Arco, Fa. Moser GmbH, Unterkirnach). Woraufhin eine 8 - $10 \mathrm{~mm}$ lange Haut- und Periostinzision $3 \mathrm{~mm}$ unterhalb des Kniegelenkes auf der Vorderseite der Tibia mit Hilfe eines 15er Skalpells vorgenommen wurde. Mit dem Raspatorium nach Partsch wurde dann die mediale Knochenfläche der Tibia freipräpariert, sodass mittels eines Knochenbohrers (1,5 mm Durchmesser) die Trepanation der Kortikalis im Bereich der Diaphyse angelegt werden konnte. Während dieses Vorganges erfolgte ein permanentes Spülen und Kühlen mit isotoner $\mathrm{NaCl}$ Lösung. Abschließend wurde die Hautwunde einschichtig mit einem 4-0 monophilen 
Kunststofffaden (Ethilon II ${ }^{\mathrm{TM}}$ 4-0, Fa. ETHICON GmbH, Norderstedt) verschlossen. In den darauf folgenden 2 Tagen erhielten die Tiere zur Schmerzprophylaxe 0,2 ml Metacam ${ }^{\circledR}(\mathrm{Fa}$. Boeringer) subkutan.

\subsection{Fluoreszenzmarkierung}

Die in den jeweiligen Serien gewonnenen Knochenmaterialien sollten der histologischen Aufarbeitung zur Verfügung stehen. Aus diesem Grund wurden den Versuchstieren zu zwei unterschiedlichen Zeitpunkten 2 verschiedenfarbige Fluoreszenzfarbstoffe verabreicht, um die Knochenheilung und -bildung bewerten zu können. Zehn Tage nach Beginn der ersten Vibration wurde den Ratten Calcein s.c. verabreicht. Dagegen erfolgte die Gabe von Alizarin (Merk, Darmstadt) 3 Tage nach Trepanation aller Ratten und Futterumtausch. Die jeweiligen Dosierungen sind in Tabelle 4 angegeben.

Tab. 2 Lösung, Dosierung ( $\mathrm{mg} / \mathrm{kg} \mathrm{KG)}$ und der Fluoreszenzen Calcein und Alizarin, die in einem zeitlichen Abstand von 28 Tagen verabreicht wurden.

\begin{tabular}{|c|c|c|c|}
\hline Fluorochrom & $\begin{array}{c}\text { Lösung } \\
\mathbf{g} / \mathbf{m l} \text { aqua dest. }\end{array}$ & $\begin{array}{c}\text { Dosierung } \\
\mathbf{m g} / \mathbf{k g ~ K G}\end{array}$ & Applikationszeitpunkt \\
\hline Calcein & $9 \mathrm{~g} / 100 \mathrm{ml}$ aqua dest. & 10 & $\begin{array}{c}\text { 10 Tage nach Beginn } \\
\text { der 1. Vibration }\end{array}$ \\
\hline Alizarin & $3 \mathrm{~g} / 100 \mathrm{ml}$ aqua dest. & 30 & $\begin{array}{c}\text { 3 Tage nach } \\
\text { Zeitpunkt } 0\end{array}$ \\
\hline
\end{tabular}

\subsection{Histologische Aufarbeitung}

Die Herstellung histologischer Hartschnittpräparate erforderte 3 Schritte: Die Fixierung, die Einbettung und das Schneiden. Aus diesem Grund wurden die Tibia-Präparate der Ratten 1 Woche lang in 4\%iger, neutraler und gepufferter Formalinlösung eingelegt. Dieser Vorgang führt im Wesentlichen zu einer Proteinfällung. Zur Vorbereitung auf die nachfolgende Einbettung mussten die Präparate mehrere Tage mit Alkohol in ansteigender Konzentration dehydriert werden (Ethanol 70-100\%), um dann für 72 Stunden in ein organisches Intermedium (z.B. Xylol) eingebracht zu werden. Dabei dient Xylol zum Entfetten der Knochenzylinder.

Der nächste Schritt bestand in der Einbettung der unentkalkten Tibia-Präparate in Kunststoff auf Methylmethacrylat-Basis (Technovit 9100®, Heraeus Kulzer GmbH, 
Wehrheim). Dafür wurden die Tibiae in einer Einbettform ausgerichtet und anschließend mit einer Polymerisationsmischung überzogen. Insgesamt wurden der proximale Teil der Tibia sowie das anschließende Kniegelenk und ein kleiner, distaler Anteil des Femurs eingebettet. Das Dünnschnittpräparat sollte später einen Längsschnitt durch das Gelenk, den Femur und besonders der Tibia zeigen. Die Kunststoffmischung bestand zu 9 Volumenanteilen aus Stammlösung $\mathrm{A}$ und zu 1 Volumenanteil aus Stammlösung B, unter Mithilfe eines Magnetrührtisches wurden diese zusammengefügt. Zur vollständigen Polymerisation mussten die Einbettformen für 2-3 Tage bei $-8{ }^{\circ} \mathrm{C}$ luftdicht gelagert werden. Die dadurch entstandenen Blöcke mit den eingeschlossenen Knochenpräparaten wurden mit Hilfe eines Hartschnittmikrotoms (Leica RM 2165, Leica Biosystems GmbH, Nussloch) in $5 \mu \mathrm{m}$ dicke Längsschnitte geschnitten. Während des Schneidevorgangs musste $40 \%$ iges Ethanol auf die Dünnschnitte aufgetragen werden. Dadurch konnte ein Abschwimmen der Präparate vom Kunststoffblock erreicht und ein mögliches Abrollen der Schnitte verhindert werden. Diese wurden auf einen mit Alkohol benetzten Objektträger aufgezogen, um dann durch 96\%iges Ethanol gestreckt und abschließend mit Kisolfolie bedeckt zu werden. Die überschüssige Flüssigkeit konnte daraufhin durch Filterpapier abgesaugt werden. Über Nacht mussten die Präparate bei $+50^{\circ} \mathrm{C}$ unter Druck getrocknet werden. Insgesamt standen 10 Dünnschnitte zur Verfügung. Davon wurden 2 Längsschnitte nach Goldner koloriert und für eine zusätzliche Auswertung verwendet. Die übrigen 8 Präparate standen der Fluoreszenzauswertung zur Verfügung.

\subsection{Histometrie und Imageanalyse der Appositionsrate}

Die Fluoreszenzpräparate jeder Ratte konnten mit Hilfe eines hochauflösenden Mikroskops (Axioskop 2 plus, Fa. Zeiss, Carl Zeiss Microlmaging GmbH, Jena) ausgewertet werden. Die Präparate wurden mittels einer HBO-Lampe, einer energiereichen Quecksilberdampf-Kurzbogenlampe, und einem geeigneten Fluoreszenzfilter (Filtersatz 16, Zeiss) im Auflichtstrahlengang zum Leuchten der Calcein- und Alizarinbande angeregt. Durch die gleichzeitig angeschlossene digitale Farbkamera (Axio Cam MRc5, Fa. Zeiss, Carl Zeiss Microlmaging $\mathrm{GmbH}$, Jena) und die Mikroskop-Software Axio Vision Vernon 4.8 (Fa. Zeiss, Carl Zeiss Microlmaging $\mathrm{GmbH}$, Jena) konnten die Präparate digital dokumentiert werden. Es konnte die optimale Belichtungszeit, der Kontrast und die Helligkeit ermittelt werden, um eine geeignete Bildqualität für die Auswertung sowohl der Calcein- als auch der Alizarinbande zu erreichen. 


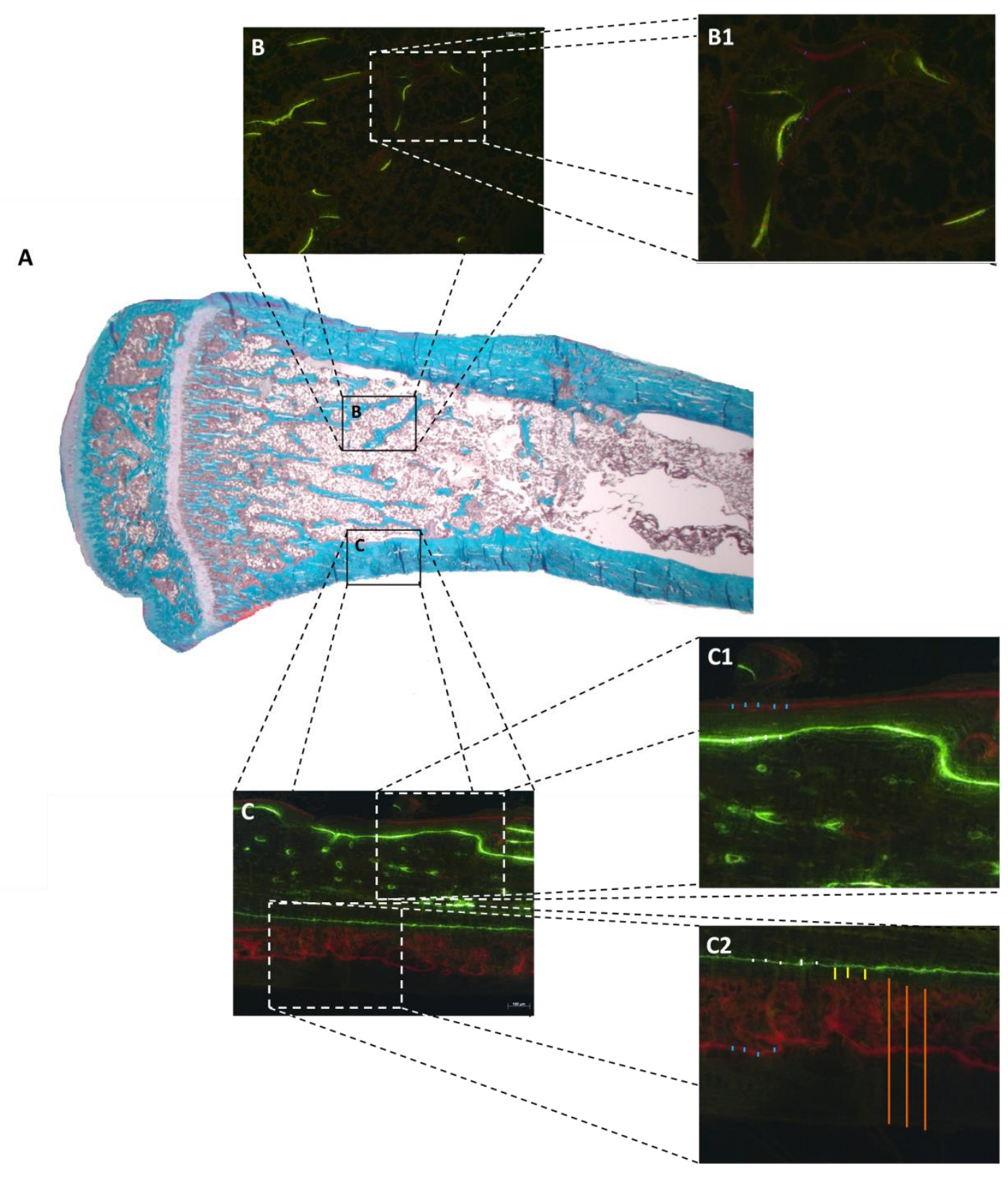

Abb. 11 Imageauswertung; A) Tibialängsschnitt nach Goldner gefärbt, B) zeigt Spongiosa markiert durch Alizarin (rot) und Calcein (grün), B1 Ausschnittvergrößerung aus B mit Messbalken zur Bestimmung der Bandendicke, C) Kortikalisübersicht mit Vergrößerung der periostalen (C2) und endostalen (C1) Seite, erkennbar sind beispielhafte Messungen der Calcein- und Alizarinbande sowie der Abstandsmessung (gelb) und Bestimmung der Geflechtknochendicke (orange).

Von jeder Ratte wurden Spongiosa- und Kortikalisbilder beider Seiten in 10-facher Vergrößerung und mit ähnlicher Belichtungszeit angefertigt (Abb. 11). Es musste für alle Präparate die gleiche Vergrößerung gewählt werden, um die Vergleichbarkeit zu gewährleisten. Die Fluoreszenzbanden der Spongiosa- und Kortikalisbilder konnten 
durch die Software Sigma Scan Pro (Sigma Scan Pro 5.0, SPSS Inc., Chicago, USA) am Computer vermessen und statistisch ausgewertet werden. Mit Hilfe dieses Programmes war es möglich, die Bandendicke beider Fluoreszenzfarbstoffe zu bestimmen.

Dafür konnten senkrechte Messbalken, die die Dicke der Fluoreszenzbanden erfassten, eingezeichnet werden. Die Messbalken wurden im Abstand von etwa $50 \mu \mathrm{m}$ eingefügt. Grundsätzlich ließen sich die Kortikalisbilder in zwei Abschnitte einteilen: periostale Seite mit bzw. ohne Geflechtknochen und endostale Seite.

Auf der periostalen Seite konnte die Breite des vorhandenen Geflechtknochens und die in ihm enthaltenen Alizarinbanden ausgewertet werden. Die Dicke entsprach dabei dem äußersten periostalen Anteil des Geflechtknochens bis zur innersten Alizarinbande des Geflechtknochens (Abb. $11 \mathrm{C} 2$, orange und blaue Markierung).

Das Ausmaß des Remodellings der nach innen folgenden, periostalen Calcein-Bande sowie der Abstand zum Geflechtknochen wurde durch die Messung der Fluoreszenzbande erfasst (Abb. $11 \mathrm{C} 2$, weiße und gelbe Markierung). Die beim Fehlen des Geflechtknochens vorhandene Alizarinbande, die parallel zur Calceinbande verläuft, konnte ebenfalls einer Breitenmessung unterzogen werden. Sowohl die Geflechtknochenabstände als auch die Geflechtknochendicke wurden jeweils nach $100 \mu \mathrm{m}$ gemessen. Dagegen erfolgte die Messung der Bandendicke in einem Abstand von $50 \mu \mathrm{m}$.

Auch auf der endostalen Seite der Kortikalis konnten die Bandendicke der Fluoreszenzen Alizarin und Calcein in gleicher Weise bestimmt werden (Abb. 11 C1, weiße und blaue Markierungen). Das geschilderte Vorgehen wurde an den Spongiosabildern wiederholt (Abb. 11 B1, blaue und rote Markierungen).

Zusätzlich wurden die Mittelwerte der Alizarin- und der entsprechenden Calceinbanden graphisch zueinander in Beziehung gesetzt. Da die Bandenbreite der Fluorochrome selbst als ein Maß für die Höhe der Knochenapposition aufgefasst werden kann. Dabei diente der Calcein-Mittelwert der jeweiligen Futtergruppe als $100 \%$-Referenzwert. Gleichzeitig wurde die Alizarinbande dagegen prozentual aufgeführt. Dafür muss sichergestellt sein, dass beide Farbstoffe unter gleichen Bedingungen identische Bandenbreiten ergeben. Zur Klärung dieser Problematik wurde ein Vorversuch durchgeführt, bei dem jeweils 4 Tiere Calcein und Alizarin im Abstand von 4 Tagen und 4 weitere Tiere die beiden Farbstoffe zur gleichen Zeit hintereinander verabreicht bekamen. Die entnommenen Tibiae wurden analog des Hauptversuches präpariert und analysiert. Bei beiden Vorversuchsgruppen wurden für den jeweiligen Farbstoff nicht signifikant verschiedene Bandenbreiten gefunden. Die Bandenbreiten von Calcein und Alizarin unterschieden sich jedoch signifikant. Die Mittelwerte und die 
Standardabweichung betrug dabei für Calcein 5,66 \pm 2,59 $\mu \mathrm{m}$ und für Alizarin 6,38 $\pm 2,55 \mu \mathrm{m}(\mathrm{n}=109)$. Die Alizarinbanden waren somit um $13 \%$ größer als die

Calceinbanden (t-test, $\mathrm{P}=0,042)$. Um die Vergleichbarkeit dieser beiden Fluoreszenzen für die relative Apposition zu gewährleisten, wurden die Mittelwerte der Alizarinbanden für die jeweiligen Futtergruppen um $13 \%$ reduziert.

\section{$3.9 \quad$ Statistik}

Die Aufbereitung der erfassten Daten sowie deren Auswertung und graphische Darstellung erfolgte mit Hilfe der Software SigmaSTAT und SigmaPLOT (SPSS Inc., Chicago, USA). Es wurden alle Daten als Messreihen in Spalten erfasst und bei Normalverteilung als Mittelwerte (Mean) \pm Standardabweichung (SD) bzw. Standardfehler (SEM) wiedergegeben. Nicht normal verteilte Werte wurden als Mediane und $25 \%$ bzw. $75 \%$ Perzentilen dargestellt. Die Signifikanztestung wurde mit der Varianzanalyse und dem Holm-Sidak-Test bei normalverteilten Werten vorgenommen und auf ein Niveau von $p \leq 0,05$ festgelegt. Nicht parametrische Daten wurden entsprechend der ANOVA und dem ad-hoc-Test nach Kruskal-Wallis oder dem Test nach Dunn zum Gruppenvergleich ausgewertet. 


\section{Ergebnisse}

In den histologischen Präparaten lassen sich in den Längsschnitten der Tibia der proximale Gelenkkopf mit der Epiphyse und der Spongiosa sowie die beiden Kortikalisausschnitte deutlich erkennen. In vielen Schnitten ist auch das Bohrloch sichtbar. In diesen Bereichen ist über längere Kortikalisabschnitte Geflechtknochen in unterschiedlicher Dicke der Kompakta aufgelagert.

\subsection{Ergebnisse der polychromen Sequenzmarkierung}

Allen Tieren wurden zu 2 unterschiedlichen Zeitpunkten die Fluorochrome Calcein und Alizarin verabreicht. In der Tibia lassen sich charakteristische Fluoreszenzbanden im Bereich der Diaphyse erkennen. Im Längsschnitt der Tibia ist die Kortikalis zweimalig angeschnitten, wobei sich eine Kortikalis in der Nähe der Trepanationsöffnung befindet oder dieses sogar gleichzeitig angeschnitten ist (Abb.11).
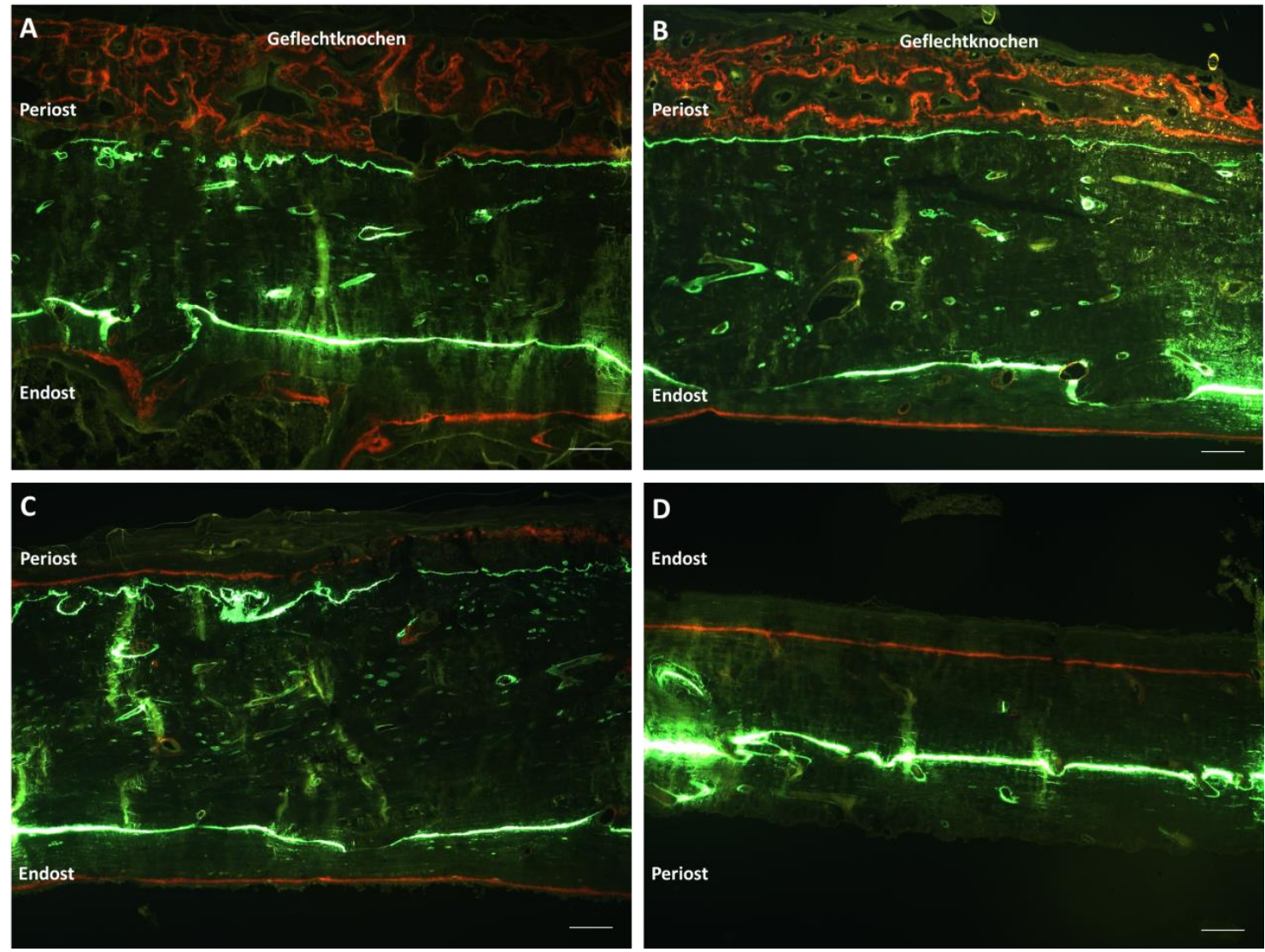

Abb. 12 Kortikalisausschnitte (A-D) mit den Fluoreszenzen Alizarin (rot) und Calcein (grün); A-C) zeigen Fluoreszenzbanden in der Nähe der Trepanationsöffnung; A) und B) mit Geflechtknochen; C) ohne Geflechtknochen allerdings mit periostaler Alizarinbande; D) Fluoreszenzbandenverlauf in der Kortikalis gegenüber der Trepanationsöffnung; Größenstandard: $100 \mu \mathrm{m}$. 
Mit Nähe zum Trepanationsloch zeigt die Kompakta charakteristische Fluoreszenzeinlagerungen, die sich von denen der gegenüberliegenden Kortikalis unterscheiden. Die Kompakta mit Nähe zur Trepanationsöffnung zeigt periostal anliegenden Geflechtknochen (vgl. Abb. 12 A-B mit Abb. 12 D). Dieser ist ausschließlich durch die Fluoreszenz Alizarin farblich markiert. Die roten Banden liegen dabei schleifenförmig übereinander (Abb. 12 A-B). Unterhalb des periostalen Geflechtknochens befindet sich eine schmale Calceinbande (Abb. 12 A-B). Bei gleichzeitigem Anschnitt des Trepanationsloches zeigt sich, dass dieses von Geflechtknochen ausgefüllt ist (Abb. 13).
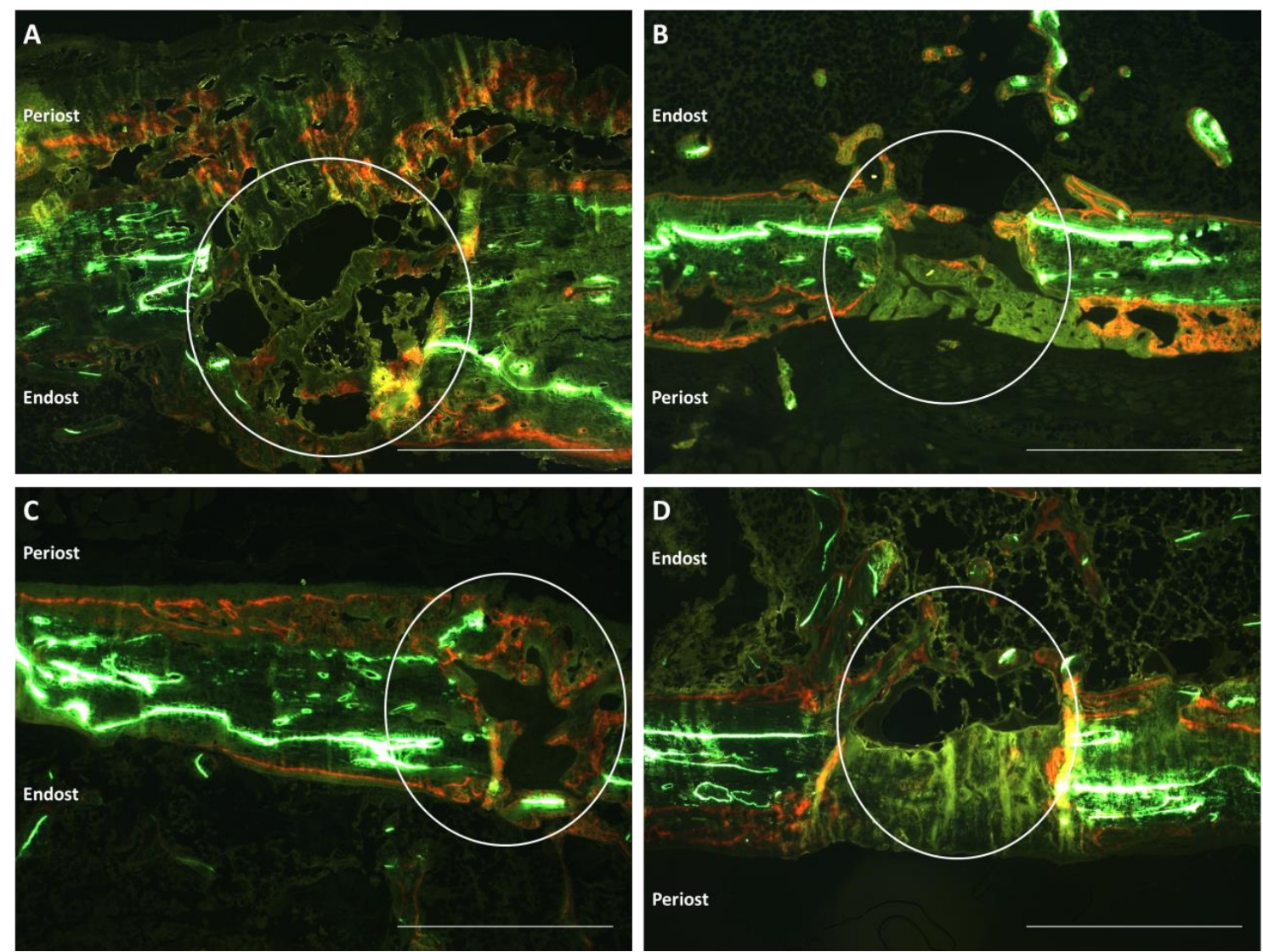

Abb. 13 A-D) zeigen Trepanationslöcher der Kortikalis (Kreis), beschriftet sind jeweils die periostale und endostale Seite der Kortikalis; A-B) Bohrlöcher der 1. Serie; C) der 2. Serie; D) der 3. Serie; Größenstandard: $1000 \mu \mathrm{m}$.

Statt Geflechtknochen lässt sich in einigen histologischen Präparaten eine periostale Alizarinbande finden, die parallel zur Calceinbande verläuft (Abb. $12 \mathrm{C}$ ). Die endostale Seite der Kortikalis, die sich in enger räumlicher Beziehung zum Trepanationsloch befindet, zeichnet sich durch den parallelen Verlauf sowohl einer Calcein- als auch einer Alizarinbande aus (Abb. 12 A-C). Abbildung 12 D zeigt im Gegensatz zu den Abbildungen 12 A-C einen Ausschnitt einer Kortikalis mit größerem Abstand zum 
Trepanationsloch. Die Kompakta ist durch einen unregelmäßigeren Verlauf von nur 2 Fluoreszenzbanden und fehlenden Geflechtknochen gekennzeichnet. Charakteristisch ist die parallel zum Endost verlaufende Alizarinbande. Auf der periostalen Seite hingegen zeigt sich eine Calceinbande, die sich durch einen wechselnden Verlauf auszeichnet. Dabei ist es möglich, dass die Bande vom Endost ins Periost oder umgekehrt kreuzt.

Der Spongiosaraum ist durch Trabekel markiert, die im Bereich der Diaphyse sowohl Calcein- als auch Alizarinbanden aufweisen. Mit zunehmender Nähe zur Epiphysenfuge lassen sich ausschließlich Trabekel mit Alizarinbanden vorfinden. Abbildung 13 zeigt die Trepanationslöcher nach 2, 3 und 8 Wochen. Während nach 2 Wochen die Trepanationsöffnungen von Geflechtknochen ausgefült werden, ist die Kontinuität der Kortikalis nach 8 Wochen schon fast vollends durch Lamellenknochen hergestellt.

\subsection{Analyse des Geflechtknochens}

Der Geflechtknochen stellt unreifen Knochen dar, der als Reaktion auf einen Reiz gebildet wird. Um das Ausmaß der Geflechtknochenbildung zu charakterisieren, wurde die Geflechtknochendicke, die Bandenbreite der Alizarin-Fluoreszenz und der Abstand der Alizarin- zur Calceinbande gemessen.

Grundsätzlich weisen die Ratten 2 Wochen nach Trepanation und Futterumtausch die höchsten Werte der Geflechtknochendicke auf (Abb. 14). Die mit SF-Futter versorgten Tiere dienen als Kontrollgruppen und zeigen in jeder Serie einen dicken Geflechtknochen. Nach 2 Wochen besitzen die mit EQ behandelten Ratten mit $348 \mu \mathrm{m}$ signifikant dickeren Geflechtknochen als die Kontrollgruppe. Auch die mit DHT und E2 behandelten Tiere zeigten signifikant dickeren Geflechtknochen als die Kontrollgruppe (siehe Tab.1-A).

Für die unterschiedlichen Therapiegruppen sind im Verlauf der 2. bis 8. Woche abnehmende Geflechtknochendicken zu erkennen. Nach 3 Wochen beträgt die Geflechtknochendicke grundsätzlich etwa $200 \mu \mathrm{m}$. Für diesen Zeitpunkt ist der höchste Wert für die mit SF- Futter versorgten Ratten mit $242 \mu \mathrm{m}$ zu verzeichnen. Dagegen liegt der Wert für die mit DHT behandelten Ratten nur bei etwa $180 \mu \mathrm{m}$. Mit Ausnahme der GEN-behandelten Tiere zeigen die übrigen Futtergruppen eine signifikant geringere Geflechtknochendicke gegenüber der Kontrollgruppe. 
8 Wochen nach Hormongabe und Trepanation nimmt die Geflechtknochendicke weiter ab, wobei grundsätzlich die Dicke der nicht zusätzlich vibrierten Ratten geringer ist als die der vibrierten Ratten.
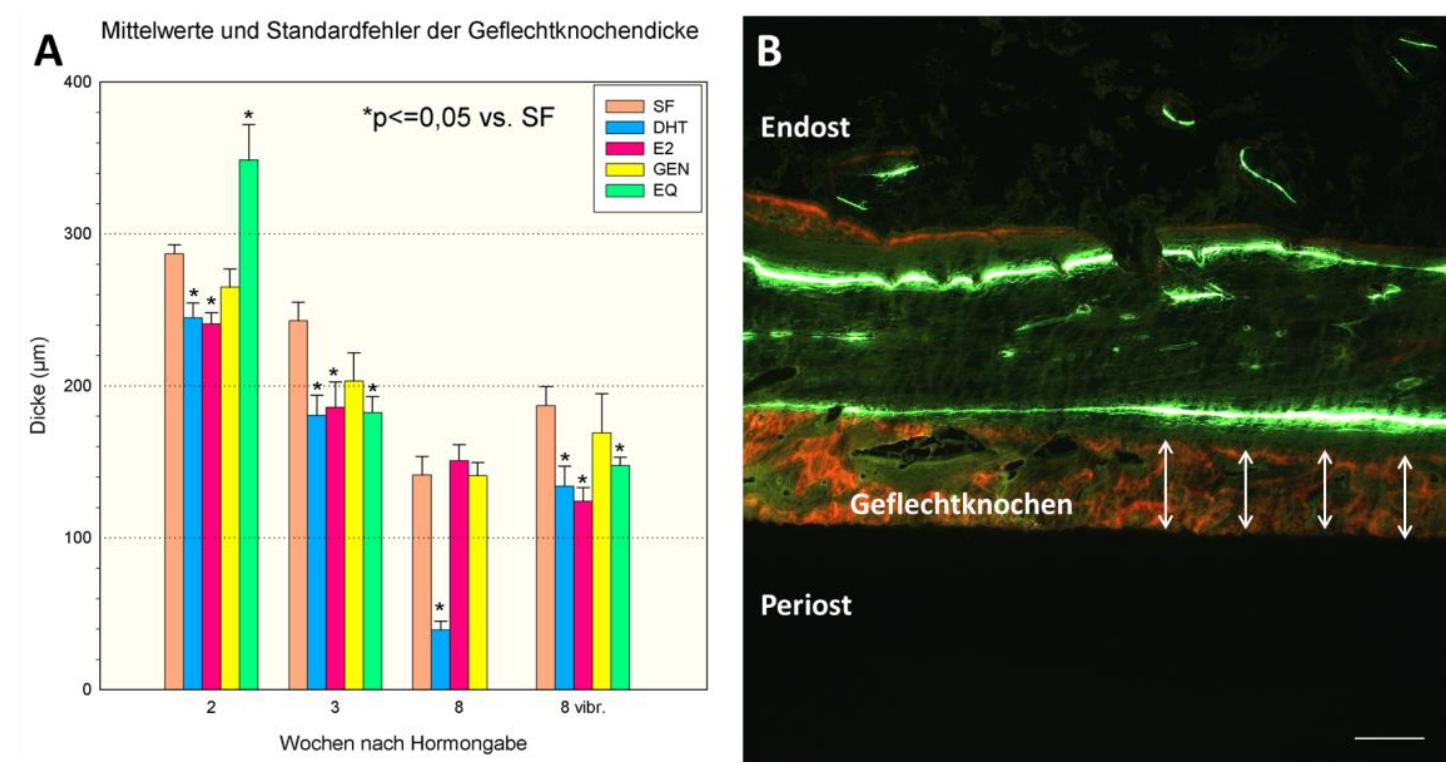

Abb. 14 Mittelwerte und Standardfehler der Geflechtknochendicke (A) nach 2-, 3- und 8-wöchiger Substanzapplikation in der SF-, DHT-, E2-, GEN- und EQ-Gruppe; die zusätzlich noch einmal vibrierten Tiere sind mit 8 vibr. gekennzeichnet ( ${ }^{*} p \leq 0,05$ vs. SF; $5 \leq n \leq 64$; ANOVA und multipler Vergleich nach Holm-Sidak). Das rechte Bild (B) zeigt einen Kortikalis-Ausschnitt in 10x Vergrößerung, Pfeile markieren die Dicke des Geflechtknochens; Größenstandard: $100 \mu \mathrm{m}$.

Der Geflechtknochen der mit E2 und GEN behandelten, in der 8. Woche nicht vibrierten Tiere ist dicker als bei den Tieren der SF-Gruppe. Die mit DHT versorgten Tiere weisen dagegen eine signifikant geringere Geflechtknochendicke auf. Für die mit $E Q$ behandelten Ratten konnte kein messbarer Geflechtknochen ermittelt werden.

Ratten, die zwischen der 3. und 8. Woche zusätzlich noch einmal vibriert wurden, zeigen mit Ausnahme der mit E2 versorgten Ratten im Vergleich zu den nicht zusätzlich vibrierten Ratten der 8. Woche eine größere Geflechtknochendicke. Auch für die mit EQ gefütterten Tiere konnte die Dicke des Geflechtknochens gemessen werden. Der höchste Wert von ca. $187 \mu \mathrm{m}$ wurde für die Tibia der mit SF-Futter versorgten Ratten ermittelt. Für die mit DHT behandelten Ratten ist im Gegensatz zu den nicht vibrierten Ratten der gleichen Futtergruppe der 8. Woche ein Geflechtknochendickenzuwachs von $39,3 \mu \mathrm{m}$ auf $134 \mu \mathrm{m}$ erkennbar. Dahingegen zeigen die mit E2 versorgten Ratten in der 3. und zugleich vibrierten Serie mit ca. 124,2 $\mu \mathrm{m}$ ihren geringsten Wert im Vergleich zu den übrigen Serien. Nur die Tiergruppe mit GEN-Zusatz zeigt keine signifikanten Veränderungen gegenüber den mit SF-Futter behandelten Tieren. 
Der niedrigste Wert $(39,4 \mu \mathrm{m})$ aller Serien wurde für die Tiere mit DHT-Zusatz in der 8., nicht zusätzlich vibrierten Woche ermittelt. Mit Ausnahme der 3., unvibrierten Serie weisen die Ratten, denen DHT und E2 unter das Futter gemischt wurde, in allen Serien ähnliche Werte auf. Diese sind grundsätzlich geringer als die Geflechtknochendicken der Gruppe mit SF- und GEN-Zusatz.

Die Abbildung 15 zeigt die nach 2, 3 und 8 Wochen ermittelte Alizarinbandenbreite im Geflechtknochen. Die Serie nach 8 Wochen wurde dabei jeweils in eine vibrierte und unvibrierte Gruppe unterteilt. Tendenziell ist zu erkennen, dass die Werte für alle Futtergruppen im Verlauf von der 2. bis zur 3. Woche nach Trepanation und Futterumtausch ansteigen und sich in den folgenden Wochen die Größe der Alizarinbande reduziert. Die Ratten mit sojafreiem Futter zeigen fortwährend die geringsten Bandendicken.

Nach 2 Wochen weisen die Tiere der DHT-Futtergruppe die signifikant dickste Alizarinbande mit ca. 5,9 $\mu \mathrm{m}$ auf. Die geringste Bandendicke mit ca. 5,3 $\mu \mathrm{m}$ findet sich für die mit sojafreier Nahrung gefütterten Ratten. Ebenso weisen die Ratten, die mit Equol behandelt wurden, einen signifikant höheren Wert als die KG auf.

A Alizarin-Bandenbreite des Geflechtknochens
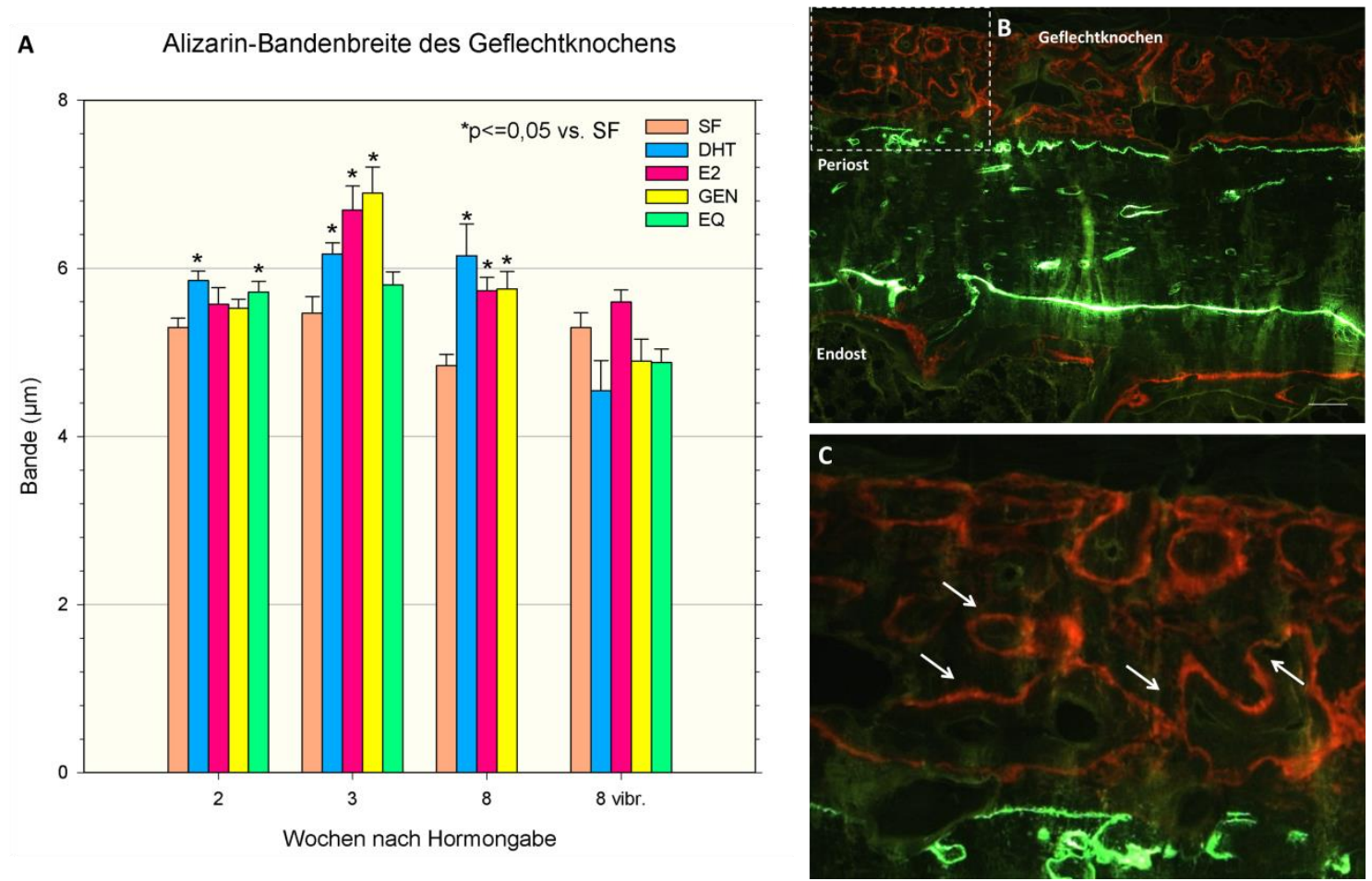

Abb. 15 Mittelwerte und Standardfehler der Alizarinbandenbreite (A) des Geflechtknochens nach 2-, 3und 8-wöchiger Substanzapplikation der SF-, DHT-, E2-, GEN- und EQ-Gruppe; die zusätzlich noch einmal vibrierten Tiere sind mit 8 vibr. gekennzeichnet ( $p \leq 0,05$ vs. SF; $13 \leq n \leq 349$; ANOVA und multipler Vergleich nach Holm-Sidak). Die rechte Bildreihe zeigt eine Kortikalis-Übersicht (B) in 10x Vergrößerung, gestricheltes Kästchen markiert Geflechtknochenausschnitt (C), Pfeile in C) deuten auf Alizarinbande im Geflechtknochen, Größenstandard: $100 \mu \mathrm{m}$. 
Nach 3 Wochen ergibt sich für alle Futtergruppen eine Zunahme im Bereich der Alizarinbande. GEN- und E2-behandelte Ratten besitzen hierbei eine besonders große Fluoreszenzbande. Mit Ausnahme der EQ-Futtergruppe zeigen die übrigen Futtergruppen signifikant höhere Werte gegenüber den SF-Tieren. Nach 8 Wochen nimmt die Größe der Alizarinbande in allen Tieren ab.

Für die mit GEN und E2 behandelten Ratten zeichnen sich ähnliche Werte von 5,7 $\mu \mathrm{m}$ bzw. 5,8 $\mu \mathrm{m}$ ab. Dagegen weist die DHT-versorgte Gruppe keine Veränderungen bezüglich der Alizarinbandengröße auf. Der niedrigste Wert wurde auch hier für die mit sojafreiem Futter behandelten Tiere mit $4,8 \mu \mathrm{m}$ gefunden. Diese Bandendicke liegt damit sogar unter dem Wert, der nach 2 Wochen ermittelt wurde.

Betrachtet man im Gegensatz dazu die Werte der zusätzlich vibrierten Tiere nach 8 Wochen, so ist lediglich der Wert für die SF-behandelten Ratten im Gegensatz zu den unvibrierten Ratten auf 5,3 $\mu \mathrm{m}$ angestiegen. Die Größe der Alizarinbanden für die Futterzusätze DHT, E2 und GEN nimmt dagegen ab. Mit 4,5 $\mu \mathrm{m}$ weisen die mit DHT behandelten Tiere in dieser Serie den geringsten Wert aller untersuchten Tiere auf. Die Tiere mit EQ-Futterzusatz besitzen eine Alizarinbande $(4,9 \mu \mathrm{m})$, die in ihrer Größe vergleichbar ist mit der durch GEN induzierten Bande $(4,9 \mu \mathrm{m})$. Im Vergleich dazu zeigen die vibrierten Ratten nach 3 Wochen eine Reduktion der Bandendicke.

Auffällig ist, dass die mit sojafreiem Futter versorgten Ratten zu allen Zeitpunkten die geringste Bandendicke zeigen. Mit Ausnahme der zusätzlich vibrierten Ratten der 8. Woche wurden für die Tiere, die mit GEN und E2 versorgt worden sind, jeweils ähnliche Werte erhoben. Im Gegensatz zur Geflechtknochendicke weichen die Werte der Alizarinbandenbreite für die Futterzusätze E2 und DHT deutlich voneinander ab.

Nach Ermittlung der Geflechtknochendicke und des Ausmaßes der in ihm enthaltenen Alizarinbande wurde eine mögliche Korrelation untersucht. 2 Wochen nach Trepanation und Futterumtausch zeigen die Ratten unabhängig von ihrer Futtergruppe den dicksten Geflechtknochen. Während sich die Geflechtknochendicke im Versuchsverlauf verringert, besitzt die Alizarinbande für alle Futtergruppen 3 Wochen nach Trepanation und Futterumtausch ihren höchsten Wert (Abb. 16).

Die durchschnittliche Alizarinbandendicke liegt in allen Serien in einem Bereich zwischen $5,39 \mu \mathrm{m}$ und $7,49 \mu \mathrm{m}$. Im Vergleich erweist sich diese für den Geflechtknochen nach 3 Wochen am größten. In den Serien selber zeigt der Geflechtknochen 2 Wochen nach Trepanation und Futterumtausch bei gleichzeitiger Dickenzunahme auch eine geringfügige Vergrößerung der in inm enthaltenen Alizarinbande. Dies lässt sich für die übrigen Serien nicht bestätigen. Der 
Regressionskoeffizient liegt in allen Serien zwischen 0,01 und 0,0003, d.h. die Geflechtknochendicke korreliert nicht mit der Breite der Alizarinbande.

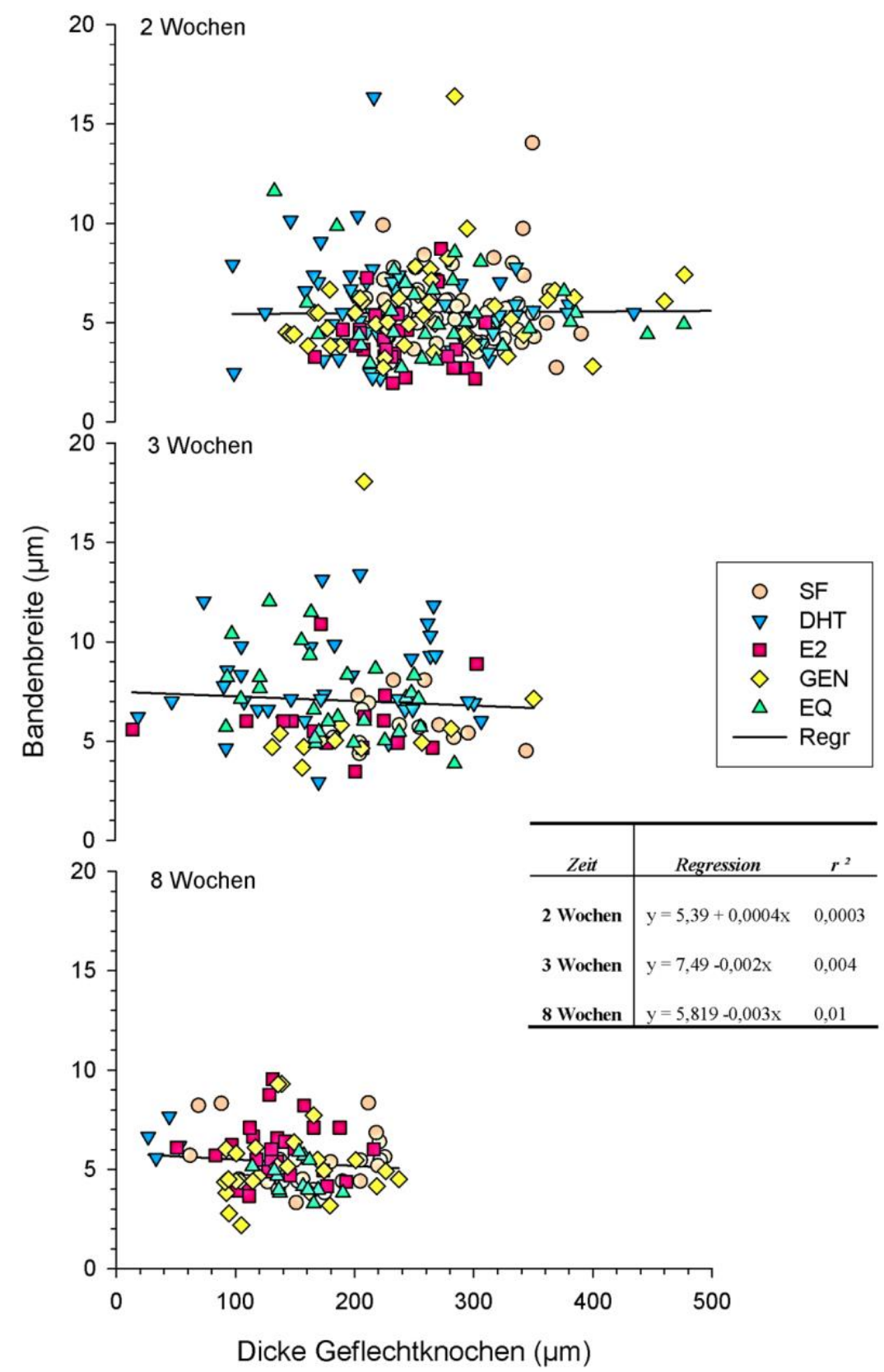

Abb. 16 Korrelation der Breite von Geflechtknochen und Alizarinbande. Aufgeführt sind die Daten aller untersuchten Gruppen nach der 2. (oben), 3. (Mitte) und 8. (unten) Woche. In der Tabelle sind die Regressionen und deren Bestimmtheitskoeffizient $r^{2}$ angegeben. Der Stichprobenumfang betrug $n=238(2$ Wochen), $\mathrm{n}=105$ (3 Wochen) und $\mathrm{n}=95$ (8 Wochen). 
Zusätzlich wurde der Abstand der kortikalen Calceinbande von der Alizarinbande des Geflechtknochens erhoben (Abb. 17). Dieser gibt an, wie viel Knochen sich zwischen den Fluoreszenzgaben gebildet hat. Die intravitalen Markierungen wurden mit einer zeitlichen Verzögerung von 28 Tagen gesetzt, sodass die Knochenbildung pro Tag errechnet werden kann.

A Abstand kortikale und Geflechtknochenbande
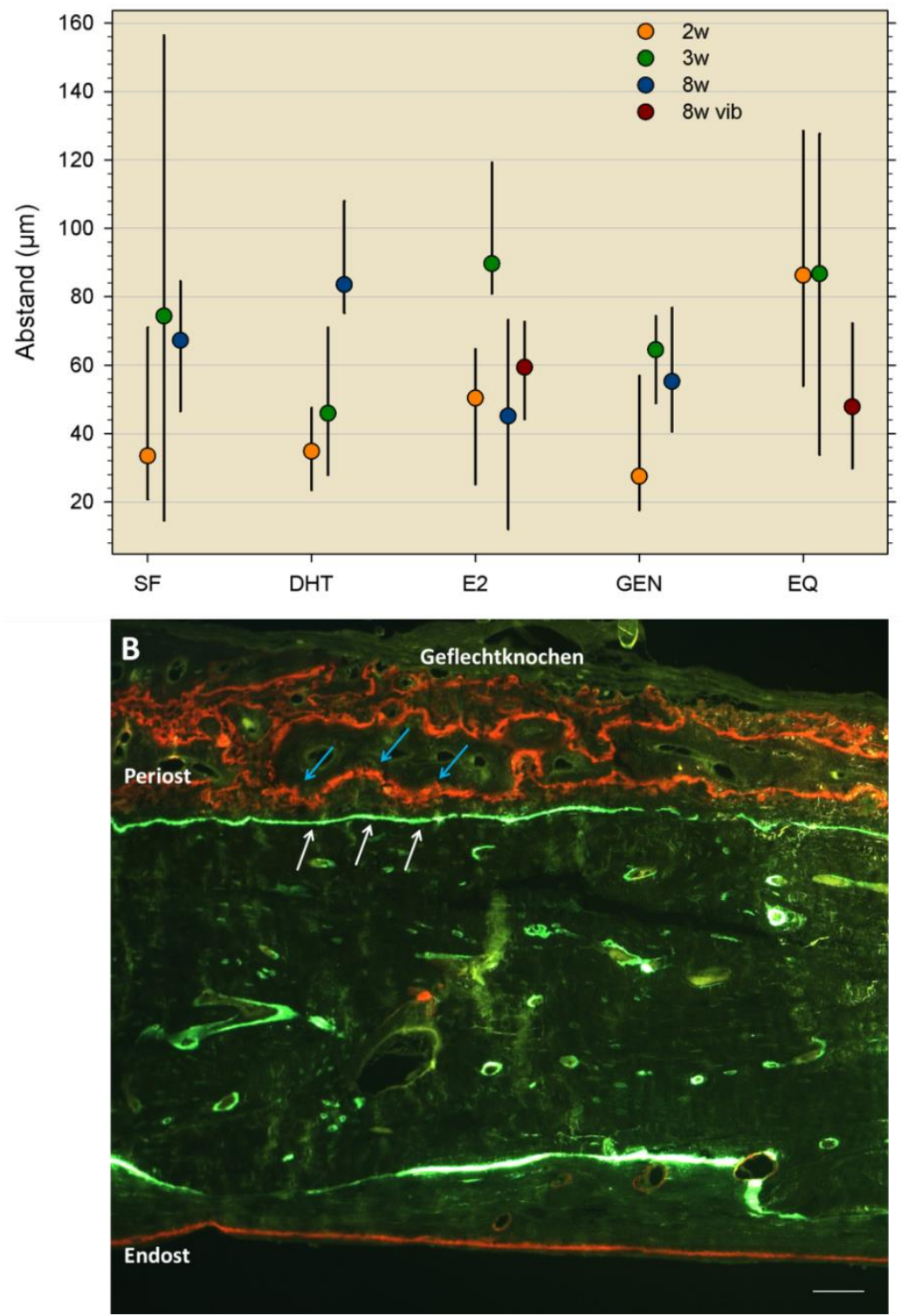

Abb. 17 Abstand der periostalen Calceinbande zur Alizarinbande des Geflechtknochens (A) nach 2, 3 und 8 Wochen; angegeben sind sowohl die Medianwerte als auch die $25 \%$ bzw. $75 \%$ Perzentilen; die zusätzlich noch einmal vibrierten Tiere sind mit $8 \mathrm{w}$ vib. dargestellt. Kortikalisausschnitt in B) dargestellt, Calcein- (weiße Pfeile) und Alizarinbande (blaue Pfeile) sind markiert, Abstand zwischen diesen Banden wurde gemessen; Größenstandard: $100 \mu \mathrm{m}$. 
Nach 2 Wochen weisen die Tiere der EQ- und E2-Futtergruppe mit einem

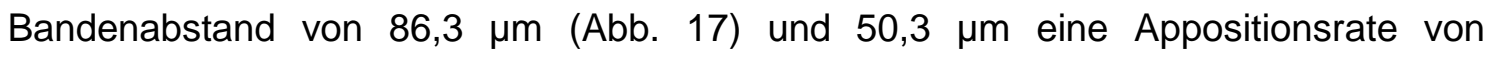
$3,08 \mu \mathrm{m} / \mathrm{Tag}$ bzw. $1,80 \mu \mathrm{m} / \mathrm{Tag}$ auf. Die übrigen Futtergruppen weisen einen durchschnittlichen Abstand von ca. $32 \mu \mathrm{m}$ auf, sodass sich daraus eine Apposition von etwa 1,14 $\mu \mathrm{m} /$ Tag ergibt.

Betrachtet man die Abstände der periostalen Calceinbande 3 Wochen nach Trepanation und Futterumtausch, so zeigt sich, dass mit Ausnahme der EQFuttergruppe der Abstand in allen Gruppen im Vergleich zur 1. Serie größer wird. Besonders bei den mit SF-, E2- und GEN-Futter behandelten Tieren vergrößert sich der Abstand um 40,89 $\mu \mathrm{m}, 39,30 \mu \mathrm{m}$ bzw. 37,0 $\mu \mathrm{m}$, sodass sich für diese Tiere zwischen der 2. und 3. Woche eine Appositionsrate von etwa 5,5 $\mu \mathrm{m}$ ergibt. Zu diesem Zeitpunkt besitzen die mit E2 behandelten Ratten mit 89,1 $\mu \mathrm{m}$ den größten Abstand zwischen der Calceinbande und dem Geflechtknochen.

Nach 8 Wochen lässt sich nur für die unvibrierten Ratten der DHT-Gruppe eine Vergrößerung des Abstandes festhalten. Für die unvibrierten Ratten mit EQ-Futter konnte dieser Abstand nicht ermittelt werden. Für die vibrierten Tiere der 8. Woche konnte diese Auswertung nur für die E2- und EQ-Gruppe vorgenommen werden. Die mit E2 gefütterten und zusätzlich vibrierten Ratten zeigen mit 59,3 $\mu \mathrm{m}$ höhere Werte als die unvibrierten E2-Tiere der 8. Woche und gleichzeitig geringere Werte als die der Vergleichstiere nach 3 Wochen. 


\subsection{Periostales Remodelling}

In der periostalen Kortikalis lassen sich beide Fluoreszenbanden nachweisen. Die Ergebnisse sind in Abb. 18 ersichtlich. Die mit SF-Futter versorgte Kontrollgruppe weist 2 Wochen nach Futterumtausch und Trepanation mit 4,3 $\mu \mathrm{m}$ wie die mit EQ behandelten Tiere eine schmale Alizarinbande auf. Im Vergleich dazu zeigen die Tiere mit DHT-Futterzusatz eine signifikant dickere Bande mit 6,6 $\mu \mathrm{m}$. Die Banden der mit E2 und mit GEN behandelten Ratten sind signifikant dicker gegenüber der Kontrollgruppe.
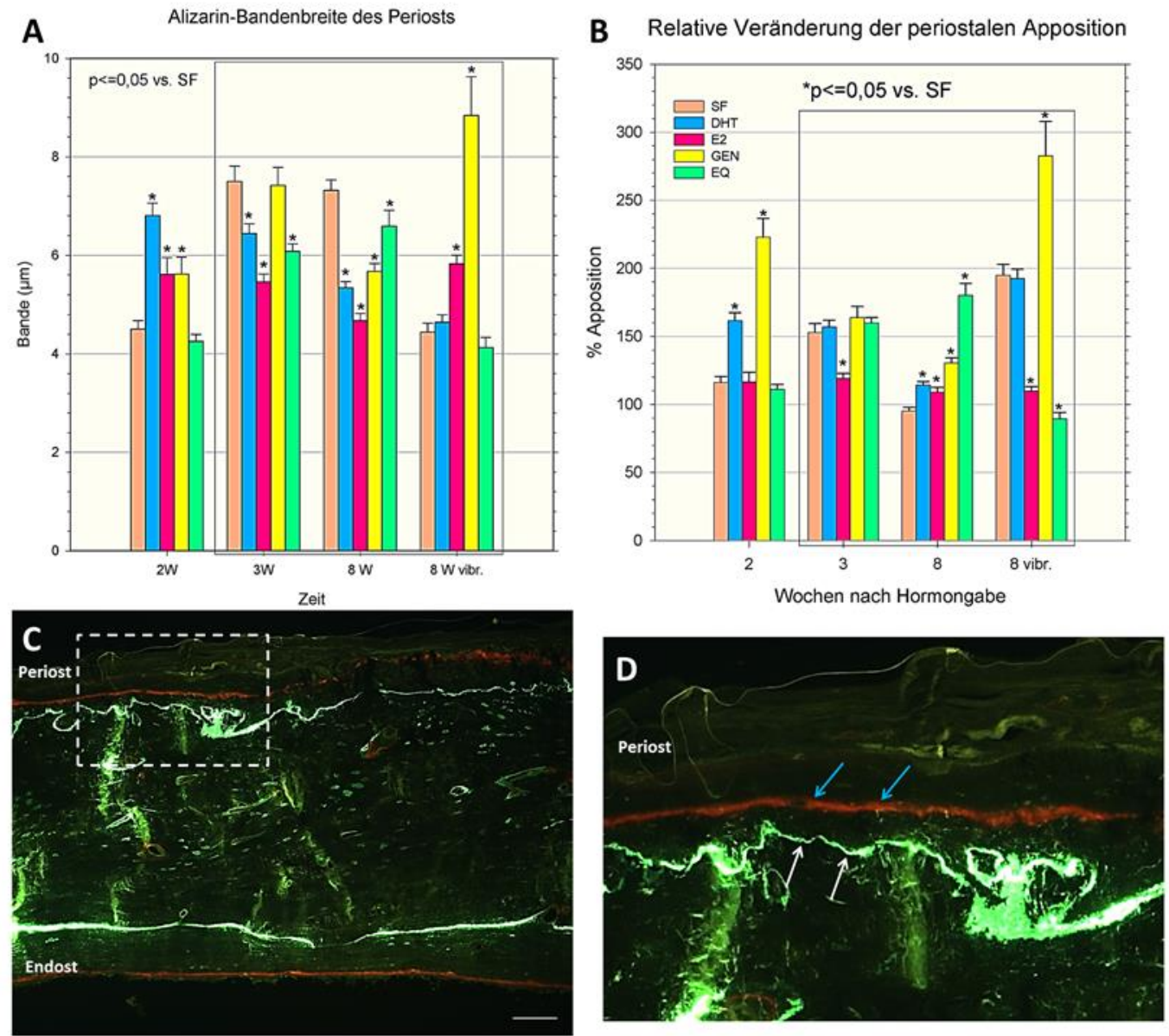

Abb. 18 Mittelwerte und Standardfehler der Alizarin-Bandenbreite des periostalen Knochens (A) nach 2-, 3- und 8-wöchiger Substanzapplikation der SF-, DHT-, E2-, GEN- und EQ-Gruppe; die zusätzlich vibrierten Tiere sind mit $8 \mathrm{~W}$ vibr. bzw. 8 vibr. gekennzeichet $\left(^{*} p \leq 0,05\right.$ vs. SF; $9 \leq n \leq 212$; ANOVA und multipler Vergleich nach Holm-Sidak). B) Relative Werte der periostalen Apposition, wobei die Dicke der Calceinbanden als Basis (100\%) dient ( ${ }^{*} p \leq 0,05$ vs. SF; $9 \leq n \leq 212$ ); untere Bildreihe zeigt Kortikalisübersicht (C) in 10x Vergrößerung und Ausschnitt (D) der endostalen Calcein- (weiße Pfeile) und Alizarinbande (blaue Pfeile); Größenstandard: $100 \mu \mathrm{m}$. 
Interessant ist, dass die mit GEN und E2 gefütterten Tiere ähnliche Werte für die Alizarinbandenbreite (Tab. A-5) aufweisen. Es ist zu erkennen, dass zwischen den Serien starke Schwankungen vorliegen. So sind nach 3 Wochen die Werte der mit den Isoflavonen GEN und EQ versorgten Ratten auf 7,5 $\mu \mathrm{m}$ bzw. 6,1 $\mu \mathrm{m}$ angestiegen. Ebenso weist die Kontrollgruppe mit SF-Futter eine Vergrößerung der Bandenbreite auf und nimmt damit den höchsten Wert für die Alizarinbandendicke ein $(7,6 \mu \mathrm{m})$. Wie schon in der 1. Serie zeigt sich auch nach 3 Wochen, dass die mit DHT behandelten Ratten $(6,2 \mu \mathrm{m})$ größere Alizarinbanden besitzen als die mit E2 behandelten Tiere $(5,4 \mu \mathrm{m})$. Nach 8 Wochen haben alle Futtergruppen signifikant kleinere Alizarinbanden als die Kontrollgruppe mit 7,4 $\mu \mathrm{m}$. Lediglich die mit EQ behandelten Tiere zeigen eine Zunahme der Bande im Vergleich zur 3. Woche $(6,6 \mu \mathrm{m})$. Die Werte der nicht zusätzlich vibrierten Ratten der 8 . Woche unterscheiden sich von den Werten der vibrierten Ratten der gleichen Serie. Erwähnenswert für die zusätzlich vibrierten Ratten ist die gegenüber der Kontrollgruppe signifikante Vergrößerung der Bandendicken sowohl der Ratten mit E2-Futter als auch der mit GEN-Futter gegenüber allen anderen Zeitpunkten. Der Wert für die mit GEN behandelte Gruppe liegt sogar bei 8,8 $\mu \mathrm{m}$ und ist somit der höchste Wert dieser Auswertung.

Neben der absoluten Alizarinbande konnte zusätzlich die relative Veränderung der periostalen Apposition bestimmt werden. Dafür mussten die beiden Fluoreszenzbanden zueinander in Beziehung gesetzt werden. 2 Wochen nach Trepanation und Futterumtausch sind die Werte der Alizarinbanden für alle Gruppen höher als die der vergleichbaren Calceinbanden (Abb. 18 B). Dabei weisen die mit GEN versorgten Ratten mit 222,9\% die größte Alizarinbande auf, die mehr als doppelt so dick ist wie die zugehörige Calceinbande. Sowohl die Werte der mit GEN als auch mit DHT gefütterten Hormongruppen sind mit 161,5\% signifikant größer gegenüber der Kontrollgruppe. Die dünnste Alizarinbande $(111,1 \%)$ weisen die Tiere mit EQ-Futter auf.

Nach 3 Wochen sind die Alizarinbanden wiederholt breiter als die zugehörigen Calceinbanden. Die dickste Alizarinbande im Vergleich zur Calceinbande wurde in den Tieren mit GEN-Futter gefunden. Im Gegensatz zu den Tieren mit GEN- und DHTFutter konnten für die Kontrollgruppe und die mit $\mathrm{EQ}$ gefütterten Ratten eine Zunahme der Alizarinbandenbreite im Vergleich zur Calceinbande zwischen der 2. und 3. Woche ermittelt werden. Die gegenüber der Kontrollgruppe signifikant kleinere Alizarinbande der mit E2 gefütterten Tiere weist nur eine geringfügige Vergrößerung mit 119,2 \% auf. Mit Blick auf die vibrierte und unvibrierte Serie der 8. Woche weisen die mit E2 behandelten Tiere nur geringe Veränderungen der Prozentwerte auf, sodass sich in der letzten Serie mit und ohne Vibration Bandenwerte von 109 \% ergeben. Die übrigen 
Futtergruppen zeigen dagegen deutlichere Schwankungen zwischen den unterschiedlichen Wochen. Für die nicht zusätzlich vibrierten Tiere mit Hormonfutter ist die Alizarinbande im Vergleich zur 2. Woche nur noch geringfügig größer gegenüber der zugehörigen Calceinbande. Eine Ausnahme stellen dagegen die Ratten mit EQFutter dar, denn für diese Tiere nimmt die Alizarinbande im Vergleich zur Calceinbande zu. Die prozentuale Apposition ist für alle Tiere mit Hormonzusatz signifikant größer gegenüber der Kontrollgruppe mit 95,2\%.

Dagegen zeigen die Tiere der KG, der mit DHT und GEN gefütterten Tiere die größten relativen Bandendicken des Versuches in der 8. Woche mit zusätzlicher Vibration. Der Wert der Ratten mit GEN-Futter imponiert mit 282,7\%. Die Bande der mit EQ behandelten Tiere ist dagegen mit 89,5\% signifikant reduziert.

\subsection{Endostales Remodelling}

Neben der periostalen Seite der Kortikalis imponiert auch die endostale Seite mit fluoreszierenden Banden. Ähnlich der periostalen Kortikalis befinden sich die absoluten Werte der Alizarinbandenbreite der endostalen Kortikalis etwa zwischen $4 \mu \mathrm{m}$ und $6 \mu \mathrm{m}$ nach 2 Wochen (vgl. Abb. 18 u. Abb. 19). Dabei wurden die größten Banden 2 Wochen nach Trepanation und Futterumtausch mit etwa 6,1 $\mu \mathrm{m}$ für die mit E2 behandelten Tiere ermittelt. Die Kontrollgruppe und Tiergruppe mit DHT-Futter zeigen vergleichbare Werte von 5,4 $\mu \mathrm{m}$ und 5,3 $\mu \mathrm{m}$. Die geringsten Banden konnten für die Ratten mit den verabreichten Phytohormonen GEN und EQ gemessen werden $(4,1 \mu \mathrm{m}$ und $5 \mu \mathrm{m}$ ). Zwischen der 2. und 3. Woche steigen die Werte aller Futtergruppen an. Allerdings lässt sich für die Tiere, die mit E2 bzw. EQ gefüttert wurden, nur eine Zunahme von $10 \mu \mathrm{m}$ bzw. $20 \mu \mathrm{m}$ festhalten. Im Gegensatz dazu weisen die mit GEN gefütterten Tiere ebenso wie die Kontrollgruppe eine Alizarinbande von 6,2 $\mu \mathrm{m}$ auf. Die abnehmende Tendenz der Werte zwischen der 3. und 8. Woche (unvibriert) lässt sich mit Ausnahme der Tiere mit EQ-Futter $(6 \mu \mathrm{m})$ für alle Futtergruppen bestätigen. Nur die mit E2 und EQ gefütterten Tiere zeigen signifikant größere Banden gegenüber der Kontrollgruppe. Vergleicht man die Werte der Ratten der 3. Woche mit der Bandendicke der Ratten der 8. und zusätzlich vibrierten Woche, ist zu erkennen, dass die mit DHT und EQ behandelten Tiere signifikant niedrigere Banden als die Kontrollratten mit SF-Futter zeigen. Gleichzeitig stellen diese Werte die kleinsten Banden aller Tiere mit diesem Futterzusatz im gesamten Zeitverlauf dar. Nach 8 Wochen ist dagegen die Alizarinbande $(6,4 \mu \mathrm{m})$ für die Tiere, die mit GEN behandelt und zusätzlich vibriert wurden, am größten. 


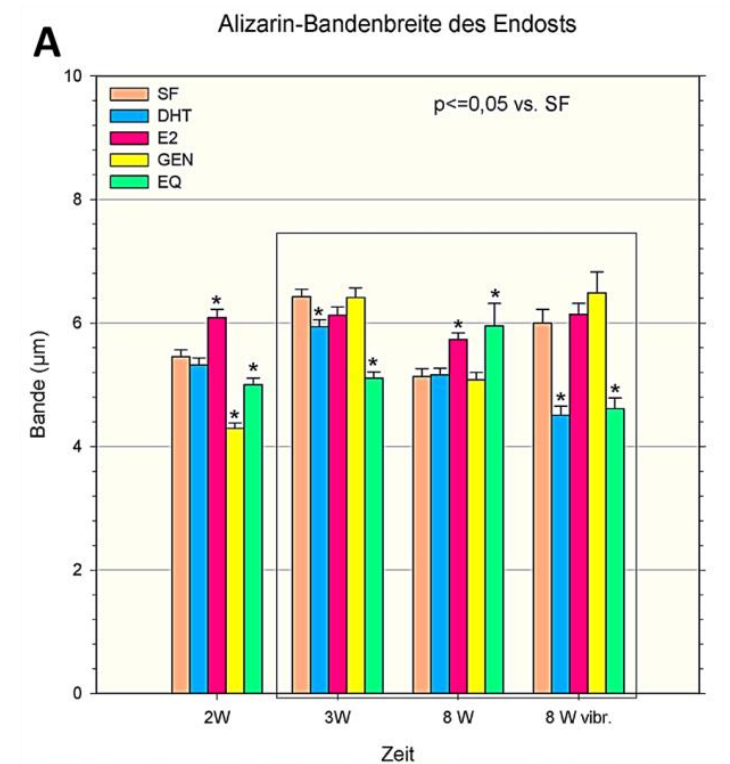

B Relative Veränderung der endostalen Apposition
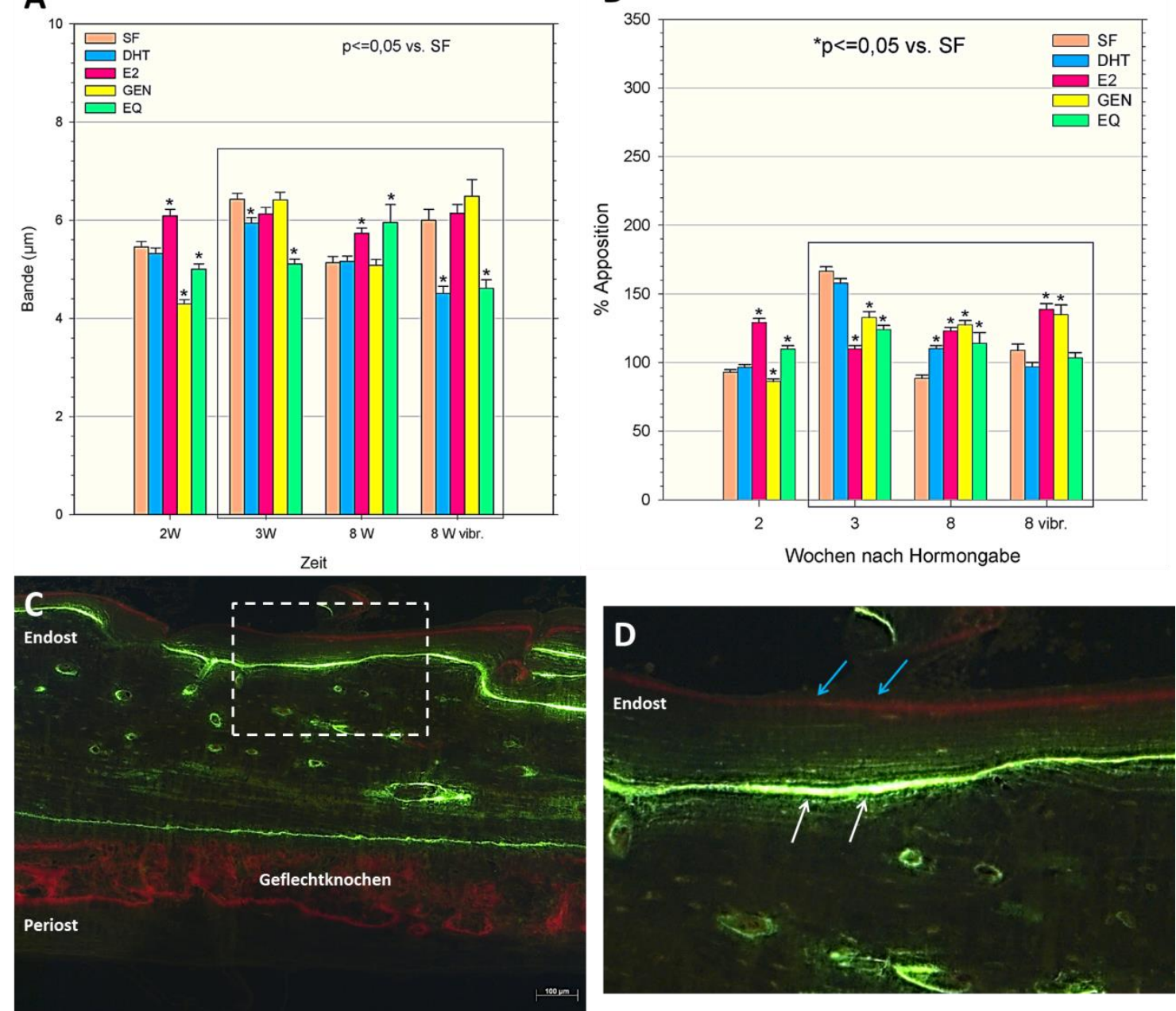

Abb. 19 Mittelwerte und Standardfehler der Alizarin-Bandenbreite (A) des endostalen Knochens nach 2-, 3- und 8-wöchiger Substanzapplikation der SF-, DHT-, E2-, GEN- und EQ-Gruppe; die zusätzlich vibrierten Tiere sind mit $8 \mathrm{~W}$ vibr. gekennzeichet ( ${ }^{*} \mathrm{p} \leq 0,05$ vs. SF; $37 \leq n \leq 581$; ANOVA und multipler Vergleich nach Holm-Sidak). (B) Relative Werte der endostalen Apposition, wobei die Dicke der Calceinbanden als Basis $(100 \%)$ dient (* $p \leq 0,05$ vs. SF; $38 \leq n \leq 581)$. Untere Bildreihe zeigt Kortikalisübersicht (C) in 10x Vergrößerung; zusätzlich endostale Calcein- (weiße Pfeile) und Alizarinbande (blaue Pfeile) im Ausschnitt (D) vergrößert; Größenstandard: $100 \mu \mathrm{m}$.

Die Abb. 19 (B) zeigt die relative Apposition an der endostalen Kortikalis. Dafür mussten die Alizarin- und Calceinbande prozentual zueinander in Beziehung gesetzt werden. Mit Blick auf die Therapiegruppen 2 Wochen nach Trepanation und Futterumtausch fällt auf, dass nur die Ratten mit E2- und EQ-Futterzusatz mit 129,2 \% und 109,9 \% signifikant größere Alizarin- als Calceinbanden aufweisen.

Im Vergleich dazu sind die Alizarin-Appositionsbanden 3 Wochen nach Trepanation und Futterumtausch für alle Therapiegruppen größer als die entsprechenden Calceinbanden. Dies äußert sich in der Überschreitung der $100 \%$-Schwelle. Gleichzeitig zeigen die mit E2 versorgten Tiere mit $109,9 \%$ die schmalste 
Alizarinbande auf. Der höchste Wert wird von der Kontrollgruppe mit 166,6 \% erreicht. Dies ist gleichzeitig der höchste Wert im gesamten Zeitverlauf.

Nach 8 Wochen ändert sich für die nicht zusätzlich vibrierte Serie die zunehmende Tendenz der relativen Alizarinbandendicke. Mit Ausnahme der mit E2 versorgten Ratten zeigen die übrigen Futtergruppen einen Abfall des Bandendickenverhältnisses. Gleichzeitig sind die Alizarinbanden der Tiere mit DHT-, GEN- und EQ-Futterzusatz größer als die entsprechenden Calceinbanden. Die Werte der Kontrollgruppe liegen mit $88,5 \%$ unter ihren entsprechenden Calceinbanden und gleichzeitig unter ihrem Wert, der nach 2 Wochen ermittelt wurden. Für die Ratten, die nach 8 Wochen zusätzlich vibriert wurden, zeigen die SF-, E2- und GEN-Futtergruppe höhere Werte als die Ratten der 3. Serie, die nicht zusätzlich vibriert wurden. Diese liegen für die mit E2 und GEN gefütterten Ratten mit 138,8\% bzw. 134,9\% über den Werten, die für die gleichen Tiere nach 2 und 3 Wochen ermittelt werden konnten.

\subsection{Trabekuläres Remodelling}

Um ein Gesamtbild von den absoluten Werten der Alizarinbanden zu erhalten, wurden diese ebenso in den Trabekeln gemessen. Zu keinem Zeitpunkt überschreiten die Alizarinbanden der Futtergruppen die $6 \mu \mathrm{m}$-Grenze. Die durchschnittliche Bandendicke beträgt etwa 3 und $4 \mu \mathrm{m}$ (Abb. 20).

Zwei Wochen nach Futterumtausch zeichnen sich nur für die Ratten, die mit den Sexualhormonen gefüttert wurden, Werte ab, die die $4 \mu \mathrm{m}$-Grenze überschreiten und signifikant größer sind als die der Kontrollgruppe. Die Werte der übrigen Futtergruppen liegen dagegen um einen mittleren Wert von 3,4 $\mu \mathrm{m}$. Zwischen der 2. und 3. Woche legen alle Futtergruppen an Bandendicke zu. Die mit GEN gefütterten Tiere haben mit einem Wert von 5,1 $\mu \mathrm{m}$ die größte und eine zugleich signifikante Alizarinbande gegenüber der KG. Ebenso weisen die Tiere, die mit E2 gefüttert wurden, eine vergrößerte Bande mit 4,9 $\mu \mathrm{m}$. Diese ist zugleich signifikant gegenüber der KG. Im Vergleich dazu zeigen die mit SF-, DHT- und EQ-Futter versorgten Ratten eine geringere Bandenbreite mit jeweils 4,4 $\mu \mathrm{m}, 4,2 \mu \mathrm{m}$ und 4,0 $\mu \mathrm{m}$ nach 3 Wochen. Ein Blick auf die 8., nicht zusätzlich vibrierte Woche lässt erkennen, dass die Werte aller Futtergruppen signifikant kleiner sind als die der Kontrolltiere mit SF-Futter $(5,4 \mu \mathrm{m})$. Verglichen mit den Werten der zusätzlich vibrierten Ratten der 8. Woche, zeigen diese eine größere Abnahme der Alizarinbandenbreite. Die Kontrolltiere weisen mit 4,4 $\mu \mathrm{m}$ wiederholt die dickste Alizarinbande auf. 

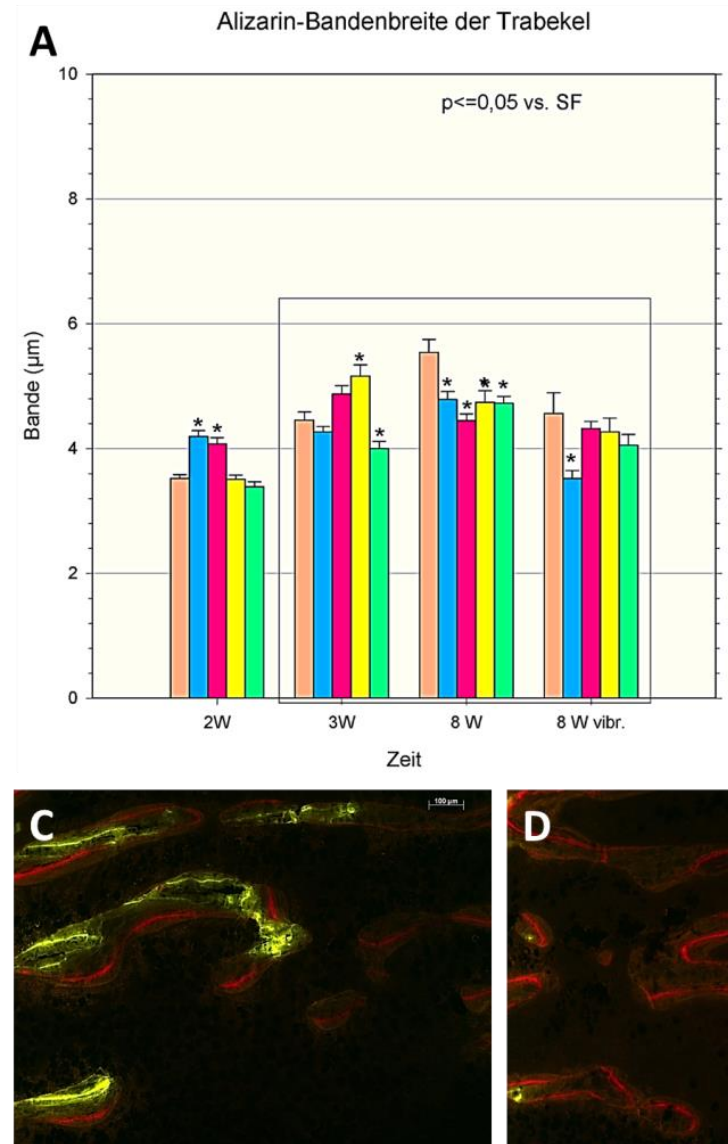

B Relative Veränderung der trabekuläre Apposition

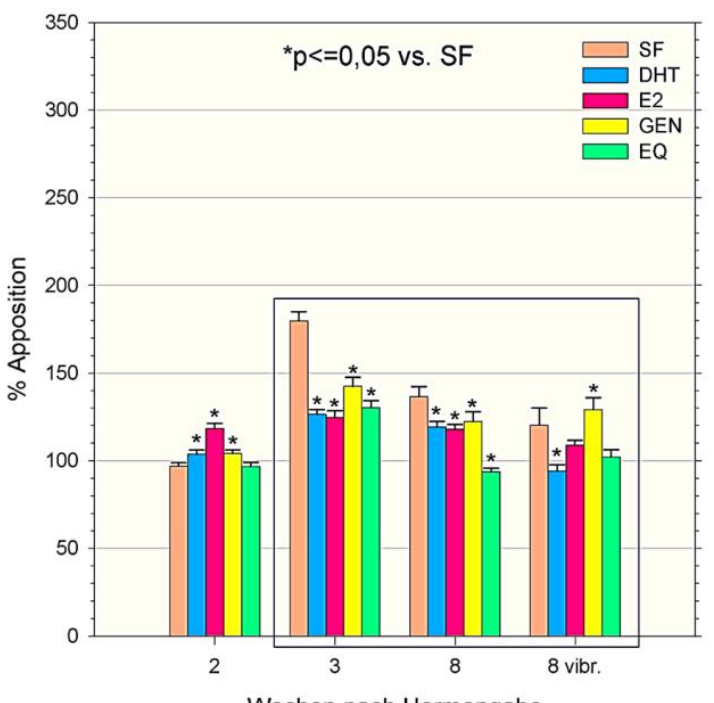

Wochen nach Hormongabe

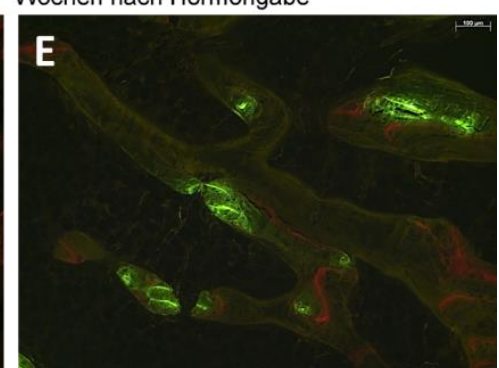

Abb. 20 Mittelwerte und Standardfehler der absolute Alizarin-Bandenbreite des trabekulären Knochens (A) nach 2-, 3- und 8-wöchiger Substanzapplikation der SF-, DHT-, E2-, GEN- und EQ-Gruppe; die zusätzlich vibrierten Tiere sind mit $8 \mathrm{~W}$ vibr. bzw. 8 vibr. gekennzeichnet ( ${ }^{*} p \leq 0,05$ vs. SF; $31 \leq n \leq 586$; ANOVA und multipler Vergleich nach Holm-Sidak). (B) Relative Werte der trabekulären Apposition, wobei die Dicke der Calceinbanden als Basis (100\%) dient ( $p \leq 0,05$ vs. SF; $30 \leq n \leq 590)$. Die untere Reihe (C, D, E) zeigt Fluoreszenzbilder der Trabekel; Größenstandard: $100 \mu \mathrm{m}$.

Im Gegensatz dazu sind die Banden der mit DHT gefütterten Ratten durchschnittlich nur 3,5 $\mu \mathrm{m}$ dick und somit signifikant kleiner. Um den Überblick über die relative Apposition im tibialen Knochen der Ratte zu vervollständigen, wurden auch die trabekulären Calcein- und Alizarinbandenverhältnisse ausgewertet (Abb. 20).

Nach 2 Wochen liegen die Prozentzahlen für alle Hormongruppen zwischen 96,7\% und 118,4\%. Dabei überschreiten sowohl die mit EQ- also auch die mit SF-Futter versorgten Tiere nicht die $100 \%$ Grenze. Dies bedeutet, dass diese Tiere eine schmalere Alizarin- als Calceinbande besitzen. Für die DHT- und GEN-Futtergruppen ließen sich Werte ermitteln, die mit 103,7 \% bzw. 104,1 \% nur knapp über den Werten ihrer Calceinbande liegen. Sie erweisen sich jedoch als signifikant größer gegenüber denen der Kontrolltiere.

Mit Blick auf die Ratten der 3. Woche lässt sich eine deutliche relative Vergrößerung der Alizarinbandendicke gegenüber Calcein bestätigen. Besonders die Alizarinbande 
der Kontrollgruppe konnte um 82,9 Prozentpunkte auf 179,7\% zulegen und weist damit die größte prozentuale Apposition des gesamten Zeitverlaufes auf. Die übrigen Futtergruppen zeigen signifikant kleinere Banden.

Für die nicht zusätzlich vibrierten Ratten der 8. Woche lässt sich diese Tendenz nicht weiter beobachten. Die Werte aller Futtergruppen sinken im Vergleich zur 3. Woche, wobei die Reihenfolge der Futtergruppenwerte beibehalten wird. Zudem weisen alle Futtergruppen signifikant niedrigere Werte gegenüber der Kontrollgruppe auf. Die Tiere mit EQ-Futter zeigen mit 93,6\% die geringste prozentuale Apposition des gesamten Zeitverlaufs. Die Bandenverhältnisse der Tiere mit DHT- und E2-Zusatz weichen mit $119,4 \%$ und $117,9 \%$ wie auch in der 3 . Woche geringfügig voneinander ab. Der größte Wert kann wiederholt mit 136,6 \% der Kontrollgruppe zugeordnet werden. Nach 8 Wochen und einer zusätzlichen Vibration zeichnet sich für die Kontrollgruppe ein im Vergleich zu den übrigen Futtergruppen hoher Wert von 120,2 \% ab. Allerdings kann hier für die mit GEN behandelten Ratten mit 129,1\% die höchste prozentuale Apposition der 8. Woche (zusätzlich vibriert) verzeichnet werden. Im Vergleich zur 3. Woche sind die Dicken der Alizarinbanden im Vergleich zur Calceinbande aller Futtergruppen gesunken. Stellt man die jeweils vibrierten und nicht vibrierten Tiere der 8. Woche gegenüber, so zeigen alle vibrierten Futtergruppen mit Ausnahme der mit GEN gefütterten Tiere eine geringere prozentuale Apposition. 


\section{Diskussion}

Lange Zeit wurde das Krankheitsbild der Osteoporose nur mit dem weiblichen Geschlecht in Verbindung gebracht. Durch die zunehmend älter werdenden Männer und Frauen in unserer Gesellschaft tritt die Problematik stärker in den Vordergrund, dass auch Männer von dieser Krankheit betroffen sein können. Die Bone-Eva-Studie (2006) konnte ermitteln, dass es in Deutschland bis zum heutigen Jahr (2013) einen Anstieg der männlichen Osteoporose-Patienten um $21 \%$ geben wird (Bone-Eva-Studie 2006). Mit dem zunehmenden Alter geht ein hohes Frakturrisiko einher. Diese Knochenbrüche sind insbesondere am Schenkelhals lokalisiert (Bone-Eva-Studie 2006). Auch in der Wissenschaft findet die Thematik der Osteoporose beim Mann zunehmend mehr Beachtung.

Die Untersuchungen der vorliegenden Arbeit sind Teil einer umfangreichen DFGgeförderten Studie. Der Versuch wird durch 3 Parameter beeinflusst. Auf die orchiektomierte Ratte als etabliertes Osteoporose-Tiermodell (Frost und Jee 1992, Vanderschueren et al. 1993, Verhas et al. 1986, Vorwerk 2010) wirken zum einen Futtersubstanzen, die mit Hormonen angereichert sind, um deren osteoprotektive Wirkung zu testen. Der Kontrollgruppe wurde sojafreies Futter verabreicht, um eine östrogene Wirkung der Sojapräparate auszuschließen (Seidlová-Wuttke et al. 2008). Als hormonelle Futterzusätze dienten zum einen die Sexualhormone DHT und E2, zum anderen die Phytohormone GEN und EQ. Diese Isoflavone haben in jüngster Zeit verstärkt Beachtung in der Osteoporoseforschung gefunden, wobei deren Wirkung vorwiegend in Bezug auf den weiblichen Organismus getestet wurde (Ishimi et al. 1999, Ishimi et al. 2000, Ma et al. 2008, Wuttke et al. 2008). Als weiterer Versuchsparameter wurde eine Trepanation der Tibia vorgenommen. Die Tiere befinden sich 2, 3 und 8 Wochen nach Futterumtausch in unterschiedlichen Stadien der Knochenheilung. Des Weiteren wurde der Versuch um den Parameter der Vibration ergänzt, der in der Literatur als Ganz-Körper-Vibration (GKV) bezeichnet wird (Wysocki et al. 2011). Die vorliegenden Ergebnisse konnten deshalb sowohl durch unterschiedliche Hormongaben, die Trepanation sowie die Vibration beeinflusst werden. Diese Art des Versuchsaufbaus ist neu und findet nur wenige Vergleichsmöglichkeiten in der internationalen Literatur.

In den ersten Wochen wurden die Ratten einer Orchiektomie mit anschließender, 4-wöchiger GKV unterzogen, um eine Osteoporose im Knochen zu induzieren. Die Behandlung der Tiere unterscheidet sich erst ab dem Zeitpunkt, an dem das Futter ausgetauscht wurde. Die Orchiektomie führt definitionsgemäß zu einer Osteoporose bzw. Osteopenie. Schon 1989 stellte man an Sexualstraftätern in der 
Tschechoslowakei, die einer Orchiektomie unterzogen worden waren, fest, dass sich ihre Knochenmasse reduzierte (Stĕpán et al. 1989). In zahlreichen Arbeiten konnte belegt werden, dass die Orchiektomie zu einer signifikanten Reduktion der Knochendichte und somit Osteoporose führt (Daniell 1997, Vorwerk 2010, Schot und Schuurs 1990, Wink und Felts 1980).

Die Auswirkungen der ersten, 4-wöchigen GKV auf den Knochen der orx Ratten, konnte von Papenberg (2011) beleuchtet werden (Papenberg 2011). Dafür wurden 2 Kontrollgruppen bezüglich ihrer Spongiosafläche und -dichte mit Hilfe der quantitativen Computertomographie untersucht. Die Tiere beider Kontrollgruppen wurden zuvor orchiektomiert, gleichzeitig ist jedoch nur eine Gruppe für eine Zeitspanne von 4 Wochen vibriert worden. Die Auswertung der Spongiosafläche und dichte zeigte, dass nur die unvibrierten Tiere eine Osteoporose ausbildeten. Die vibrierten Ratten wiesen nahezu keine Verringerung der Spongiosadichte auf (Papenberg 2011). Übertragen auf den vorliegenden Versuch bedeutet dies, dass die Tiere zum Zeitpunkt des Futterumtausches keine osteoporotischen Knochen aufweisen. Auch wenn der Versuch grundsätzlich das Ziel besaß, effiziente Therapiemaßnahmen für die Osteoporose des Mannes zu entwickeln. So muss dieser durch die Ergebnisse von Papenberg nun aus dem Blickwinkel der Prävention betrachtet werden. Denn weder die Futterzusätze noch die 2. Vibration wirken im vorliegenden Versuch als Therapeutikum auf einen osteoporotischen Knochen, sondern als Präventivmaßnahme auf den gesunden Knochen der männlichen Ratte.

\subsection{Diskussion der Methodik}

Die polychrome Sequenzmarkierung stellt eine etablierte Methode zur zeitabhängigen Bestimmung der Appositionsrate des mineralisierten Knochens dar. Bei adulten Individuen ist die Appositionsrate daher ein Maß für das Knochenremodelling. Zudem lassen sich unterschiedliche Fluorochrome farblich voneinander abgrenzen. Dadurch kann zu bestimmten Zeitpunkten die Menge oder Richtung der Knochenbildung visualisiert werden. Der vorliegende Versuchsablauf beinhaltet die Injektion von Calcein und Alizarin zu unterschiedlichen Zeitpunkten. Die Fluoreszenzen stellen damit den Mineralisationsgrad zum jeweiligen Zeitpunkt der Applikation dar. Mit Blick auf die Versuchsdurchführung (siehe Material und Methoden) zeigt sich, dass die Tiere bei Calcein-Verabreichung bereits der Orchiektomie und einer 10-tägigen Vibration unterzogen worden waren. Dagegen fand die Alizarin-Gabe statt, nachdem zusätzlich die Tibia trepaniert und das Futter durch Zusätze modifiziert worden war. 
In der Wissenschaft wird die Applikation der Fluorochrome genutzt, um die mineral apposition rate (MAR) $\mathrm{zu}$ bestimmen. Hierbei werden Querschnitte der Knochenpräparate angefertigt und der Abstand zwischen den Fluoreszenzbanden erfasst. Dieser Abstand wird dann mit der Anzahl der Tage verrechnet, die zwischen den Verabreichungen der Fluoreszenzen liegen. So kann die $M A R$ in $\mu \mathrm{m} / \mathrm{d}$ ermittelt werden (Thomsen et al. 2012). Erstbeschreiber dieser Knochenhistomorphometrie waren H. M. Frost und R. A. Milch (Frost 1969, Milch et al 1957, Turner et al. 2004). Dafür nutzten sie die fluoreszierenden Eigenschaften des Antibiotikums Tetrazyklin (Frost 1969, Milch et al 1957, Wu und Frost 1969). In der vorliegenden Arbeit wurden die Ergebnisse nach dem Prinzip der MAR bestimmt. Ein entscheidender Unterschied liegt darin, dass sich hier nicht am Abstand zwischen den Fluoreszenzbanden orientiert wurde, sondern hierfür die Doppelmarkierungen selbst gewählt wurden. Eine vergleichbare Anwendung der Methodik konnten wir nur bei Hirschinger (2011) vorfinden (Hirschinger 2011).

Die 172 Tiere sind in diesem Versuch in 3 Serien unterteilt, die nach 2, 3 oder 8 Wochen untersucht wurden. Durch diese Auswertungsweise ist es möglich, die Calcein- bzw. Alizarinbanden unterschiedlicher Zeitpunkte miteinander zu vergleichen. Es kann deutlich gezeigt werden, dass sich die periostalen, endostalen und trabekulären Fluoreszenzbanden in ihrer Breite zeitabhängig verändern. Die Werte der 2. Woche zeigen in der Regel die kleinste Bandenbreite. Während nach 3 Wochen die höchsten Breiten gemessen wurden (Abb. 18, Abb. 19 und Abb. 20). Nach 8 Wochen tritt eine Verkleinerung der Banden durch Kompaktierung auf. Die in der 8. Woche zusätzlich verabreichte Vibration führte zu einer Vergrößerung der Banden, was für eine zusätzliche Mineralisierung sprechen könnte. Durch die gleichbleibende Anzahl an Fluorochrom-Molekülen würden sich diese auf eine größere Fläche verteilen. Als Konsequenz müsste sich eine Intensitätsabnahme der Fluoreszenzemission ergeben. Aufschluss über die Vorgänge könnten durch Farbintensitätsmessungen erreicht werden. Die Veränderung der angefärbten Zonen ist Ausdruck einer noch nicht abgeschlossenen Mineralisation. Die fluoreszierenden Mineralisationszonen werden nach der Färbung durch eingelagertes Apatit deutlich verbreitert. Anschließend kommt es durch Verdichtung des Knochens zwischen der 3. und 8. Woche zu einer Schrumpfung der Banden. Hieraus leitet sich eine wichtige Konsequenz für die Bestimmung des Knochenremodellings und der Appositionsrate ab. Die Bestimmung dieser ist offensichtlich entscheidend davon abhängig, zu welchem Zeitpunkt nach der Fluoreszenzgabe die Bandenbreite gemessen wird. Diese Tatsache war bislang nicht bekannt. Gleichzeitig kann der Verlauf der Knochenentwicklung mit Hilfe einer einzigen 
Fluoreszenz visualisiert werden, indem die gleiche Fluoreszenz zu unterschiedlichen Zeitpunkten ausgewertet wird.

\subsection{Diskussion der Ergebnisse}

\subsubsection{Versuchsbedingte Effekte auf die Geflechtknochenbildung}

Histologisch existieren zwei unterschiedliche Arten von Knochen: Geflecht- und Lamellenknochen. Der Geflechtknochen entsteht sowohl bei der chondralen und desmalen Knochenentwicklung als auch bei der Frakturheilung des Knochens. Dieser kann schnell gebildet werden und wird später, bis auf wenige Ausnahmen, durch den belastbareren Lamellenknochen ersetzt. Im Gegensatz zum Lamellenknochen ist der Geflechtknochen durch eine zufällige Anordnung der Kollagenfibrillen charakterisiert. Die Osteozyten liegen eingemauert in kalzifizierter Interzellularsubstanz vor (Kugler 2006). In den untersuchten Präparaten kann der Lamellenknochen durch den parallelen Verlauf der Fluoreszenzbanden zur Knochenoberfläche identifiziert werden. Dagegen sind die Alizarinbanden im Geflechtknochen durch einen gewundenen Verlauf gekennzeichnet. Die molekularen Eigenschaften, die diese unterschiedlichen Knochenformen voneinander trennen, sind noch nicht ausreichend verstanden. Es gilt zu klären, ob die Vibration oder die Trepanation die auslösenden Faktoren der Geflechtknochenbildung darstellen. Frühere Studien zeigen die Geflechtknochenbildung als eine Reaktion auf das Einwirken von erhöhten mechanischen Belastungen, die jedoch oftmals zu Stressfrakturen innerhalb des Knochens führen (McKenzie et al. 2011, Turner et al. 1994). Die Vibration kann somit ebenso als mechanischer Stimulus verstanden werden. Allerdings ist fraglich, ob dieser ausreicht, um Geflechtknochenbildung zu induzieren. Bekanntermaßen bildet sich Geflechtknochen als Reaktion auf eine Fraktur oder Periostreizung. Nur unter absolut stabilen Verhältnissen ist es möglich, die direkte Knochenheilung in Form von Lamellenknochen zu induzieren. Die Trepanation der Ratten führt zu einem nur einseitigen Bohrloch in der Tibia. Aus diesem Grund ist keine Stabilisierung der Kortikalisenden beispielsweise durch Osteosyntheseplatten notwendig und die Ratten können sich weiterhin frei bewegen (He et al. 2011). Gleichzeitig stellt dieses DefektModel eine Methodik dar, um die Mechanismen der diaphysären Kortikalisheilung nachzuvollziehen ( $\mathrm{He}$ et al. 2011, Monfoulet et al. 2010). Auch wird die Bohrlochheilung von der intramembranösen Ossifikation beherrscht (He et al. 2011, 
Komatsu et al. 2009). Bei dieser desmalen Ossifikation wird ohne knorpelige Vorstufe Geflechtknochen synthetisiert. Später erfolgt der Ersatz durch Lamellenknochen.

Im vorliegenden Versuch wurde Geflechtknochen gefunden, der Einlagerungen des Fluorochroms Alizarin aufweist. Calcein-markierter Geflechtknochen liegt nicht vor. Dies deutet darauf hin, dass die Vibration kein Stimulus für die Geflechtknochenbildung darstellt bzw. nicht ausreicht, denn zum Zeitpunkt der Calcein-Gabe waren die Ratten ausschließlich der Vibration ausgesetzt. Dagegen wurde Alizarin nach 4-wöchiger Vibrationstherapie und Beendigung der Trepanation und Futterumtausch verabreicht. Allein die Trepanation provoziert durch die Verletzung des Knochens die Geflechtknochenbildung. Deshalb liegt der Geflechtknochen in den histologischen Präparaten ausschließlich der periostalen Kortikalis auf, die sich in Nähe zur Trepanationsöffnung befindet. Im Längsschnitt der Tibiapräparate sind deshalb nur auf einer Kortikalisseite Geflechtknochenauflagerungen auffindbar. Die Alizarinbanden sind schleifenförmig übereinander angeordnet (Abb. 12), wodurch die Geflechtknochenbildung dieser Menge in so kurzer Zeit ermöglicht wird. Aus der Unabhängigkeit der Geflechtknochendicke und der Breite der Alizarinbande (Abb. 17) kann geschlossen werden, dass die Mineralisierung im Geflechtknochen immer in der gleichen "Größenordnung" vorgenommen wird. Eine größere Dicke des Geflechtknochens ist deshalb entweder auf eine zeitliche Expansion der Geflechtknochenbildung oder eine höhere Anzahl an Mineralisationspunkten zurückzuführen.

In anderen Studien konnte die Bildung von Geflechtknochen ebenfalls beobachtet werden. Die Arbeitsgruppe Uthgenannt et al. (2007) führte über ein Kompressionsmodell Ermüdungsfrakturen an männlichen Ratten herbei. Diese stellen Knochenbrüche dar, die durch eine wiederkehrende Überbelastung hervorgerufen werden. Ermüdungsfrakturen können insbesondere durch das Krankheitsbild der Osteoporose begünstigt werden. Wie in unserem Versuch erfolgte die Frakturheilung über die Bildung einer Geflechtknochenmanschette, die sich nicht über den gesamten Knochen erstreckte, sondern nur im Bereich der Knochenverletzung lokalisiert war (Tami et al. 2003, Uthgenannt et al. 2007). Die Trepanation kann eindeutig als Stimulus für die Geflechtknochenbildung identifiziert werden.

Interessant ist, inwieweit die Vibration in der Lage ist, die Defektheilung zu unterstützen. Es liegen Studien vor, die den Einfluss von mechanischer Stimulation auf die Frakturheilung bei gesunden Tieren testen (Augat et al. 2001, Shadmehr et al. 2009, Usui et al. 1989, Wolf et al. 2001). Die Ergebnisse werden kontrovers diskutiert. Zum einen konnten positive Effekte auf die Heilung festgestellt werden (Shadmehr et al. 2009, Usui et al. 1989). Die Arbeitsgruppe Shadmehr et al. (2009) konnte 
abschließend festhalten, dass eine 3-wöchige Vibration röntgenologisch zu einer verbesserten Kallusqualität und -fläche führt. Zusätzlich zeigten die defekten Kaninchen-Tibiae bessere mechanische Eigenschaften im Biegeversuch als die entsprechende Kontrollgruppe (Shadmehr et al. 2009). Zum anderen sprechen einige Autoren auch von keiner Verbesserung der biomechanischen Eigenschaften und damit der Frakturheilung (Wolf et al. 2001, Augat et al. 2001). Dabei bedienen sich die unterschiedlichen Wissenschaftler diverser Methoden der mechanischen Stimulation. Neben der GKV kommt es auch zum Einsatz von Fixateuren, über welche die Bewegung direkt auf die Fraktur übertragen wird. Stuermer et al. (2010) konnte an ovarektomierten Ratten keinen optimalen Effekt der GKV bei $90 \mathrm{~Hz}$ feststellen (Stuermer et al. 2010). Allerdings zeigten die ovarektomierten Tiere nach Vibration eine schnellere Überbrückung des Defektes, als die nicht ovarektomierten Ratten.

Der Einfluss der Vibration kann durch die Analysen der 3. und vibrierten Serie (8 Wochen) geklärt werden. Mit Ausnahme der mit E2 behandelten Tiere zeigen alle Futtergruppen ein höheres Ausmaß an Geflechtknochen als es in der 3. und nicht zusätzlich vibrierten Serie der Fall ist (Abb. 14). Auch Usui et al. (1989) stellten an Kaninchen, die einer mechanischen Stimulation ausgesetzt worden waren, ein erhöhtes Kallusvolumen fest (Usui et al. 1989). Zu dieser Erkenntnis kamen auch Wolf et al. (2001). Die Arbeitsgruppe testete die Knochenheilung an Schafen, die mit ihren Hinterbeinen auf einer Vibrationsplatte standen. Im Gegensatz zur Kontrollgruppe zeigten die vibrierten Tiere eine größere Kallusmenge. Allerdings war dies nicht gleichzusetzen mit einer qualitativ besseren Knochenheilung. Abschließend konnten die Autoren keinen positiven Einfluss der mechanischen Stimulation auf die Frakturheilung belegen (Wolf et al. 2001, Augat et al. 2001). Im vorliegenden Versuch erfolgte unter Vibration eine Zunahme der quantitativen Kallusmenge. Um die Qualität dieses Geflechtknochens beurteilen zu können, müssten jedoch noch weitere Untersuchungen folgen.

Neben der Beeinflussung der Geflechtknochenbildung durch die Vibration üben auch die hormonellen Futterzusätze Wirkungen aus. Grundsätzlich zeigen die Ratten, die 2 Wochen nach Trepanation und Futterumtausch geopfert wurden, die größte Geflechtknochendicke auf. Diese sinkt für alle Hormongruppen nach 3 bzw. 8 Wochen (unvibriert) (Abb. 14). Diese Abnahme der Dicke lässt sich möglicherweise dadurch erklären, dass der zuvor gebildete Geflechtknochen durch den reifen Lamellenknochen ersetzt wird. Demnach ist 2 Wochen nach Trepanation die Bildung des Geflechtknochens beendet gewesen und die Reifung zu Lamellenknochen eingeleitet worden, da die Geflechtknochendicke ab diesem Zeitpunkt kontinuierlich sinkt. Unterstützt wird diese Aussage dadurch, dass der Abstand zwischen der kortikalen 
Calceinbande und der ersten Alizarinbande des Geflechtknochens (Abb. 16) zwischen der 2. und 3. Woche in allen Gruppen vergrößert wird. Dies deutet auf einen Umbau des Geflechtknochens in den reifen Lamellenknochen hin. Dabei vollzieht sich die Reifung von innen nach außen.

Uthgenannt et al. (2003) stellten fest, dass sich als Antwort auf an Ratten herbeigeführten Stressfrakturen eine Manschette aus Geflechtknochen um den Defekt legt. Die Größe der Manschette korreliert dabei mit dem Ausmaß des Schadens (Uthgenannt et al. 2003). In dem hier vorliegenden Versuch wurden alle Ratten der gleichen Vibrationsstärke ausgesetzt und mit dem gleichen Trepanationsloch versehen. Folglich müssten alle Ratten die gleiche Menge an Geflechtknochen aufweisen. Demnach können die unterschiedlichen Dicken des Geflechtknochens zwischen den einzelnen Stoffgruppen als Wirkung der Hormongabe verstanden werden. Im Vergleich zu den Hormongruppen zeigt die Kontrollgruppe besonders 2 und 3 Wochen nach Trepanation ein höheres Ausmaß an Geflechtknochen. Eine Ausnahme bilden die mit EQ behandelten Tiere, denn zum einen zeigen sie die höchste Geflechtknochendicke 2 Wochen nach Trepanation und zum anderen weisen sie die stärkste Defektheilung auf. Denn die Geflechtknochendicke konnte zwischen der 2. und 3. Woche um 47,65\% reduziert werden. Nach 8 Wochen wurde der Geflechtknochen sogar vollständig in Lamellenknochen umgebaut. Die Kontrolltiere zeigen hingegen die niedrigste Defektheilung auf, denn ihr Geflechtknochen reduzierte sich zwischen der 2. und 3. Woche um lediglich 15,2\% (Abb. 14). Zusammenfassend zeigen die hier dargestellten Resultate, dass alle verabreichten Hormone einen positiven Effekt auf die Defektheilung des Knochens haben.

Kolios et al. (2009) beschäftigten sich mit der metaphysären Frakturheilung. Dabei zeigten ebenfalls die mit EQ behandelten Tiere neben den mit E2 versorgten Tieren eine Verbesserung der Frakturheilung an orchiektomierten Ratten. Auch wiesen die Knochenpräparate eine hohe biomechanische Qualität auf. Die mit EQ behandelten Ratten erreichten dies über eine höhere periostale Kallusbildung (Kolios et al. 2009). Auch in unserem Versuch zeigte diese Hormongruppe die höchste periostale Geflechtknochenbildung auf. Fraglich ist an dieser Stelle, ob die Quantität der periostalen Kallusmenge mit der Kallusqualität gleichzusetzen ist. Deshalb muss in nachfolgenden Untersuchungen zusätzlich die biomechanische Qualität des Knochens durch Strukturuntersuchungen oder Biegeversuche ermittelt werden, um die Frakturheilung umfassender beurteilen zu können. 


\subsubsection{Effekte auf die Kortikalis}

Mit der Pubertät ergeben sich erhebliche Unterschiede zwischen den Kortikali von Frauen und Männern. Während sich das Verhältnis von Spongiosa und Kortikalis im Knochen von jungen Mädchen und erwachsenen Frauen ähnelt, zeichnet sich der Knochen der Männer durch eine dickere Kortikalis aus. Mit dem Alter setzt bei beiden Geschlechtern eine endostale Resorption ein. Diese wird jedoch vom Mann im Gegensatz zur Frau zum Teil durch eine 3-fach höhere, periostale Apposition kompensiert (Seeman 2001a, Seeman 2001b). Klassischerweise wird angenommen, dass Androgene eine stimulierende Wirkung auf die periostale Apposition ausüben (Kim et al. 2003). So konnten Turner et al. (1990) durch die Gabe von Androgenen einen stimulierenden Effekt auf die Kortikalis aufzeigen, der zuvor durch die Orchiektomie in seinem periostalen Wachstum gehemmt worden war (Turner et al. 1990). Im vorliegenden Versuch zeigt sich an der periostalen Kortikalis der DHTbehandelten Ratten eine signifikant höhere Appositionsrate als für die Ratten, die mit SF- und E2-Futter versorgt wurden. DHT stellt dabei einen aktiven Metaboliten des Testosterons dar. Dieser reagiert nur über den AR, denn DHT kann nicht durch die Aromatase in Östrogen umgewandelt werden. Unter Berücksichtigung der Ergebnisse nach 3 und 8 Wochen zeigt sich, dass die Wirkung von DHT am subperiostalen Remodelling stärker ist als die von E2. Dies deckt sich mit den Ergebnissen von Venken et al. (2006). Diese Arbeitsgruppe konnte an männlichen Mäusen zeigen, dass sowohl die Gabe von DHT als auch Testosteron an orchiektomierten Tieren eine Stimulierung der periostalen Knochenbildung bewirkten. Dagegen wiesen männliche Aromatase-Knockout-Mäuse keine Reaktion auf (Venken et al. 2006). Diese Studien lassen vermuten, dass eine hohe periostale Apposition auf eine höhere Konzentration von Androgenen zurückzuführen ist.

Unsere Ergebnisse decken sich mit denen von Papenberg (2011). Dieser hat an den Ratten unseres Versuches den periostalen und endostalen Umfang der Tibia zu unterschiedlichen Zeitpunkten mit Hilfe von computertomographischen Aufnahmen bestimmt. Er konnte zeigen, dass die mit DHT behandelten Ratten 2 Wochen nach Futterumtausch den größten periostalen Umfang aufwiesen, gefolgt von den mit E2 versorgten Tieren. Die Sexualhormone demonstrierten auch hier größere Werte als die Kontrollgruppe (Papenberg 2011). Die Summe dieser Ergebnisse bestätigt die wichtige Rolle von DHT als Androgen auf die periostale Apposition.

Gleichzeitig sollen Östrogene dagegen bei der Frau die endostale Bildungsrate begünstigen oder sogar die periostale Apposition unterdrücken (Seeman 2001a, Turner et al. 1989). Die mit E2 behandelten Tiere weisen an der endostalen Kortikalis 2 Wochen nach Futterumtausch die dickste Alizarinbande auf. Die Apposition ist 
signifikant größer als die Apposition der Kontrollgruppe (Abb. 19). Dieser Trend wird in den folgenden Wochen beibehalten (Abb. 19). Im Gegensatz dazu zeigen die mit DHT versorgten Tiere an der endostalen Seite der Kortikalis ein geringeres Knochenremodelling als die Kontrollgruppe. Papenberg (2011) konnte an denselben Ratten unseres Versuches mit Hilfe des endostalen Umfangs ebenfalls eine hohe endostale Appositionsrate für die mit E2 therapierten Ratten ermitteln (Papenberg 2011). Die positive Beeinflussung der endostalen Appositionsrate durch E2 kann daher von uns bestätigt werden.

Zusätzlich muss die Wirkung von E2 auf die periostale Seite der Kompakta Beachtung finden. Diese entspricht nicht den hohen Appositionsraten der mit DHT versorgten Tiere. Dennoch ist sie signifikant größer als die der Kontrollgruppe, sodass man von einem erkennbaren Effekt der Östradiolgabe auf die periostale Kortikalis sprechen kann. Wir können an dieser Stelle eine positive Beeinflussung der Appositionsraten durch E2 sowohl auf die periostale als auch endostale Kortikalisseite festhalten. Das anfangs erläuterte klassische Konzept, in dem Androgene auf die periostale und Östrogene auf die endostale Kortikalis wirken, kann in diesem Sinne nicht bestätigt werden.

In der Literatur wird die vorherrschende Sichtweise der Sexualhormonwirkung auf die Kortikalis durch viele Forscher zunehmend in Frage gestellt (Ohlsson et al. 2009, Vanderschueren et al. 2006). An einem erwachsenen Mann mit Aromatasemangel und einem simultanen leichten Hypogonadismus konnte gezeigt werden, dass die Knochenmineraldichte (BMD) und die Knochenstruktur unter kombinierter Zufuhr von E2 und Testosteron deutlich gegenüber deren Einzelgabe verbessert werden konnten (Rochira 2007). Vanderschueren et al. (2006) diskutieren die Möglichkeit, ob als Voraussetzung für die Androgenreaktion eine gewisse Menge an Östrogenen vorhanden sein müssen. Gleichzeitig sollen geringe Konzentrationen an Östrogenen die Empfindlichkeit des Periosts steigern, wobei hohe Mengen das Gegenteil bewirken (Vanderschueren et al. 2006). Allerdings ist fraglich, inwieweit unsere orx Ratten östrogenfrei sind. Auch Venken et al. (2006) kommen zusammenfassend zu dem Schluss, dass sowohl die Stimulierung des AR als auch des ER nötig ist, um das periostale Wachstum optimal zu stimulieren (Ophoff et al. 2009, Venken et al. 2006). Offensichtlich sind beide Hormone DHT und E2 für das kortikale Knochenwachstum bei Männern nötig. Der Effekt von DHT ist an der periostalen Seite größer als der von E2. Im Vergleich zu den Kontrolltieren zeigen auch die mit E2 behandelten Ratten eine breitere Alizarinbande. Es wäre daher interessant zu untersuchen, welche Effekte die kombinierte Gabe beider Sexualhormone an der Kortikalis hervorbringt. 
Auf Grundlage dieser Ergebnisse sind Alternativen wie die Phytohormone GEN und $E Q$ von besonderem Interesse. Diese Isoflavone erfahren zunehmend mehr Interesse in der experimentellen Osteoporose-Forschung. Die protektiven Wirkungen dieser Substanzen auf den weiblichen Knochenstoffwechsel konnten vielfach aufgezeigt werden (Hertrampf et al. 2007, Rachón et al. 2007, Sehmisch et al. 2010). Es stellt sich die Frage, ob sich deren Wirkungen auch auf das männliche Geschlecht übertragen lassen. Bisher finden sich nur wenige Studien, die dieser Thematik nachgehen. Ishimi et al. (2002) stellten an männlichen Mäusen fest, dass der durch Orchiektomie bedingte Knochenverlust durch GEN verhindert werden konnte (Ishimi et al. 2002).

Die oben genannten Studien lassen erwarten, dass sowohl GEN als auch EQ einen positiven Effekt auf den Knochen zeigen und folglich breitere Appositionsbanden als die Kontrollgruppe mit SF-Futter aufweisen.

Mit Blick auf die Ergebnisse des vorliegenden Versuches zeigt sich, dass grundsätzlich die mit Sexualhormonen behandelten Tiere 2 Wochen nach Futterumtausch sowohl auf der periostalen als auch auf der endostalen Kortikalisseite höhere Appositionsraten aufweisen als die mit Phytohormonen gefütterten Ratten (Abb. 18 und Abb. 19).

Allerdings konnte auf der periostalen Seite der Kortikalis eine Alizarinbande für die GEN-Gruppe ausgewertet werden, die der Bande der mit E2 gefütterten Tiere entsprach und folglich signifikant größer gegenüber den Kontrolltieren gewesen ist (Abb. 18). Dagegen sind die Appositionsbanden der mit EQ gefütterten Tiere an der periostalen und endostalen Kortikalis kleiner als die der Kontrollgruppe. Die Ratten mit GEN-Zusatz zeigen an der endostalen Kortikalis ebenfalls eine geringere Knochenapposition als die Kontrollgruppe. Die Ergebnisse des vorliegenden Versuches zeigen einen osteogenen Effekt von GEN ausschließlich auf die periostale Kortikalis.

Unsere Ergebnisse decken sich nur zum Teil mit den Ergebnissen von Sehmisch et al. (2010), die ovariektomierte, unvibrierte Ratten mit E2-, GEN- und EQ-Zusatz fütterten. Die E2-Gabe wirkte sich sowohl auf die Kortikalis als auch auf die Trabekel positiv aus. Allerdings konnten Sehmisch et al. (2010) bei den mit EQ behandelten Tieren im Gegensatz zu den Tieren der GEN-Gruppe eine Verbesserung der knöchernen Mikroarchitektur und BMD des osteoporotischen Knochens der weiblichen Ratte feststellen. Die Autoren erklären dies mit einer höheren transkriptionalen Tätigkeit von EQ in den Effektorzellen (Sehmisch et al. 2010). Die Werte dieser Arbeitsgruppe wurden nach 35 Tagen ermittelt. Dies entspricht in unserem Versuch in etwa der 2. Serie. In dieser zeigen die mit GEN behandelten Tiere sowohl in der Kortikalis als auch in den Trabekeln höhere Appositionsraten als die mit EQ gefütterten Ratten (Abb. 18, Abb. 19 und Abb. 20). Im Verlauf der 8. Woche nimmt die Appositionsbande 
der mit EQ behandelten Tiere kontinuierlich sowohl in der Kortikalis als auch in den Trabekeln an Breite zu. Dies könnte bedeuten, dass der Futterzusatz der Sexualhormone in kürzerer Zeit eine höhere Wirkung an der Kortikalis und den Trabekeln des Knochens erzeugt. Die Phytohormongabe könnte auch einen entsprechenden Effekt auf den Knochen der männlichen Ratte haben, wobei dieser später eintritt (Abb. 18 und Abb. 19). In der Literatur wird von einigen Autoren diskutiert, ob ein Verzehr über einen längeren Zeitraum notwendig ist, damit von den Phytohormonen entsprechende Wirkungen auf den Körper hervorgerufen werden können (Piekarz und Ward 2007, Shu et al. 2001, Ward und Piekarz 2007). Unter dieser Annahme weisen die Tiere mit Phytohormonzusatz 3 bzw. 8 Wochen nach Futterumtausch sogar höhere absolute Appositionsraten als die Ratten der Sexualhormongruppe auf. Im Vergleich zwischen den mit Phytohormonen behandelten Tieren wirkt der Futterzusatz GEN dann schneller und stärker als EQ. Diese Ausführung macht gleichzeitig noch einmal deutlich, dass der Zeitpunkt, zu dem die Auswertung erhoben wird, eine bedeutende Rolle spielt. Allerdings ist die Voraussetzung, dass die Ausdehnung der Banden einer Mineralisationszunahme entspricht und die später eintretende Verkleinerung Ausdruck einer Kompaktierung darstellt. Es ist zusätzlich von Interesse, ob eine höhere Appositionsrate gleichbedeutend ist mit einem hohen Ausmaß an Osteoprotektion bei der Osteoporose. Die osteoprotektive Wirkung von GEN auf die periostale Kortikalis könnte auf die Vibration zurückgeführt werden. Hertrampf et al. (2007) konnten zeigen, dass GEN eine protektive Wirkung auf den Knochen weiblicher Ratten hat, die sich zusätzlich im Laufrad bewegten. Gleichzeitig beruht dieser Effekt auf der Aktivierung von ERa, sodass von den Autoren die Vermutung geäußert wird, dass trotz der höheren Affinität für ER $\beta$ die Wirkung am Knochen durch ERa erzeugt wird (Hertrampf et al. 2007).

Auch Wu et al. (2001) bescheinigen für GEN in Kombination mit Bewegung einen guten Effekt auf den Knochen der ovx Mäuse (Wu et al. 2001). Die Untersuchung an orx Mäusen zeigte, dass GEN in Kombination mit Bewegung einen knochenprotektiven Effekt hat. Dieser konzentrierte sich allerdings auf die Spongiosa durch Hemmung der Knochenresorption (Wu et al. 2003). Für die 3. und zusätzlich vibrierte Serie (nach 8 Wochen) zeigt sich, dass die Zugabe von GEN eine Zunahme der Appositionsbande sowohl an der endostalen als auch an der periostalen Kortikalis im Vergleich zur 2. Serie (nach 3 Wochen) bewirkt (Abb. 18 und Abb. 19). Geht man davon aus, dass diese Vergrößerung der Bande eine weitere Einlagerung von Substanz bedeutet, dann reagieren die mit GEN behandelten Ratten an der Kortikalis am stärksten. Demzufolge zeigen die Ratten mit diesem Zusatzstoff im Futter die stärkste Reaktion auf die Vibration. Diese Ergebnisse lassen sich dagegen für EQ nicht bestätigen, denn die 
Tiere zeigen in der 3. und nicht vibrierten Serie größere Bandendicken als die zusätzlich vibrierten Ratten, sodass man sogar von einer Hemmung der EQ-Wirkung durch die Vibration sprechen kann (Abb. 18 und Abb. 19).

\subsubsection{Effekte auf den trabekulären Knochen}

Die Folgen der Osteoporose offenbaren sich in erster Linie in den spongiösen Strukturen des Knochens (Bartl 2011). Deshalb sind Therapie- bzw. Präventivmaßnahmen, die die Trabekel positiv beeinflussen von besonderer Bedeutung. Die Orchiektomie führt zu einem trabekulären Knochenverlust. Sowohl aromatisierbare Androgene wie Testosteron als auch nicht aromatisierbare Androgene wie DHT sind in der Lage, diesen Knochenverlust zu verhindern (Vanderschueren et al. 1992). DHT entfaltet seine Wirkung über den AR.

Zwei Wochen nach Futterumtausch zeigen die Tiere, die mit E2 oder DHT gefüttert wurden, im trabekulären Knochen höhere Appositionsraten als die Phytohormongruppen. Die Werte sind zusätzlich signifikant gegenüber den Tieren der Kontrollgruppe (Abb. 20). Demnach kann sowohl für E2 als auch für DHT eine Wirkung auf den spongiösen Anteil des Knochens der männlichen Ratte beschrieben werden. Folglich zeigen die Tiere mit der Sexualhormonbehandlung in der Kortikalis als auch in der Spongiosa die höchsten Appositionsraten. Dies bedeutet, dass sowohl über den AR als auch über ER durch E2 und DHT ähnliche Wirkungen erzeugt werden können. Weitere Autoren machen für die Aufrechterhaltung der trabekulären Knochenmasse männlicher Mäuse ebenfalls den AR und den ERa verantwortlich (Lindberg et al. 2002, Movérare et al. 2003, Sims et al. 2003). Dies könnte auch die Begründung dafür liefern, warum die Wirkung des Phytohormons GEN auf den trabekulären Anteil des Knochens geringer ausfällt (Abb. 20), denn GEN zeigt eine höhere Affinität zum ER $\beta$ (Kuiper et al. 1998, McCarty 2006).

Die Tiere aller Futtergruppen zeigen in den Trabekeln Fluoreszenzbanden, die in ihrer Breite um ca. $4 \mu \mathrm{m}$ schwanken (Abb. 20). Dagegen weisen die absoluten Mineralappositionsraten der Kortikalis mit Werten um die $5 \mu \mathrm{m}$ auf eine deutlich stärkere Knochenapposition in der Kompakta hin (Abb.18 und Abb. 19). Der osteogene Effekt manifestiert sich an der Kortikalis wesentlich mehr. Allerdings ist es im Hinblick auf das Krankheitsbild der Osteoporose wünschenswert, die präventiven und therapeutischen Maßnahmen so zu gestalten, dass besonders die trabekulären Strukturen, auf die sich die Osteoporose stark auswirkt, positiv beeinflusst werden. Für die GKV werden in der Literatur unterschiedliche Effekte auf den Knochen dokumentiert (Bloomfield et al. 2002). Rubin et al. (2002) konnten an den ebenfalls bei 
einer Frequenz von $30 \mathrm{~Hz}$ vibrierten Hinterbeinen weiblicher Schafe eine Stimulierung am trabekulären Knochen zeigen (Rubin et al. 2002). Eine Verbesserung insbesondere der trabekulären Parameter von ovx Ratten wurde bei einer Vibration von $90 \mathrm{~Hz}$ erzielt (Judex et al. 2007). Dagegen führten Versuche einer GKV an ovx Ratten weder zu einem signifikanten Effekt an den Trabekeln noch an der Kortikalis (Brouwers et al. 2010).

Im vorliegenden Versuch deuten die schmaleren absoluten Mineralappositionsraten an den Trabekeln auf eine größere Wirkung in der Kortikalis hin. Auch nach 8 Wochen und zusätzlicher Vibration zeigen die Tiere keiner Futtergruppe eine Verbreiterung ihrer Appositionsbanden in den Trabekeln im Vergleich zu den Serien 3 und 8 (unvibriert) Wochen nach Futterumtausch auf. In der Kortikalis dagegen nehmen die Appositionsbanden insbesondere der Ratten, die mit E2 und GEN gefüttert wurden, unter zusätzlicher Vibration zu. Möglicherweise könnten die Effekte der Vibration auf die trabekulären Strukturen durch die Auswirkungen der Kortikalistrepanation überlagert werden. Schon anhand der Vielzahl an Fluoreszenzbanden in den histologischen Bildern der Kortikalis wird das Ausmaß des Knochenwachstums in der Kompakta deutlich (Abb. 12). 


\section{Zusammenfassung}

Bedingt durch den demographischen Wandel gewinnt das Krankheitsbild der männlichen Osteoporose zunehmend an Bedeutung. Es stellt sich daher die Frage, ob die präventiven und therapeutischen Ansätze, die sich bei der Behandlung der weiblichen, postmenopausalen Osteoporose der Frau bewährt haben, auf Männer übertragbar sind.

Es war daher das Ziel der vorliegenden Arbeit, den Einfluss verschiedener Hormonbehandlungen mit einer kombinierten Ganz-Körper-Vibration (GKV) auf das Knochenremodelling des defekten Knochens bei der Osteoporose zu untersuchen. Als Hormongabe wurden die Sexualhormone Dihydrotestosteron (DHT) bzw. Östradiol (E2) oder die Phytohormone Genistein (GEN) bzw. Equol (EQ) verabreicht. Als Osteoporosemodell wurde die orx Ratte gewählt. Zur Durchführung des Versuches wurden 172 Tiere in 5 Gruppen eingeteilt. Neben einer Kontrollgruppe, die nur sojafreies Futter und keine Hormongabe erhielt, wurden den anderen Gruppen die jeweils oben genannten Hormone mit dem Futter verabreicht.

Unter der Gabe von sojafreier Nahrung erfolgte zunächst für alle Tiere eine 4-wöchige GKV. Nach Abschluss des Vibrationstrainings wurden die Trepanation beider Tibiae mit einem Bohrer und der Austausch des sojafreien Futters gegen das Verum vorgenommen. 4 Gruppen erhielten als Verum DHT, E2, GEN oder EQ, wobei zusätzlich eine Kontrollgruppe weiterhin mit sojafreiem Futter versorgt wurde. Während der ersten GKV und nach Umtausch des Futters wurden den Ratten die Fluorochrome Calcein (10 Tage nach 1. GKV) und Alizarin (2 Tage nach Trepanation und Futterumtausch) s.c. injiziert, um die Knochenbildung zu markieren. Die Tiere einer Serie wurden 2, 3 oder 8 Wochen nach Therapiebeginn geopfert. Die Hälfte der Ratten der 3. Serie wurde noch einer zusätzlichen 4-wöchigen GKV unterzogen. Mit Hilfe von histologischen Hartschnittpräparaten der Ratten-Tibia konnte die Appositionsbandenbreite sowohl an der periostalen als auch endostalen Seite der Kortikalis sowie in der Spongiosa bestimmt werden. Zusätzlich war es möglich, die Defektheilung mit Hilfe des Ausmaßes der Geflechtknochenbildung zu bewerten.

Die Auswertungen der Fluoreszenzbanden zeigten eine Zunahme der Bandendicke zwischen der 2. und 3. Woche sowie eine Reduzierung der Appositionsbande zwischen der 3. und 8. Woche. Die zeitabhängigen Änderungen der Bandenbreiten sind Ausdruck einer weiteren Mineralisierung bzw. einer Kompaktierung des Knochens. Die Bestimmung des Knochenremodellings ist daher zusätzlich abhängig vom zeitlichen Abstand zwischen Fluoreszenzgabe und Zeitpunkt der Probenentnahme. 
An der Kortikalis der Tibia induzierte die Trepanation innerhalb von 2 Wochen eine deutliche Geflechtknochenbildung. Diese war am Bohrloch lokalisiert und wurde ab der 2. Woche in Lamellenknochen umgebaut. Im Vergleich zur Kontrollgruppe führte die Hormonbehandlung, insbesondere die von EQ, zu einer schnelleren Reifung des Geflechtknochens zu Lamellenknochen. Zusätzlich konnte unter dem Einfluss der 2. Vibration eine Zunahme der periostalen Geflechtknochendicke verzeichnet werden. Unter den Versuchsbedingungen war die Knochenapposition 2 Wochen nach Futterumtausch bei allen Versuchsgruppen an der Kortikalis größer als in der Spongiosa. Beide Sexualhormone, sowohl DHT als auch E2, stimulierten das Knochenwachstum an der Kortikalis der Ratte. DHT wirkte hierbei auf der periostalen Kortikalisseite am stärksten. E2 übte einen Effekt sowohl an der periostalen als auch an der endostalen Kortikalisseite aus. In Vergleich zur Kontrollgruppe bewirkten beide Sexualhormone am trabekulären Knochen eine signfikant höhere Apposition.

Die Phytohormone GEN und EQ wiesen mit einer Ausnahme sowohl in der Kortikalis als auch in der Spongiosa eine deutlich geringere Knochenapposition sowohl gegenüber den mit Sexualhormonen behandelten Tieren als auch der Kontrollgruppe auf. An der periostalen Kortikalis zeigten die mit GEN behandelten Tiere eine vergleichbar hohe Appositionsrate wie die mit E2 behandelten Tiere. Auch zeigte die GEN-Gruppe den stärksten Effekt auf die zusätzliche Vibration der 3. Serie (nach 8 Wochen).

Zusammenfassend kann festgestellt werden, dass die Gabe von DHT oder E2 sowohl an der Kortikalis als auch an der Spongiosa höhere Appositionsraten erzeugt als die Phytohormone GEN und EQ. DHT und E2 steigern das Knochenremodelling in der männlichen Ratte signifikant stärker als GEN und EQ. Hingegen bewirkt EQ einen schnelleren Umbau von unreifen Geflecht- zu reifen Lamellenknochen. Die Gabe von EQ wäre daher eine optimale Ergänzung zu einer Vibrationstherapie, da durch Vibration besonders im Defektbereich subperiostaler Geflechtknochen aufgebaut wird. Dieser wird dann mit Hilfe von EQ schneller in reifen Lamellenknochen umgebaut. 


\section{Anhang}

Tab. A-1 Übersicht der Serien I, II und III, die nach 2, 3 bzw. 8 Wochen untersucht wurden. Jede Serie umfasst eine SF-, DHT-, E2-, GEN- und EQ-Futtergruppe. Das X markiert die durchgeführte Orchiektomie, Trepanation bzw. Vibration. Die 2. Vibration wurde nur an der Hälfte der Tiere der Serie III vollzogen.

\begin{tabular}{|c|c|c|c|c|c|}
\hline Gruppe & SF & DHT & E2 & GEN & EQ \\
\hline \multicolumn{6}{|c|}{ Serie I: Untersuchung nach 2 Wochen } \\
\hline Anzahl der Tier & 12 & 11 & 11 & 11 & 11 \\
\hline Orchiektomie & $\mathrm{X}$ & $\mathrm{X}$ & $\mathrm{X}$ & $\mathrm{X}$ & $\mathrm{X}$ \\
\hline Trepanation & $\bar{X}$ & $\bar{X}$ & $\mathrm{X}$ & $\mathrm{X}$ & $\bar{X}$ \\
\hline 1. Vibration & $\bar{X}$ & $\bar{X}$ & $\mathrm{X}$ & $\mathrm{X}$ & $\mathrm{X}$ \\
\hline 2. Vibration & - & - & - & - & - \\
\hline \multicolumn{6}{|c|}{ Serie II: Untersuchung nach 3 Wochen } \\
\hline Anzahl der Tier & 12 & 10 & 12 & 12 & 11 \\
\hline Orchiektomie & $\mathrm{X}$ & $\mathrm{X}$ & $\mathrm{X}$ & $\mathrm{X}$ & $\mathrm{X}$ \\
\hline Trepanation & $\bar{X}$ & $\bar{X}$ & $\bar{X}$ & $\bar{X}$ & $\mathrm{X}$ \\
\hline 1. Vibration & $\mathrm{X}$ & $\mathrm{X}$ & $\mathrm{X}$ & $\mathrm{X}$ & $\mathrm{X}$ \\
\hline 2. Vibration & - & - & - & - & - \\
\hline \multicolumn{6}{|c|}{ Serie III: Untersuchung nach 8 Wochen } \\
\hline $\begin{array}{l}\text { Anzahl der } \\
\text { Tiere }\end{array}$ & 12 & 12 & 12 & 11 & 12 \\
\hline Orchiektomie & $\bar{X}$ & $\bar{X}$ & $\bar{X}$ & $\bar{X}$ & $\mathrm{X}$ \\
\hline Trepanation & $\mathrm{X}$ & $\mathrm{X}$ & $\bar{X}$ & $\mathrm{X}$ & $\mathrm{X}$ \\
\hline 1. Vibration & $\mathrm{X}$ & $\mathrm{X}$ & $\mathrm{X}$ & $\mathrm{X}$ & $\mathrm{X}$ \\
\hline 2. Vibration & $50 \%$ & $50 \%$ & $50 \%$ & $50 \%$ & $50 \%$ \\
\hline
\end{tabular}

Tab. A-2 Mittelwerte (Mean) der Geflechtknochendicke $(\mu \mathrm{m})$ für die verschiedenen Testgruppen nach 2-, 3- und 8-wöchiger Applikation sowie Stichprobenumfang (N) der Messwerte, Standardabweichung (SD) und Standardfehler (SEM). Die vibrierten Tiere der 8. Woche sind mit 8vibr. gekennzeichnet.

\begin{tabular}{|c|c|c|c|c|c|}
\hline Wochen & Futtergruppe & $\mathbf{N}$ & Mean $(\mu \mathrm{m})$ & SD & SEM \\
\hline & SF & 64 & 286,991 & 46,762 & 5,845 \\
\hline & DHT & 57 & 244,835 & 72,651 & 9,623 \\
\hline \multirow[t]{5}{*}{2} & E2 & 26 & 240,758 & 36,948 & 7,246 \\
\hline & GEN & 50 & 264,984 & 84,168 & 11,903 \\
\hline & EQ & 41 & 348,688 & 149,574 & 23,359 \\
\hline & SF & 14 & 242819 & 45136 & 12063 \\
\hline & DHT & 35 & 180,568 & 77,591 & 13,115 \\
\hline \multirow[t]{5}{*}{3} & E2 & 16 & 185,958 & 66,763 & 16,691 \\
\hline & GEN & 12 & 203,142 & 64,744 & 18,69 \\
\hline & EQ & 28 & 182,559 & 55,415 & 10,472 \\
\hline & SF & 16 & 141,388444 & 46,9551626 & 12.1237709 \\
\hline & DHT & 5 & 39,3601155 & 11,5544426 & 5,77722128 \\
\hline \multirow[t]{5}{*}{8} & E2 & 12 & 150,838635 & 34,1025966 & 10,2823198 \\
\hline & GEN & 27 & 140,791028 & 44,6927723 & 8,76497378 \\
\hline & $E Q$ & & -- & -- & -- \\
\hline & 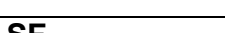 & 15 & 10707612 & 166050530 & 121550301 \\
\hline & DH & $\begin{array}{r}15 \\
5\end{array}$ & $\begin{array}{r}187,07642 \\
134005028\end{array}$ & $\frac{46,6058539}{262286642}$ & $\begin{array}{l}12,4559384 \\
13,1143321\end{array}$ \\
\hline \multirow{3}{*}{8 vibr. } & E2 & 16 & 124,190061 & 34,4535183 & 8,89586018 \\
\hline & GEN & 7 & 169,049836 & 62,9672709 & 25,7062807 \\
\hline & EQ & 16 & 147,630291 & 21,1904335 & 5,47134641 \\
\hline
\end{tabular}


Tab. A-3 Mittelwerte (Mean) der Alizarinbandenbreite $(\mu \mathrm{m})$ im Geflechtknochen für die verschiedenen Testgruppen nach 2-, 3- und 8-wöchiger Applikation sowie Stichprobenumfang (N) der Messwerte, Standardabweichung (SD) und Standardfehler (SEM). Die vibrierten Tiere der 8 . Woche sind mit 8 vibr. gekennzeichnet.

\begin{tabular}{|c|c|c|c|c|c|}
\hline Wochen & Futtergruppen & $\mathbf{N}$ & Mean $(\mu \mathrm{m})$ & SD & SEM \\
\hline & SF & 317 & 5,298 & 1,963 & 0,11 \\
\hline & DHT & 349 & 5,854 & 2,089 & 0,112 \\
\hline \multirow[t]{5}{*}{2} & E2 & 160 & 5,573 & 2,501 & 0,198 \\
\hline & GEN & 309 & 5,524 & 1,947 & 0,111 \\
\hline & EQ & 323 & 5,719 & 2,25 & 0,125 \\
\hline & SF & 103 & 5,467 & 1.984 & 0.196 \\
\hline & DHT & 244 & 6,17 & 2,094 & 0,134 \\
\hline \multirow[t]{5}{*}{3} & E2 & 65 & 6,694 & 2,278 & 0,285 \\
\hline & GEN & 84 & 6,896 & 2,798 & 0,307 \\
\hline & EQ & 186 & 5,803 & 2,125 & 0,156 \\
\hline & SF & 191 & 4843 & 1662 & 0132 \\
\hline & DHT & 13 & 6,152 & 1,299 & 0,375 \\
\hline \multirow[t]{6}{*}{8} & E2 & 199 & 5,736 & 1,676 & 0,156 \\
\hline & GEN & 127 & 5,754 & 2,321 & 0,207 \\
\hline & EQ & -- & -- & -- & -- \\
\hline & & & & & \\
\hline & SF & 104 & 5,295 & 1,783 & 0,176 \\
\hline & DHT & 19 & 4,547 & 1,511 & 0,356 \\
\hline \multirow[t]{3}{*}{ 8vibr. } & E2 & 141 & 5,597 & 1,7 & 0,144 \\
\hline & GEN & 36 & 4,897 & 1,536 & 0,26 \\
\hline & EQ & 108 & 4,881 & 1,659 & 0,16 \\
\hline
\end{tabular}

Tab. A-4 Medianwerte (Median) des Abstandes der kortikalen Calceinbande von der Alizarinbande des Geflechtknochens für die verschiedenen Testgruppen nach 2-, 3- und 8 wöchiger Applikation sowie die Streuung (Range) und die $25 \%$ bzw. $75 \%$ Perzentilen. Die vibrierten Tiere der 8 . Woche sind mit 8 vibr. gekennzeichnet.

\begin{tabular}{|c|c|c|c|c|c|}
\hline Wochen & Futtergruppen & Range & Median & 25 \% Perz. & 75 \% Perz. \\
\hline & SF & 175,94 & 33,442 & 20,765 & 71,04 \\
\hline & DHT & 108,649 & 34,782 & 23,51 & 47,543 \\
\hline \multirow[t]{5}{*}{2} & E2 & 74,388 & 50,324 & 25,142 & 64,663 \\
\hline & GEN & 119,231 & 27,478 & 17,666 & 56,868 \\
\hline & EQ & 140,144 & 86,264 & 53,958 & 128,469 \\
\hline & SF & 293,445 & 74,317 & 14,617 & 156,432 \\
\hline & DHT & 130,055 & 45,902 & 27,869 & 71,038 \\
\hline \multirow[t]{6}{*}{3} & E2 & 52,6 & 89,617 & 80,9 & 119,207 \\
\hline & GEN & 62,843 & 64,482 & 48,907 & 74,317 \\
\hline & $E Q$ & 161,203 & 86,677 & 33,804 & 127,596 \\
\hline & & & & & \\
\hline & SF & 69,945 & 67,213 & 46,563 & 84,552 \\
\hline & DHT & 56,389 & 83,494 & 75,298 & 107,978 \\
\hline \multirow[t]{6}{*}{8} & E2 & 89,617 & 45,082 & 12,071 & 73,224 \\
\hline & GEN & 101,639 & 55,191 & 40,574 & 76,776 \\
\hline & $E Q$ & -- & -- & -- & -- \\
\hline & & & & & \\
\hline & SF & -- & -- & -- & -- \\
\hline & DHT & -- & -- & -- & -- \\
\hline \multirow[t]{3}{*}{8 vibr. } & E2 & 42,64 & 59,309 & 44,262 & 72,678 \\
\hline & GEN & -- & -- & -- & - \\
\hline & $E Q$ & 75,117 & 47,795 & 29,848 & 72,268 \\
\hline
\end{tabular}


Tab. A-5 Alizarin-Mittelwerte (Mean in $\mu \mathrm{m}$ ) der absoluten, periostalen Apposition für die verschiedenen Testgruppen nach 2-, 3- und 8 wöchiger Applikation sowie Stichprobenumfang (N) der Messwerte, Standardabweichung (SD), Standardfehler (SEM) und das Konfidenzintervall ( $\mathrm{Cl}$ of Mean). Die vibrierten Tiere der 8 . Woche sind mit 8 vibr. gekennzeichnet.

\begin{tabular}{|c|c|c|c|c|c|c|}
\hline Wochen & Futtergruppen & $\mathbf{N}$ & Mean $(\mu \mathrm{m})$ & SD & SEM & $\mathrm{Cl}$ of Mean \\
\hline & SF & 94,00 & 4,50 & 1,67 & 0,17 & 0,35 \\
\hline & DHT & 35,00 & 6,81 & 1,45 & 0,25 & 0,51 \\
\hline \multirow[t]{5}{*}{2} & E2 & 27,00 & 5,61 & 1,69 & 0,34 & 0,70 \\
\hline & GEN & 83,00 & 5,62 & 3,16 & 0,35 & 0,70 \\
\hline & EQ & 189,00 & 4,26 & 1,87 & 0,14 & 0,27 \\
\hline & SF & 30,00 & 7,50 & 1,65 & 0,31 & 0,64 \\
\hline & DHT & 101,00 & 6,44 & 2,00 & 0,20 & 0,40 \\
\hline \multirow[t]{5}{*}{3} & E2 & 153,00 & 5,46 & 2,00 & 0,16 & 0,32 \\
\hline & GEN & 49,00 & 7,42 & 2,52 & 0,37 & 0,74 \\
\hline & EQ & 191,00 & 6,08 & 2,08 & 0,15 & 0,30 \\
\hline & SF & 103,00 & 7,32 & 2,12 & 0,21 & 0,42 \\
\hline & DHT & 212,00 & 5,34 & 1,85 & 0,13 & 0,25 \\
\hline \multirow[t]{6}{*}{8} & E2 & 120,00 & 4,67 & 1,60 & 0,15 & 0,29 \\
\hline & GEN & 110,00 & 5,68 & 1,67 & 0,16 & 0,32 \\
\hline & EQ & 57,00 & 6,59 & 2,36 & 0,32 & 0,64 \\
\hline & & 0? & & & & \\
\hline & SF & 82,00 & 4,44 & 1,62 & 0,18 & 0,36 \\
\hline & DHT & 56,00 & 4,64 & 1,17 & 0,16 & 0,32 \\
\hline \multirow[t]{3}{*}{8 vibr. } & E2 & 26,00 & 5,83 & 0,87 & 0,18 & 0,37 \\
\hline & GEN & 9,00 & 8,84 & 2,09 & 0,79 & 1,93 \\
\hline & $\mathbf{E Q}$ & 47,00 & 4,13 & 1,40 & 0,21 & 0,42 \\
\hline
\end{tabular}

Tab. A-6 Mittelwerte (Mean in \%) der relativen Veränderung der periostalen Apposition für die verschiedenen Testgruppen nach 2-, 3- und 8 wöchiger Applikation sowie Stichprobenumfang (N) der Messwerte, Standardabweichung (SD) und Standardfehler (SEM). Die vibrierten Tiere der 8. Woche sind mit 8 vibr. gekennzeichnet.

\begin{tabular}{|c|c|c|c|c|c|}
\hline Wochen & Futtergruppe & $\mathbf{N}$ & Mean (\%) & SD & SEM \\
\hline & SF & 94 & 116,023 & 43,06 & 4,489 \\
\hline & DHT & 35 & 161,508 & 34,382 & 5,985 \\
\hline \multirow[t]{5}{*}{2} & E2 & 27 & 116,488 & 34,982 & 6,996 \\
\hline & GEN & 83 & 222,879 & 125,197 & 13,911 \\
\hline & $\mathbf{E Q}$ & 189 & 111,09 & 48,712 & 3,562 \\
\hline & SF & 30 & 153,015 & 33,573 & 6,345 \\
\hline & DHT & 100 & 157 & 48,706 & 4,895 \\
\hline \multirow[t]{5}{*}{3} & E2 & 153 & 119,198 & 43,65 & 3,552 \\
\hline & GEN & 49 & 163,827 & 55,592 & 8,109 \\
\hline & EQ & 191 & 159,948 & 54,766 & 3,984 \\
\hline & SF & 103 & 95,216 & 27,536 & 2,74 \\
\hline & DHT & 212 & 114,15 & 39,448 & 2,722 \\
\hline \multirow[t]{5}{*}{8} & E2 & 120 & 109,032 & 37,344 & 3,438 \\
\hline & GEN & 110 & 130,475 & 38,302 & 3,686 \\
\hline & $\mathbf{E Q}$ & 57 & 180,117 & 64,555 & 8,705 \\
\hline & SF & 82 & 194,979 & 71,04 & 7,943 \\
\hline & DHT & 56 & 192,665 & 48,654 & 6,621 \\
\hline \multirow[t]{3}{*}{8 vibr. } & E2 & 26 & 109,685 & 16,41 & 3,35 \\
\hline & GEN & 9 & 282,652 & 66,856 & 25,269 \\
\hline & EQ & 47 & 89,526 & 30,407 & 4,533 \\
\hline
\end{tabular}


Tab. A-7 Alizarin-Mittelwerte (Mean in $\mu \mathrm{m}$ ) der absoluten, endostalen Apposition für die verschiedenen Testgruppen nach 2-, 3- und 8 wöchiger Applikation sowie Stichprobenumfang (N) der Messwerte, Standardabweichung (SD), Standardfehler (SEM) und Konfidenzintervall (Cl of Mean). Die vibrierten Tiere der 8 . Woche sind mit 8 vibr. gekennzeichnet.

\begin{tabular}{|c|c|c|c|c|c|c|}
\hline & SF & 581,00 & 5,46 & 2,68 & 0,11 & 0,22 \\
\hline & DHT & 315,00 & 5,32 & 2,08 & 0,12 & 0,23 \\
\hline \multirow[t]{5}{*}{2} & E2 & 288,00 & 6,09 & 2,28 & 0,13 & 0,27 \\
\hline & GEN & 392,00 & 4,29 & 1,82 & 0,09 & 0,18 \\
\hline & EQ & 447,00 & 5,00 & 2,25 & 0,11 & 0,21 \\
\hline & SF & 263.00 & 6.43 & 1.93 & 0,12 & 0.24 \\
\hline & DHT & 321,00 & 5,94 & 2,09 & 0,12 & 0,23 \\
\hline \multirow[t]{6}{*}{3} & E2 & 287,00 & 6,13 & 2,26 & 0,13 & 0,26 \\
\hline & GEN & 169,00 & 6,41 & 2,06 & 0,16 & 0,31 \\
\hline & EQ & 412,00 & 5,11 & 2,07 & 0,10 & 0,20 \\
\hline & & & & & & \\
\hline & SF & 119,00 & 5,13 & 1,44 & 0,13 & 0,26 \\
\hline & DHT & 228,00 & 5,16 & 1,53 & 0,10 & 0,20 \\
\hline \multirow[t]{6}{*}{8} & E2 & 262,00 & 5,73 & 1,77 & 0,11 & 0,22 \\
\hline & GEN & 145,00 & 5,08 & 1,45 & 0,12 & 0,24 \\
\hline & EQ & 37,00 & 5,95 & 2,20 & 0,37 & 0,74 \\
\hline & & & & & & \\
\hline & SF & 88,00 & 6,00 & 2,05 & 0,22 & 0,44 \\
\hline & DHT & 78,00 & 4,51 & 1,27 & 0,14 & 0,29 \\
\hline \multirow[t]{3}{*}{8 vibr. } & E2 & 127,00 & 6,14 & 2,02 & 0,18 & 0,36 \\
\hline & GEN & 42,00 & 6,49 & 2,15 & 0,34 & 0,68 \\
\hline & EQ & 89,00 & 4,61 & 1,61 & 0,17 & 0,34 \\
\hline
\end{tabular}

Tab. A-8 Mittelwerte (Mean in \%) der relativen Veränderung der endostalen Apposition für die verschiedenen Testgruppen nach 2-, 3- und 8 wöchiger Applikation sowie Stichprobenumfang (N) der Messwerte, Standardabweichung (SD) und Standardfehler (SEM). Die vibrierten Tiere der 8. Woche sind mit 8 vibr. gekennzeichnet.

\begin{tabular}{l|l|r|r|r|r}
\multicolumn{1}{c|}{ Wochen } & Futtergruppe & $\mathbf{N}$ & Mean (\%) & \multicolumn{1}{c|}{ SD } & \multicolumn{1}{c}{ SEM } \\
\hline & SF & 581 & 92,867 & 45,547 & 1,891 \\
\hline $\mathbf{2}$ & DHT & 315 & 96,527 & 37,835 & 2,135 \\
\hline & E2 & 289 & 129,186 & 49,016 & 2,888 \\
\hline & GEN & 392 & 86,172 & 36,462 & 1,844 \\
\hline & EQ & 447 & 109,882 & 49,381 & 2,338 \\
\hline & & & & & \\
\hline & SF & 263 & 166,57 & 50,076 & 3,094 \\
\hline $\mathbf{3}$ & DHT & 322 & 157,901 & 56,933 & 3,178 \\
\hline & E2 & 287 & 109,92 & 40,585 & 2,4 \\
\hline & GEN & 176 & 132,895 & 55,911 & 4,226 \\
\hline & EQ & 416 & 124,048 & 61,04 & 2,996 \\
\hline & & & & & 2,285 \\
\hline & SF & 119 & 88,527 & 24,824 & 2,169 \\
\hline $\mathbf{8}$ & DHT & 228 & 110,188 & 32,674 & 2,458 \\
\hline & E2 & 263 & 123,104 & 39,792 & 3,023 \\
\hline & GEN & 145 & 127,437 & 36,276 & 7,757 \\
\hline & EQ & 38 & 113,988 & 47,187 & 4,607 \\
\hline & & & & & 3,105 \\
\hline & SF & 90 & 108,831 & 43,46 & 4,057 \\
\hline $\mathbf{8}$ vibr. & DHT & 78 & 96,916 & 27,248 & 6,984 \\
\hline & E2 & 127 & 138,807 & 45,538 & 3,835
\end{tabular}


Tab. A-9 Alizarin-Mittelwerte (Mean in $\mu \mathrm{m}$ ) der absoluten, trabekulären Apposition für die verschiedenen Testgruppen nach 2-, 3- und 8 wöchiger Applikation sowie Stichprobenumfang $(\mathrm{N})$ der Messwerte, Standardabweichung (SD), Standardfehler (SEM) und Konfidenzintervall ( $\mathrm{Cl}$ of Mean). Die vibrierten Tiere der 8 . Woche sind mit 8 vibr. gekennzeichnet.

\begin{tabular}{l|l|r|r|r|r|r} 
Wochen & Futtergruppe & $\mathbf{N}$ & Mean $(\mu \mathrm{m})$ & \multicolumn{1}{c}{ SD } & \multicolumn{1}{c}{ SEM } & CI of Mean \\
\hline & SF & 586,00 & 3,52 & 1,52 & 0,06 & 0,12 \\
\hline $\mathbf{2}$ & DHT & 281,00 & 4,20 & 1,50 & 0,09 & 0,18 \\
\hline & E2 & 235,00 & 4,08 & 1,52 & 0,10 & 0,20 \\
\hline & GEN & 341,00 & 3,51 & 1,19 & 0,06 & 0,13 \\
\hline & EQ & 267,00 & 3,39 & 1,27 & 0,08 & 0,15 \\
\hline & & & & & & \\
\hline & SF & 172,00 & 4,46 & 1,69 & 0,13 & 0,26 \\
\hline $\mathbf{3}$ & DHT & 249,00 & 4,27 & 1,39 & 0,09 & 0,17 \\
\hline & E2 & 130,00 & 4,87 & 1,55 & 0,14 & 0,27 \\
\hline & GEN & 106,00 & 5,16 & 1,83 & 0,18 & 0,36 \\
\hline & EQ & 220,00 & 4,00 & 1,71 & 0,12 & 0,23 \\
\hline & & & & & & \\
\hline $\mathbf{8}$ & SF & 66,00 & 5,54 & 1,65 & 0,20 & 0,41 \\
\hline & DHT & 139,00 & 4,79 & 1,46 & 0,12 & 0,25 \\
\hline & E2 & 163,00 & 4,45 & 1,34 & 0,11 & 0,21 \\
\hline & GEN & 78,00 & 4,74 & 1,64 & 0,19 & 0,37 \\
\hline & EQ & 93,00 & 4,73 & 1,06 & 0,11 & 0,22 \\
\hline & & & & & & 0,67 \\
\hline $\mathbf{8}$ vibr. & SF & 45,00 & 4,56 & 2,20 & 0,33 & 0,26 \\
\hline & EHT & 45,00 & 3,52 & 0,87 & 0,13 & 0,22 \\
\hline & GEN & 122,00 & 4,32 & 1,20 & 0,11 & 0,45 \\
\hline & EQ & 31,00 & 4,27 & 1,22 & 0,22 & 0,34
\end{tabular}

Tab. A-10 Mittelwerte (Mean in \%) der relativen Veränderung der trabekulären Apposition für die verschiedenen Testgruppen nach 2-, 3- und 8 wöchiger Applikation sowie Stichprobenumfang (N) der Messwerte, Standardabweichung (SD) und Standardfehler (SEM). Die vibrierten Tiere der 8. Woche sind mit 8 vibr. gekennzeichnet.

\begin{tabular}{l|l|r|r|r|r}
\multicolumn{1}{c|}{ Wochen } & Futtergruppen & $\mathbf{N}$ & Mean (\%) & \multicolumn{1}{c|}{ SD } & SEM \\
\hline & SF & 590 & 96,832 & 45,985 & 1,893 \\
\hline $\mathbf{2}$ & DHT & 280 & 103,739 & 37,111 & 2,218 \\
\hline & E2 & 234 & 118,401 & 44,252 & 2,893 \\
\hline & GEN & 340 & 104,105 & 35,161 & 1,907 \\
\hline & EQ & 267 & 96,661 & 38,134 & 2,334 \\
\hline & & & & & 5,214 \\
\hline & SF & 171 & 179,74 & 68,183 & 2,614 \\
\hline & DHT & 248 & 126,53 & 41,171 & 3,647 \\
\hline & E2 & 130 & 124,785 & 41,583 & 5,183 \\
\hline & GEN & 106 & 142,341 & 53,362 & 3,918 \\
\hline & EQ & 220 & 130,223 & 58,107 & \\
\hline & & & & & 5,644 \\
\hline $\mathbf{8}$ & SF & 66 & 136,57 & 45,856 & 3,09 \\
\hline & DHT & 138 & 119,367 & 36,305 & 2,794 \\
\hline & E2 & 162 & 117,886 & 35,558 & 5,508 \\
\hline & GEN & 78 & 122,401 & 48,645 & 2,177 \\
\hline & EQ & 92 & 93,552 & 20,884 & 9,827 \\
\hline & & & & & 3,495 \\
\hline $\mathbf{8}$ vibr. & SF & 46 & 120,225 & 66,653 & 2,74 \\
\hline & DHT & 44 & 94,118 & 23,186 & 6,71 \\
\hline & E2 & 121 & 108,802 & 30,138 & 4,318
\end{tabular}




\section{Literatur}

Anderson F, Francis R, Peaston R, Wastell H (1997): Androgen therapy in eugonadal men with osteoporosis - effects of 6 months on markers of bone formation and resorption. $J$ Bone Miner Res 12: 472-478.

Andre $T$ (1956): Studies on the distribution of tritium-labelled dihydrostreptomycin and tetracycline in the body. Acta Radiolog Suppl. 142: 1-90.

Augat P, Merk J, Wolf S, Claes L (2001): Mechanical stimulation by external application of cyclic tensile strains does not effectively enhance bone healing. J Orthop Trauma 15: 54-60.

Bartl R: Osteoporose Prävention - Diagnostik - Therapie. 4., vollständig überarbeitete und erweiterte Auflage, Georg Thieme Verlag KG, Stuttgart 2011.

Bennetts HW, Underwood EJ, Shier FL (1946): A specific breeding problem of sheep on subterranean clover pastures in Western Australia. Aust J Agric Res 22: 131-138.

Bingham SA, Atkinson C, Liggins J, Bluck L, Coward A (1998): Phyto-oestrogens: where are we now? Br J Nutr $\underline{79}(5)$ : 393-406.

Bitto A, Altavilla D, Bonaiuto A, Polito F, Minutoli L, Di Stefano V, Giuliani D, Guarini S, Arcoraci $V$, Squadrito $F$ (2009): Effects of aglycone genistein in a rat experimental model of postmenopausal metabolic syndrome. J Endocrinol 200(3): 367-376.

Bitto A, Polito F, Squadrito F, Marini H, D'Anna R, Irrera N, Minutoli L, Granese R, Altavilla D (2010): Genistein aglycone: a dual mode of action anti-osteoporotic soy isoflavone rebalancing bone turnover towards bone formation. Curr Med Chem 27: 3007-3018.

Bland R (2000): Steroid hormone receptor expression and action in bone. Clin Sci $\underline{98:}$ 217-240.

Bloomfield SA, Allen MR, Hogan HA, Delp MD (2002): Site-and compartment specific changes in bone with hindlimb unloading in mature adult rats. Bone 1: 149-157.

Bone-Eva-Studie - Osteoporose in Deutschland. Hrsg.: Institut für Gesundheits- und Sozialforschung Berlin 2006.

Braidman IP, Hainey L, Batra G, Selby PL, Saunders PT, Hoyland JA (2001): Localization of estrogen receptor beta protein expression in adult human bone. J Bone Miner Res 16(2): 214220. 
Brouwers JE, van Rietbergen B, Ito K, Huiskes R (2010): Effects of vibration treatment on tibial bone of ovariectomized rats analyzed by in vivo micro-CT. J Orthop Res $\underline{28}(1)$ : 62-69.

Bundesinstitut für Risikobewertung (2007): Isolierte Isoflavone sind nicht ohne Risiko. Aktualisierte Stellungnahme Nr.039/2007: 1-24.

Carani C, Qin K, Simoni M, Faustini-Fustini M, Serpente S, Boyd J, Korach KS, Simpson ER (1997): Effect of testosterone and estradiol in a man with aromatase deficiency. N Engl J Med 337: 91-95.

Carlson S, Peng N, Prasain JK, Wyss JM (2008): Effects of botanical dietary supplements on cardiovascular, cognitive, and metabolic function in males and females. Gend Med 5 Suppl A: 76-90.

Castel H, Bonneh DY, Sherf M, Liel Y (2001): Awareness of osteoporosis and compliance with management guidelines in patients with newly diagnosed low-impact fractures. Osteoporos Int 12(7): 559-564.

Center J, Nguyen T, Schneider D, Sambrook P, Eisman J (1999): Mortality after all major types of osteoporotic fracture in men and women: an observational study. Lancet 353: 878-882.

Chen X, Anderson JJB (2002): Isoflavones and bone: Animal and human evidence of efficacy. J Musculoskel Neuron Interact 2(4): 352-359.

Chow DH, Leung KS, Qin L, Leung AH, Cheung WH (2011): Low-magnitude high-frequency vibration (LMHFV) enhances bone Remodelling in osteoporotic rat femoral fracture healing. J Orthop Res 29 (5): 746-752.

Colvard D, Spelsberg T, Eriksen E, Keeting P, Riggs BL (1989): Evidence of steroid receptors in human osteoblast-like cells. Connect Tissue Res 20 (1-4): 33-40.

Cook LS, Goldoft M, Schwartz SM, Weiss NS (1999): Incidence of adenocarcinoma of the prostate in Asian immigrants to the United States and their descendants. J Urol 161: 152-155.

Cummings SR, Melton LJ (2002): Epidemiology and outcomes of osteoporotic fractures. Lancet 359(9319): 1761-1767.

Daniell HW (1997): Osteoporosis after orchiectomy for prostate cancer. J Urol 157(2): 439-444. 
DVO-Leitlinien (2009): Prophylaxe, Diagnostik und Therapie der Osteoporose bei Erwachsenen - Langfassung. Osteologie 18: 304-328.

Enmark, E, Gustafsson JA (1999): Oestrogen receptors - an overview. $J$ Internal Med 246: 133-138.

Eriksen EF, Colvard DS, Berg NJ, Graham ML, Mann KG, Spelsberg TC, Riggs BL (1988): Evidence of estrogen receptors in normal human osteoblast-like cells. Science 241(4861): 84-86.

European Prospective Osteoporosis Study (EPOS) Group, Felsenberg D, Silman AJ, Lunt M, Armbrecht G, Ismail AA, Finn JD, Cockerill WC, Banzer D, Benevolenskaya LI, Bhalla A (2002): Incidence of vertebral fracture in europe: results from the European Prospective Osteoporosis Study (EPOS). J Bone Miner Res 17(4): 716-724.

Faustini-Fustini M, Rochira V, Carani C (1999): Oestrogen deficiency in men: where are we today? Eur J Endocrinol 140(2): 111-129.

Foth D (2007): Alternative Therapiemöglichkeiten zur Hormontherapie in der Postmenopause. Gynäkologische Endokrinologie $\underline{5}$ : 115-119.

Frost HM (1958): Preparation of thin undecalcified bone sections by rapid manual method. Stain Technol $\underline{33}(6)$ : 273-277.

Frost HM (1969): Tetracycline-based histological analysis of bone Remodelling. Calcif Tissue Res $\underline{3}(3):$ 211-237.

Frost HM (1998): From Wolff's law to the mechanostat: a new "face" of physiology. J Orthop Sci $\underline{5}:$ 282-286.

Frost HM, Jee WS (1992): On the rat model of human osteopenias and osteoporoses. Bone Miner 18(3): 227-236.

Fujioka M, Sudo Y, Okumura M, Wu J, Uehara M, Takeda K, Hosokawa Y, Yamada K, Ikegami S, Ishimi $Y$ (2007): Differential effects of isoflavones on bone formation in growing male and female mice. Metabolism 56(8): 1142-1148.

Funk J: Die Wirkung von systemisch appliziertem rekombinantem speziesspezifischem Wachstumshormon auf den Knochenumbau am Achsenskelett. Histologische und histomorphometrische Untersuchungen bei der Distraktionsosteogenese am YucatanMinischwein. Med. Diss. Berlin 2004. 
Gao YH, Yamaguchi M (2000): Suppressive effect of genistein on rat bone osteoclasts: involvement of protein kinase inhibition and protein tyrosine phosphatase activation. Int J Mol Med ㅁ: 261-267.

Girasole G, Jilka RL, Passeri G, Boswell S, Boder G, Williams DC, Manolagas SC (1992): 17beta-estradiol inhibits interleukin- 6 production by bone marrow-derived stromal cells and osteoblasts in-vitro: a potential mechanism for the antiosteoporotic effect of estrogens. J Clin Invest 89: 883- 891.

Glazier MG, Bowman MA (2001): A review of the evidence for the use of phytoestrogens as a replacement for traditional estrogen replacement therapy. Arch Intern Med 161: 1161-1172.

Hannan MT, Felson DT, Dawson-Hughes B, Tucker KL, Cupples LA, Wilson PW, Kiel DP (2000): Risk factors for longitudinal bone loss in elderly men and women: the Framingham osteoporosis study. J Bone Miner Res 15: 710-720.

Harder L, Kuster M: Frakturen, Gelenk- und Weichteilverletzungen; in: Orthopädie und Unfallchirurgie; hrsg. von Gifka J, Kuster M; 1. Auflage; Spinger-Verlag, Berlin Heidelberg 2011.

Harris WH (1960): A microscopic method of determining rates of bone growth. Nature 188: 1038-1039.

He YX, Zhang G, Pan XH, Liu Z, Zheng LZ, Chan CW, Lee KM, Cao YP, Li G, Wei L, et al. (2011): Impaired bone healing pattern in mice with ovariectomy-induced osteoporosis: A drillhole defect model. Bone $\underline{6}$ : 1388-4000.

Hertrampf T, Gruca MJ, Seibel J, Laudenbach U, Fritzemeier KH, Diel P (2007): The boneprotective effect of the phytoestrogen genistein is mediated via ER alpha-dependent mechanisms and strongly enhanced by physical activity. Bone $\underline{6}$ : 1529-1535.

Hirschinger A: Vergleichende tierexperimentelle Studie zur Anwendung und Osseointegration eines neuartigen bovinen Knochenersatzmaterials im Schweinekiefer. Med. Diss. ErlangenNürnberg 2011.

Hobusch G, Holzer G (2011): Osteoporose und Frakturen bei primär malignen Knochentumoren. Journal für Mineralstoffwechsel 18(2): 64-68. 
Hwang CS, Kwak HS, Lim HJ, Lee SH, Kang YS, Choe TB, Hur HG, Han KO (2006): Isoflavone metabolites and their in vitro dual functions: they can act as an estrogenic agonist or antagonist depending on the estrogen concentration. J Steroid Biochem Mol Biol 101(4-5):246-253.

\section{Internetquellen}

PubChem (2012a): Estradiol (CID 5757).URL:

http://pubchem.ncbi.nlm.nih.gov/summary/summary.cgi?cid=5757\&loc=ec_rcs

[Online im Internet, Stand: 14.04.2012 um 14:00Uhr]

PubChem (2012b): Dihydrotestosterone (CID 10635). ULR:

http://pubchem.ncbi.nlm.nih.gov/image/imgsrv.fcgi?t=|\&cid=10635

[Online im Internet, Stand: 14.04.2012 um 14:00Uhr]

PubChem (2012c): Genistein (CID 5280961). ULR:

http://pubchem.ncbi.nlm.nih.gov/image/imgsrv.fcgi?t=l\&cid=5280961

[Online im Internet, Stand: 14.04.2012 um 17:00Uhr]

PubChem (2012d): Equol (CID 91469). ULR:

http://pubchem.ncbi.nlm.nih.gov/image/imgsrv.fcgi?t=|\&cid=91469

[Online im Internet, Stand: 14.04.2012 um 17:00Uhr]

\section{http://www.univie.ac.at/mikroskopie/pdf/3_Fluoreszenz.pdf}

[Online im Internet, ohne Verfasser, Stand: 28.08.2013 um 21:00Uhr]

Ishimi $\mathrm{Y}$, Miyaura $\mathrm{C}$, Ohmura $\mathrm{M}$, Onoe $\mathrm{Y}$, Sato $\mathrm{T}$, Uchiyama $\mathrm{Y}$, Ito $\mathrm{M}$, Wang $\mathrm{X}$, Suda $\mathrm{T}$, Ikegami $S$ (1999): Selective effects of genistein, a soybean isoflavone, on Blymphopoiesis and bone loss caused by estrogen deficiency. Endocrinology 140: 1893-1900.

Ishimi Y, Arai N, Wang X, Wu J, Umegaki K, Miyaura C, Takeda A, Ikegami S (2000): Difference in effective dosage of genistein on bone and uterus in ovariectomized mice. Biochem Biophys Res Commun 274: 697-701.

Ishimi Y, Yoshida M, Wakimoto S, Wu J, Chiba H, Wang X, Takeda K, Miyaura C (2002): Genistein, a soybean isoflavone, affects bone marrow lymphopoiesis and prevents bone loss in castrated male mice. Bone 1: 180-185.

Jackson RL, Greiwe JS, Schwen RJ (2011): Emerging evidence of the health benefits of Sequol, an estrogen receptor $\beta$ agonist. Nutr Rev $\underline{69}(8)$ : 432-448. 
Jilka RL, Hangoc G, Girasole G, Passeri G, Williams DC, Abrams JS, Boyce B, Broxmeyer H and Manolagas SC (1992): Increased osteoclast development after estrogen loss: mediation by interleukin-6. Science 257:88-91.

Johnell O, Kanis JA (2006): An estimate of the worldwide prevalence and disability associated with osteoporotic fractures. Osteoporos Int 17: 1726-1733.

Judex S, Lei X, Han D, Rubin C (2007): Low-magnitude mechanical signals that stimulate bone formation in the ovariectomized rat are dependent on the applied frequency but not on the strain magnitude. J Biomech 40⑹: 1333-1339.

Junqueira LC und Carneiro J: Knochen; in: Histologie, hrsg von Gratzl M, Springer Medizin Verlag Heidelberg 2005, 91-103.

Kameda T, Mano H, Yuasa T, Mori Y, Miyazawa K, Shiokawa M, Nakamaru Y, Hiroi E, Hiura K, Kameda A, et al. (1997): Estrogen inhibits bone resorption by directly inducing apoptosis of the bone-resorbing osteoclasts. J Exp Med 186(4): 489-495.

Kanis JA, Reginster JY (2008): European guidance for the diagnosis and management of osteoporosis in postmenopausal women--what is the current message for clinical practice? Pol Arch Med Wewn 118(10): 538-540.

Kerschbaumer S: Histologische Untersuchungen von Implantaten; in: Ossäre Integration, hrsg von Gradinger R und Gollwitzer H; Springer Medizin Verlag Heidelberg 2006, 39-41.

Kim BT, Mosekilde L, Duan Y, Zhang XZ, Tornvig L, Thomsen JS, Seeman E (2003): The structural and hormonal basis of sex differences in peak appendicular bone strength in rats. J Bone Miner Res 1: 150-155.

Klotzbuecher CM, Ross PD, Landsman PB, Abbott TA, Berger M (2000): Patients with prior fractures have an increased risk of future fractures: a summary of the literature and statistical synthesis. J Bone Miner Res 15: 721-739.

Kolios L, Sehmisch S, Daub F, Rack T, Tezval M, Stuermer KM, Stuermer EK (2009): Equol but not genistein improves early metaphyseal fracture healing in osteoporotic rats. Planta Med 5: 459-465.

Komatsu DE, Brune KA, Liu H, Schmidt AL, Han B, Zeng QQ, Yang X, Nunes JS, Lu Y, Geiser $A G$, et al. (2009): Longitudinal in vivo analysis of the region-specific efficacy of parathyroid hormone in a rat cortical defect model. Endocrinology 4: 1570-1579. 
Komm BS, Terpening CM, Benz DJ, Graeme KA, Gallegos A, Korc M, Greene GL, O'Malley BW, Haussler MR (1988): Estrogen binding, receptor mRNA, and biological response in osteoblast-like osteosarcoma cells. Science 241(4861): 81-84.

Kubo T, Shiga T, Hashimoto J, Yoshioka M, Honjo H, Urabe M, Kitajima I, Semba I, Hirasawa Y (1999): Osteoporosis influences the late period of fracture healing in a rat model prepared by ovariectomy and low calcium diet. J Steroid Biochem Mol Biol 68(5-6): 197-202.

Kuiper GG, Lemmen JG, Carlsson B, Corton JC, Safe SH,van der Saag PT, van der Burg B, Gustafsson JA (1998): Interaction of estrogenic chemicals and phytoestrogens with estrogen receptor beta. Endocrinology 139: 4252-4563.

Kugler P: Gewebelehre, in Kugler P: Zelle Organ Mensch: Bau, Funktion und Krankheiten 1. Auflage; Elsevier GmbH, München 2006.

Kulling SE, Watzl B (2003): Phytoöstrogene. Ernährungsumschau 50: 234-239.

Kumar N, Crozat A, Li F, Catterall JF, Bardin CW, Sundaram K (1999): 7alpha-methyl-19nortestosterone, a synthetic androgen with high potency: structure-activity comparisons with other androgens. J Steroid Biochem Mol Biol 71: 213-222.

Kurebayashi S, Miyashita Y, Hirose T, Kasayama S, Akira S, Kishimoto T (1997): Characterization of mechanisms of interleukin- 6 gene repression by estrogen receptor. $J$ Steroid Biochem Mol Biol $\underline{60}(1-2)$ : 11-7.

Lenk VS (2005): Diagnosis of the "aging male"--what is recommended? Urologe A $\underline{44}(10):$ 1167-1172.

Leung KS, Shi HF, Cheung WH, Qin L, Ng WK, Tam KF, Tang N (2009): Low-magnitude highfrequency vibration accelerates callus formation, mineralization, and fracture healing in rats. J Orthop Res 27(4): 458-465.

Lindberg MK, Moverare S, Skrtic S, Alatalo S, Halleen J, Mohan S, Gustafsson JA, Ohlsson C (2002): Two different pathways for the maintenance of trabecular bone in adult male mice. J Bone Miner Res 4: 555-562.

Lüllmann-Rauch R: Histologie. 3. Auflage, Georg Thieme Verlag KG, Stuttgart 2009, S.144-165. 
Ma DF, Qin LQ, Wang PY, Katoh R (2008): Soy isoflavone intake increases bone mineral density in the spine of menopausal women: meta-analysis of randomized controlled trial. Clin Nutr 27 (1): 57-64.

Marini H, Minutoli L, Polito F, Bitto A, Altavilla D, Atteritano M, Gaudio A, Mazzaferro S, Frisina A, Frisina N, et al. (2007): Effects of the phytoestrogen genistein on bone metabolism in osteopenic postmenopausal women: a randomized trial. Ann Intern Med 146(12): 839-847.

Mathey J, Mardon J, Fokialakis N, Puel C, Kati-Coulibaly S, Mitakou S, Bennetau-Pelissero C, Lamothe V, Davicco MJ, Lebecque P, et al. (2007): Modulation of soy isoflavones bioavailability and subsequent effects on bone health in ovariectomized rats: the case for equol. Osteoporos Int 18(5): 671-679.

Mau M.: In vitro-Wachstum und -Differenzierung porciner Skelettmuskelzellen unter dem Einfluss der Isoflavone Genistein und Daidzein. Nat. Diss. Greifswald 2007.

McCarty MF(2006): Isoflavones made simple - genistein's agonist activity for the beta-type estrogen receptor mediates their health benefits. Med Hypotheses 66(6): 1093-1114.

McKenzie JA, Bixby EC, Silva MJ (2011): Differential gene expression from microarray analysis distinguishes woven and lamellarbone formation in the rat ulna following mechanical loading. PLoS One 12: e29328.

Messina MJ (1999): Legumes and soybeans: overview of their nutritional profiles and health effects. Am J Clin Nutr $\underline{70}$ (suppl): 439S-450S.

Messina MJ (2002): Soy foods and soybean isoflavones and menopausal health. Nutr Clin Care 5: 272-282.

Milch RA, Rall DP, Tobie JE (1957): Bone localization of the tetracyclines. J. Natl Cancer Inst 19: 87-93.

Miyaura C, Toda K, Inada M, Ohshiba T, Matsumoto C, Okada T, Ito M, Shizuta Y, Ito A (2001): Sex- and age-related response to aromatase deficiency in bone. Biochem Biophys Res Commun 280: 1062-1068.

Monfoulet L, Rabier B, Chassande O, Fricain JC (2010): Drilled hole defects in mouse femur as models of intramembranous cortical and cancellous bone regeneration. Calcif Tissue Int 1: 72-81. 
Morabito N, Crisafulli A, Vergara C, Gaudio A, Lasco A, Frisina N, D'Anna R, Corrado F, Pizzoleo MA, Cincotta M, et al. (2002): Effects of genistein and hormone-replacement therapy on bone loss in early postmenopausal women: a randomized double-blind placebo-controlled study. J Bone Miner Res 17: 1904-1912.

Movérare S, Venken K, Eriksson AL, Andersson N, Skrtic S, Wergedal J, Mohan S, Lachs P, Bouillon R, Gustafsson JA, Vanderschueren D, Ohlsson C (2003): Differential effects on bone of estrogen receptor alpha and androgen receptor activationin orchidectomized adult male mice. Proc Natl Acad Sci U S A. 23: 13573-13578.

Muthyala RS, Ju YH, Sheng S, Williams LD, Doerge DR, Katzenellenbogen BS, Helferich WG, Katzenellenbogen JA (2004): Equol,a natural estrogenic metabolite from soy isoflavones: convenient preparation andresolution of $\mathrm{R}$ - and S-equols and their differing binding and biological activity throughestrogen receptors alpha and beta. Bioorg Med Chem 12(6): 1559-1567.

Namkung-Matthai H, Appleyard R, Jansen J, Hao Lin J, Maastricht S, Swain M, Mason RS, Murrell GA, Diwan AD, Diamond T (2001): Osteoporosis influences the early period of fracture healing in a rat osteoporotic model. Bone $\underline{28}(1): 80-86$.

Niethard FU, Pfeil J, Biberthaler P: Knochenerkrankungen; in: Duale Reihe Orthopädie und Unfallchirurgie; hrsg. von Bob A und Bob K; 6. Auflage; Georg Thieme Verlag KG, Stuttgart 2009, 133-150.

Ohlsson C, Vandenput L (2009): The role of estrogens for male bone health. Eur J Endocrinol 160(6): 883-889.

Ophoff J, Venken K, Callewaert F, Boonen S, Bouillon R, Vanderschueren D (2009): Sex steroids during bone growth: a comparative study between mouse models for hypogonadal and senile osteoporosis. Osteoporos Int 20(10): 1749-1757.

Orwoll E, Ettinger M, Weiss S, Miller P, Kendler D, Graham J, Adami S, Weber K, Lorenc R, Pietschmann P, Vandormael K, Lombardi A (2000): Alendronate for the treatement of osteoporosis in men. N Engl J Med 343: 604-610.

Oursler MJ, Osdoby P, Pyfferoen J, Riggs BL, Spelsberg TC (1991): Avian osteoclasts as

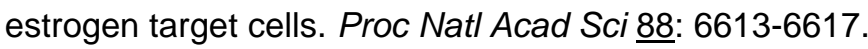

Oz OK, Zerwekh JE, Fisher C, Graves K, Nanu L, Millsaps R, Simpson ER (2000): Bone has a sexually dimorphic response to aromatase deficiency. J Bone Miner Res 15: 507-514. 
Papenberg S: Beeinflussung der Knochenparameter und der Knochendefektheilung des osteoporotischen Knochens am Modell der orchidektomierten Ratte durch Vibrationstherapie in Kombination mit Dihydrotestosteron und Östradiol. Med. Diss. Göttingen 2011.

Piekarz AV, Ward WE (2007): Effect of neonatal exposure to genistein on bone metabolism in mice at adulthood. Pediatr Res $\underline{61}(1):$ 48-53.

Pietschmann P, Kudlacek S, Peterlik M (2004): Pathogenese und Therapie der Osteoporose beim Mann. Journal für Mineralstoffwechsel 11(Sonderheft 2): 12-14.

Qu Q, Perälä-Heape M, Kapanen A, Dahllund J, Salo J, Väänänen HK, Härkönen P (1998): Estrogen enhances differentiation of osteoblasts in mouse bone marrow culture. Bone 22(3): 201-209.

Rachón D, Seidlová-Wuttke D, T Vortherms, Wuttke W (2007): Effects of dietary equol administration on ovariectomy induced bone loss in Sprague-Dawley rats.

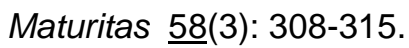

Rahn BA, Perren SM (1970): Calcein blue as a fluorescent label in bone. Experientia 26(5): 519-520.

Rahn BA, Perren SM (1971): Xylenol orange, a fluorochrome useful in polychrome sequential labeling of calcifying tissues. Stain Technol $\underline{46}(3):$ 125-129.

Rahn BA, Perren SM (1972): Alizarin complexon-fluorochrome for bone and dentine labeling. Experientia 28 (2): 180.

Rochira V, Balestrieri A, Faustini-Fustini M, Carani C (2001): Role of estrogen on bone in the human male: insights from the natural models of congenital estrogen deficiency. Mol Cell Endocrinol 178: 215-220.

Rochira V, Balestrieri A, Madeo B, Spaggiari A, Carani C (2002): Congenital estrogen deficiency in men: a new syndrome with different phenotypes; clinical and therapeutic implications in men. Mol Cell Endocrinol 193: 19-28.

Rochira V, Granata AR, Madeo B, Zirilli L, Rossi G, Carani C (2005): Estrogens in males: what have we learned in the last 10 years? Asian $J$ Androl 7: 3-20. 
Rochira V, Zirilli L, Madeo B, Aranda C, Caffagni G, Fabre B, Montangero VE, Roldan EJ, Maffei L, Carani $C$ (2007): Skeletal effects of long-term estrogen and testosterone replacement treatment in a man with congenital aromatase deficiency: evidences of a priming effect of estrogen for sex steroids action on bone. Bone (6):1662-1668.

Ruan XY, Jin FY, Liu YL, Peng ZL, Sun YG (2008): Effects of vibration therapy on bone mineral density in postmenopausal women withosteoporosis. Chin Med J 121(13): 1155-1158.

Rubin C, Xu G, Judex S (2001): The anabolic activity of bone tissue, suppressed by disuse, is normalized by briefexposure to extremely low-magnitude mechanical stimuli. FASEB J 12: 2225-9.

Rubin C, Turner AS, Mallinckrodt C, Jerome C, McLeod K, Bain S (2002): Mechanical strain, induced noninvasively in the high-frequency domain, is anabolic tocancellous bone, but not cortical bone. Bone 30(3): 445-452.

Rubin C, Recker R, Cullen D, Ryaby J, McCabe J, McLeod K (2004): Prevention of postmenopausal bone loss by a low-magnitude, high-frequency mechanical stimuli: a clinical trial assessing compliance, efficacy, and safety. J Bone Miner Res 19(3): 343-351.

Sakhri S, Gooren LJ (2007): Safety aspects of androgen treatment with 5alphadihydrotestosterone. Andrologia 39: 216-222.

Sambrook P, Cooper C (2006): Osteoporosis. Lancet 9527: 2010-2018.

Schot LP, Schuurs AH (1990): Pathophysiology of bone loss in castrated animals. J Steroid Biochem Mol Biol 37(3): 461-465.

Seeman E (2001a): During aging, men lose less bone than women because they gain more periosteal bone, not because they resorb less endosteal bone. Calcif Tissue Int 69(4): 205-208.

Seeman E (2001b): Clinical review 137: Sexual dimorphism in skeletal size, density, and strength. J Clin Endocrinol Metab 86(10): 4576-4584.

Sehmisch S, Galal R, Kolios L, Tezval M, Dullin C, Zimmer S, Stuermer KM, Stuermer EK (2009): Effects of low-magnitude, high-frequency mechanical stimulation in the rat osteopenia model. Osteoporos Int 20(12): 1999-2008. 
Sehmisch S, Erren M, Kolios L, Tezval M, Seidlova-Wuttke D, Wuttke W, Stuermer KM, Stuermer EK (2010): Effects of isoflavones equol and genistein on bone quality in a rat osteopenia model. Phytother Res 24 Suppl 2: 168-174.

Seidlová-Wuttke D, Jarry $H$, Jäger $Y$, Wuttke $W$ (2008): Bone development in female rats maintained with soy-free or soy-containing food as determined by computer-assisted tomography and serum bone markers. J Bone Miner Metab 26 (4): 321-327.

Setchell KD, Brown NM, Lydeking-Olsen E (2002): The clinical importance of the metabolite equol-a clue to the effectiveness of soy and its isoflavones. J Nutr 132(12): 3577-3584.

Setchell KD, Clerici C, Lephart ED, Cole SJ, Heenan C, Castellani D, Wolfe BE, NechemiasZimmer L, Brown NM, Lund TD, Handa RJ, Heubi JE (2005): S-equol, a potent ligand for estrogen receptor beta, is the exclusive enantiomeric form of the soy isoflavone metabolite produced by human intestinal bacterial flora. Am J Clin Nutr 81(5): 1072-1079.

Setchell KD, Clerici C (2010): Equol: history, chemistry, and formation. J Nutr 140(7): 1355S-1362S.

Shadmehr A, Esteki A, Oliaie GR, Torkaman G, Sabbaghian A (2009): Augmentation of bone healing by specific frequency and amplitude compressive strains. Orthopedics $\underline{32}(3): 173$.

Shi HF, Cheung WH, Qin L, Leung AH, Leung KS (2010): Low-magnitude high-frequency vibration treatment augments fracture healing inovariectomy-induced osteoporotic bone. Bone 46 (5): 1299-1305.

Shu XO, Jin F, Dai Q, Wen W, Potter JD, Kushi LH, Ruan Z, Gao YT, Zheng W (2001): Soyfood intake during adolescence and subsequent risk of breast cancer among Chinesewomen. Cancer Epidemiol Biomarkers Prev 10(5): 483-488.

Sims NA, Clément-Lacroix P, Minet D, Fraslon-Vanhulle C, Gaillard-Kelly M, Resche-Rigon M, Baron R (2003): A functional androgen receptor is not sufficient to allow estradiol to protect bone after gonadectomy in estradiol receptor-deficient mice. J Clin Invest 111(9): 1319-1327.

Statistisches Bundesamt (2010): Gesundheit Krankheitskosten 2002, 2004, 2006 und 2008, Fachserie 12, Reihe 7.2, 2002-2008; Statistisches Bundesamt Wiesbaden 2010.

Stĕpán JJ, Lachman M, Zvĕrina J, Pacovský V, Baylink DJ (1989): Castrated men exhibit bone loss: effect of calcitonin treatment on biochemical indices of bone Remodelling. J Clin Endocrinol Metab 69(3): 523-527. 
Stuermer EK, Komrakova M, Werner C, Wicke M, Kolios L, Sehmisch S, Tezval M, Utesch C, Mangal O, Zimmer S (2010): Musculoskeletal response to whole-body vibration during fracture healing in intact and ovariectomized rats. Calcif Tissue Int 87(2): 168-180.

Sugimoto E, Yamaguchi M (2000): Anabolic effect of genistein in osteoblastic MC3T3-E1 cells. Int J Mol Med $\underline{5}:$ 515-520.

Sugiyama F, Wu J, Fujioka M, Ezaki J, Takeda K, Miyaura C, Ishida T, Yamada K, Ishimi Y (2006): Soybean isoflavones preserve bone mass in hindlimb-unloaded mice. J Bone Miner Metab 24 (6): 439-446.

Tami AE, Nasser P, Schaffler MB, Knothe Tate ML (2003): Noninvasive fatigue fracture model of the rat ulna. J Orthop Res 21(6): 1018-1024.

Tezval M, Sehmisch S, Seidlová-Wuttke D, Rack T, Kolios L, Wuttke W, Stuermer KM, Stuermer EK (2010): Changes in the histomorphometric and biomechanical properties of the proximal femur of ovariectomized rat after treatment with the phytoestrogens genistein and equol. Planta Med 76(3): 235-240.

Thomsen JS, Christensen LL, Vegger JB, Nyengaard JR, Brüel A (2012): Loss of bone strength is dependent on skeletal site in disuse osteoporosis in rats. Calcif Tissue Int 90(4): 294-306.

Tousen Y, Ezaki J, Fujii Y, Ueno T, Nishimuta M, Ishimi Y (2011): Natural S-equol decreases bone resorption in postmenopausal, non-equol-producing Japanese women: a pilot randomized, placebo-controlled trial. Menopause 18(5): 563-574.

Travis RC, Spencer EA, Allen NE, Appleby PN, Roddam AW, Overvad K, Johnsen NF, Olsen A, Kaaks R, Linseisen J, et al. (2009): Plasma phyto-oestrogens and prostate cancer in the European Prospective Investigation into Cancer and Nutrition. Br J Cancer 100(11): 1817-1823.

Turner RT, Hannon KS, Demers LM, Buchanan J, Bell NH (1989): Differential effects of gonadal function on bone histomorphometry in male and female rats. J Bone Miner Res 4(4): 557-563.

Turner RT, Wakley GK, Hannon KS (1990): Differential effects of androgens on cortical bone histomorphometry in gonadectomizedmale and female rats. J Orthop Res $\underline{8}(4)$ : 612-617.

Turner CH, Forwood MR, Rho JY, Yoshikawa T (1994): Mechanical loading thresholds for lamellar and woven bone formation. J Bone Miner Res $\underline{9}(1): 87-97$. 
Turner C, Burr D, Jee WS, Smith S, Recker RR, Axelrod DW, Takahashi HE, Villanueva AR, High WB, Martin RB, Parfitt AM (2004): Tribute to Harold M. Frost M.D.. J Musculoskelet Neuronal Interact 4(4): 347-356.

Uchiyama S, Yamaguchi M (2007): Genistein and zinc synergistically enhance gene expression and mineralization inosteoblastic MC3T3-E1 cells. Int J Mol Med 19(2): 213-220.

Usui Y, Zerwekh JE, Vanharanta H, Ashman RB, Mooney V (1989): Different effects of mechanical vibration on bone ingrowth into porous hydroxyapatite and fracture healing in a rabbit model. J Orthop Res $\underline{7}(4)$ : 559-567.

Uthgenannt BA, Kramer MH, Hwu JA, Wopenka B, Silva MJ (2007): Skeletal self-repair: stress fracture healing by rapid formation and densification of woven bone. J Bone Miner Res 22 (10): 1548-1556

Vandenput L, Boonen S, Van Herck E, Swinnen JV, Bouillon R, Vanderschueren D (2002): Evidence from the aged orchidectomized male rat model that $17 B$-Estradiol is a more effective bone-sparing and anabolic agent than 5alpha Dihydrotestosterone. J Bone Miner Res 17(11): 2080-2086.

Vanderschueren D, Van Herck E, Suiker AM, Visser WJ, Schot LP, Bouillon R (1992): Bone and mineral metabolism in aged male rats: short and long term effects of androgen deficiency. Endocrinology 130(5): 2906-2916.

Vanderschueren D, van Herck E, Nijs J, Ederveen AG, De Coster R, Bouillon R (1997): Aromatase inhibition impairs skeletal modeling and decreases bone mineral density in growing male rats. Endocrinology 138: 2301-2307.

Vanderschueren D, Boonen S, Ederveen AG, de Coster R, Van Herck E, Moermans K, Vandenput L, Verstuyf A, Bouillon R (2000): Skeletal effects of estrogen deficiency as induced by an aromatase inhibitor in an aged male rat model. Bone 27: 611- 617.

Vanderschueren D, Vandenput L, Boonen S, Lindberg MK, Bouillon R, Ohlsson C (2004): Androgens and bone. Endocr Rev 25(3): 389-425.

Vanderschueren D, Venken K, Ophoff J, Bouillon R, Boonen S (2006): Clinical Review: Sex steroids and the periosteum -reconsidering the roles of androgens and estrogens in periosteal expansion. J Clin Endocrinol Metab 91(2): 378-382. 
Venken K, De Gendt K, Boonen S, Ophoff J, Bouillon R, Swinnen JV, Verhoeven G, Vanderschueren D (2006): Relative impact of androgen and estrogen receptor activation in the effects of androgens on trabecular and cortical bone in growing male mice: a study in the androgen receptor knockout mouse model. J Bone Miner Res 21 (4): 576-585.

Verhas M, Schoutens A, L'hermite-Baleriaux M, Dourov N, Verschaeren A, Mone M, Heilporn A (1986): The effect of orchidectomy on bone metabolism in aging rats. Calcif Tissue Int 39(2): 74-77.

Verschueren SM, Roelants M, Delecluse C, Swinnen S, Vanderschueren D, Boonen S (2004): Effect of 6-month whole body vibration training on hip density, muscle strength, and postural control in postmenopausal women: a randomized controlled pilot study. J Bone Miner Res 19(3): 352-359.

Vorwerk E.: Die therapeutischen Effekte von Estradiol, Dihydrotestosteron, Genistein und Equol auf den osteoporotischen Knochen der orchidektomierten männlichen Sprague-DawleyRatte. Med. Diss. Göttingen 2010.

Walter ED (1941): Genistin (an isoflavone glucoside) and its aglucone, genistein, from soybeans. J Am Oil Chem Soc 63: 3273-3276.

Ward WE, Piekarz AV (2007): Effect of prenatal exposure to isoflavones on bone metabolism in mice at adulthood. Pediatr Res 61(4): 438-443.

Watanabe S, Yamaguchi M, Sobue T, Takahashi T, Miura T, Arai Y, Mazur W, Wähälä K, Adlercreutz H (1998): Pharmacokinetics of soybean isoflavones in plasma, urine and feces of men after ingestion of $60 \mathrm{~g}$ baked soybean powder (kinako). J Nutr 128(10): 1710-1715.

Weaver CM, Legette LL (2010): Equol, via dietary sources or intestinal production, may ameliorate estrogen deficiency-induced bone loss. J Nutr 140(7): 1377S-1379S.

Weber K (2008): Osteoporose bei Männern mit und ohne Prostatakarzinom. Journal für Urologie und Urogynäkologie 15 (Sonderheft 3) (Ausgabe für Österreich): 9-11.

Wink CS, Felts WJ (1980): Effects of castration on the bone structure of male rats: a model of osteoporosis. Calcif Tissue Int 32(1): 77-82.

Wolf S, Augat P, Eckert-Hübner K, Laule A, Krischak GD, Claes LE (2001): Effects of highfrequency, low-magnitude mechanical stimulus on bone healing. Clin Orthop Relat Res (385): 192-198. 
Wolff J (1892): Das Gesetz der Transformation der Knochen; Reprint: hrsg. von Bergmann G, Duda G, Charité Berlin Julius Wolff Institut; 1. Auflage; Pro Business Verlag, Berlin 2011.

Wolters M, Hahn A (2004): Sojaisoflavone - ein Therapeutikum gegen menopausale Beschwerden? Wien Med Wochenschr 154: 334-341.

Wu K, Frost HM (1969): Bone formation in osteoporosis. Appositional rate measured by tetracycline labeling. Arch Pathol 88(5):508-10.

Wu J, Wang XX, Takasaki M, Ohta A, Higuchi M, Ishimi $Y$ (2001): Cooperative effects of exercise training and genistein administration on bone mass in ovariectomized mice. J Bone Miner Res 10: 1829-1836.

Wu J, Wang XX, Chiba H, Higuchi M, Takasaki M, Ohta A, Ishimi Y (2003): Combined intervention of exercise and genistein prevented androgen deficiency-induced bone loss in mice. J Appl Physiol 94(1): 335-342.

Wuttke W, Jarry H, Becker T, Schultens A, Christoffel V, Gorkow C, Seidlová-Wuttke D (2008): Phytoestrogens: endocrine disrupters or replacement for hormone replacement therapy? Maturitas $\underline{61}$ (1-2): 159-170.

Wysocki A, Butler M, Shamliyan T, Kane RL (2011): Whole-body vibration therapy for osteoporosis: state of the science. Ann Intern Med 155(10): 680-686. 


\section{Dank}

Ich möchte mich bei Prof. Dr. Dr. K.G. Wiese für die Überlassung des Themas meiner Doktorarbeit sowie für die Möglichkeit des wissenschaftlichen experimentellen Arbeitens ganz herzlich bedanken. Besonderer Dank gilt dabei seinen vielfältigen fachlichen Anregungen sowie der konstruktiven Kritik, durch die ich viel lernen konnte.

Ebenso möchte ich mit bei Prof. Dr. med. W. Wuttke und Priv.Doz. Dr. med. D. Seidlová-Wuttke bedanken, die für die Durchführung des Tierexperiments verantwortlich waren. Auch ohne das Forschungsteam der Mund-, Kiefer- und Gesichtschirurgie wäre diese Arbeit nicht möglich gewesen. Mein besonderer Dank gilt hier Frau Ahrbecker, die immer ansprechbar war.

Danken möchte ich an dieser Stelle auch Johannes Szentmiklossy von Primocz. Das gemeinsame Arbeiten an diesem Experiment ermöglichte anregende Diskussionen, durch die das Erarbeiten der Ergebnisse mehr Freude bereitet hat. Auch meiner Schwester, Karin Thole, gilt besonderer Dank für das unermüdliche und sorgfältige Korrekturlesen dieser Dissertation. 